University of Louisville

ThinkIR: The University of Louisville's Institutional Repository

$12-2010$

\title{
Distributed leadership as a mediator of whole school reform strategies for improvement planning from data.
}

Jean Elizabeth Pickup 1954-

University of Louisville

Follow this and additional works at: https://ir.library.louisville.edu/etd

\section{Recommended Citation}

Pickup, Jean Elizabeth 1954-, "Distributed leadership as a mediator of whole school reform strategies for improvement planning from data." (2010). Electronic Theses and Dissertations. Paper 1137.

https://doi.org/10.18297/etd/1137

This Doctoral Dissertation is brought to you for free and open access by ThinkIR: The University of Louisville's Institutional Repository. It has been accepted for inclusion in Electronic Theses and Dissertations by an authorized administrator of ThinkIR: The University of Louisville's Institutional Repository. This title appears here courtesy of the author, who has retained all other copyrights. For more information, please contact thinkir@louisville.edu. 


\title{
DISTRIBUTED LEADERSHIP AS A MEDIATOR OF WHOLE SCHOOL REFORM STRATEGIES FOR IMPROVEMENT PLANNING FROM DATA
}

\author{
By \\ Jean Elizabeth "Betsy” Pickup \\ B.S., University of Cincinnati, 1990 \\ M.A., University of Cincinnati, 1992 \\ A Dissertation \\ Submitted to the Faculty of the \\ College of Arts of the University of Louisville \\ in Partial Fulfillment of the Requirements \\ for the Degree of \\ Doctor of Philosophy \\ Department of Educational Leadership, Foundations, and Human Resources \\ University of Louisville \\ Louisville, Kentucky
}

December, 2010 
Copyright 2010 by Jean Elizabeth "Betsy" Pickup

All Rights Reserved 



\title{
DISTRIBUTED LEADERSHIP AS A MEDIATOR OF WHOLE SCHOOL REFORM STRATEGIES FOR IMPROVEMENT PLANNING FROM DATA
}

\author{
By \\ Jean Elizabeth "Betsy" Pickup \\ B.S., University of Cincinnati, 1990 \\ M.A., University of Cincinnati, 1992 \\ A Dissertation Approved on
}

November 2, 2010

by the following Dissertation Committee:

Dissertation Director 


\section{DEDICATION}

This dissertation is dedicated to my father and mother,

Hiram and Rachel Hutto,

true lifelong learners....

of the Book 


\section{ACKNOWLEDGMENTS}

I would like to thank my committee, Dr. Sue Lasky, Dr. Sam Stringfield, Dr. John Keedy, Dr. Eugene Schaffer, and Dr. Phyllis Connelly, for guiding me through the dissertation process. I would especially like to acknowledge the direction given by Dr.

Lasky, and for her generosity in introducing me to the world of research. She has facilitated my thinking in blending the elements of theory and practice, and scaffolded my exploration in learning. I would also like to acknowledge Laura Overman for her organization of recent contributions to the field of education in the area of data use.

From the perspective of the practitioner, I would like to thank Brenda Michaud, who mentored me for countless hours in the daily practice of school administration. Her experience and insight has helped me make daily application of improving student achievement through data use. 


\title{
ABSTRACT \\ DISTRIBUTED LEADERSHIP AS A MEDIATOR OF WHOLE SCHOOL REFORM STRATEGIES FOR IMPROVEMENT PLANNING FROM DATA
}

\author{
Jean Elizabeth "Betsy" Pickup
}

November 2, 2010

This study examines how two schools utilized elements of distributed leadership to implement strategies from a reform intervention for whole school and classroom improvement planning from data. The notion of distributed leadership was refined in a conceptual framework that includes mediating variables of procedures and processes, materials and tools, and norms and rules. Strategies were introduced through a specific intervention for reform, Effective Schools for the $21^{\text {st }}$ Century, based on high reliability organizations and co-construction. It utilized professional development sessions and distributed leadership as a vehicle to implement reform strategies in the schools. This was a qualitative study, analyzed through a sociocultural epistemological lens.

The study was anchored in mediated agency and distributed leadership. Distributed leadership was expressed through the collaborative, interdependent work as people-or in this study-teachers engaged in activities to plan improvement. Mediated agency was observed as teachers and administrators utilized various procedures and processes, materials and tools, and norms and rules as they implemented the strategies to use and plan from data, as they worked toward becoming a more high reliability organization. 
Results indicated that as initiatives enter school contexts, they are, indeed, mediated and shaped as they are distributed across the three constructs of distributed leadership. It was also found that as strategies are mediated, proximal and distal outcomes are evident, as they are influenced by the three variables within each school context. Implications for understanding how distributed leadership was operationalized and co-constructed among school leaders were made. Also, implications were made for recognizing that relevant data was a powerful tool in leading and monitoring change when used intentionally for specific purposes. 


\section{TABLE OF CONTENTS}

PAGE

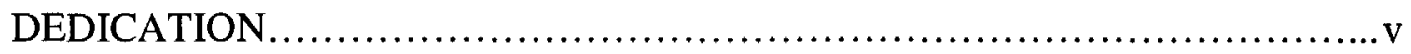

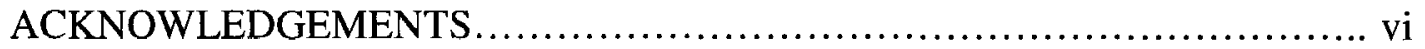

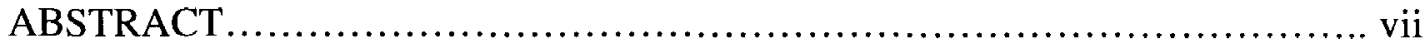

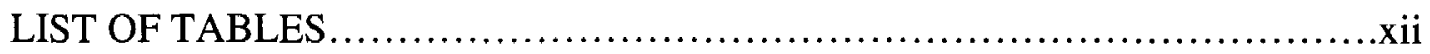

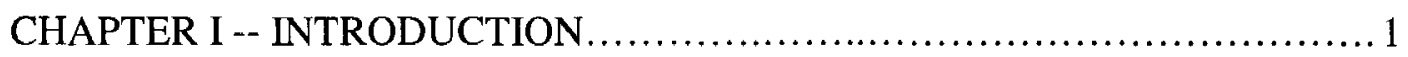

The Study and What Drew Me to This Topic ................................ 1

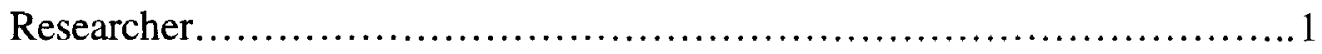

Professional Experiences.........................................................

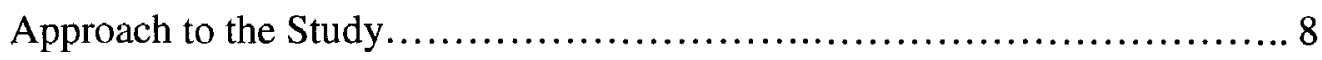

Organization of the Dissertation........................................... 8

CHAPTER II -- LITERATURE REVIEW .................................. 10

Educational Reform............................................... 11

Current Political Context for Data Use ................................... 16

Interaction of Policy and Data.......................................... 19

Change in Reform Processes.......................................... 20

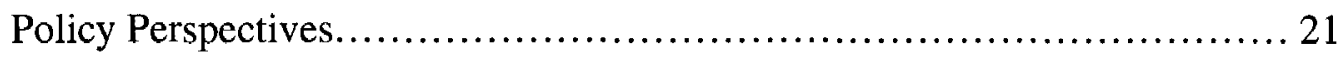

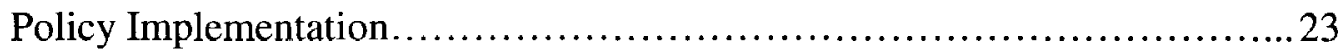

Sociocultural Lens................................................... 25

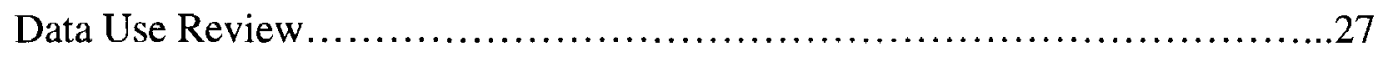




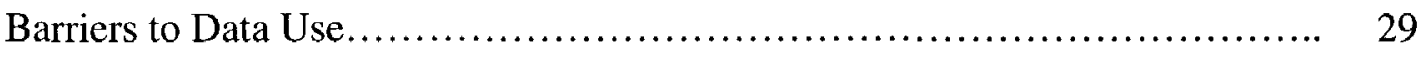

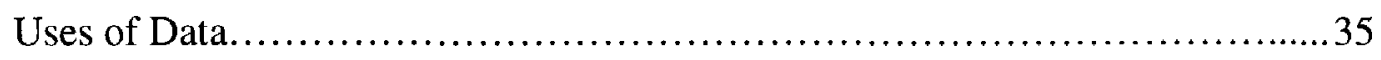

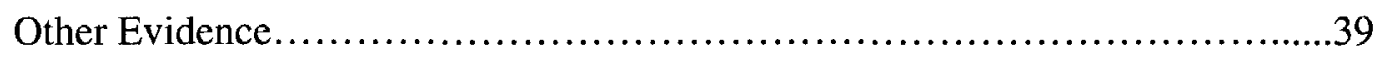

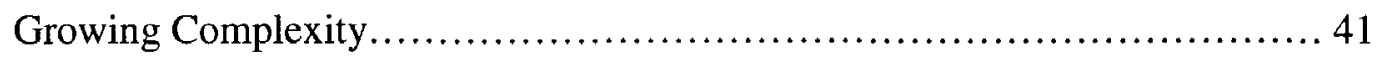

Distributed Leadership.................................................. 42

Proximal Outcomes......................................................... 45

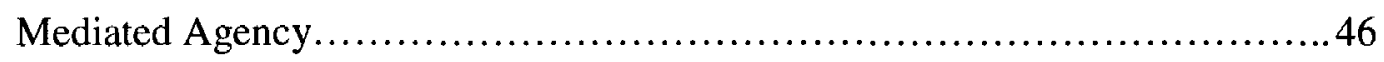

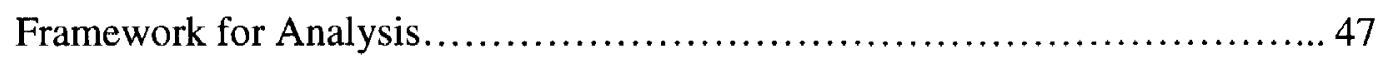

Conceptual Framework.................................................... 49

Significance of the Study ................................................... 52

Research Questions............................................... 52

CHAPTER III -- METHODOLOGY........................................ 54

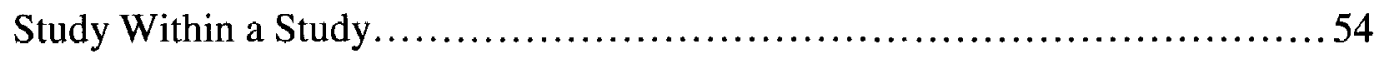

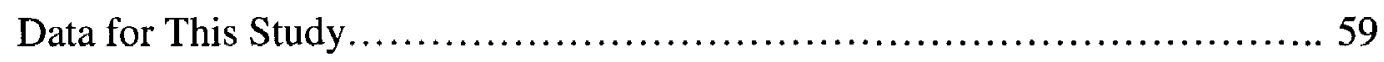

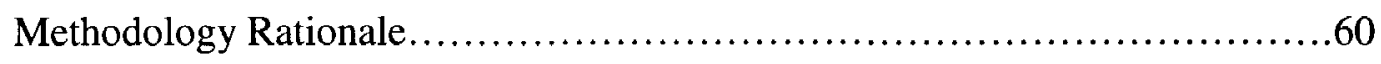

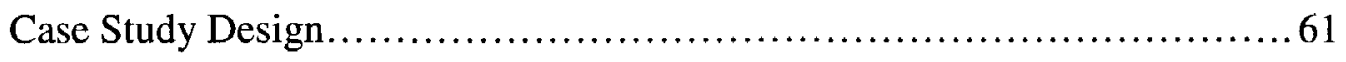

Checking for Researcher Bias...........................................64

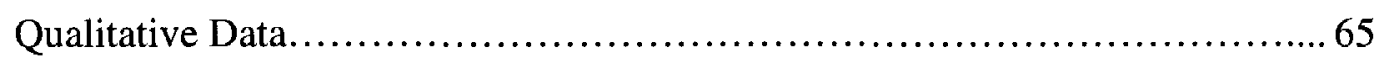

Sample Selection.........................................................

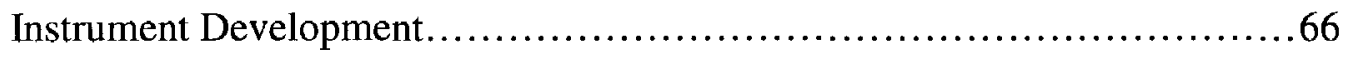

Data Collection......................................................... 68

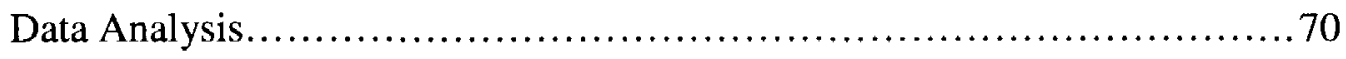

Limitations of the Study ................................................ 73 


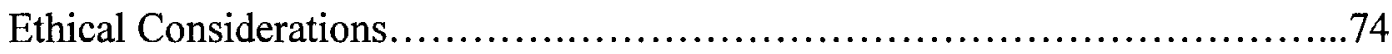

CHAPTER IV -- PROFESSIONAL DEVELOPMENT ..........................75

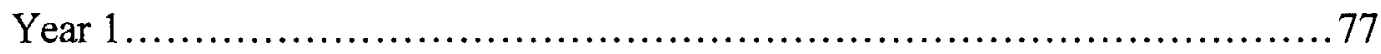

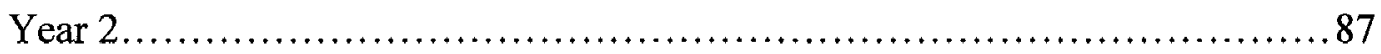

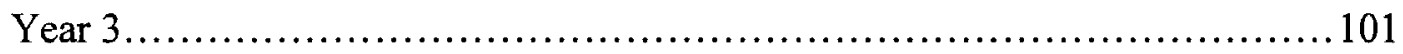

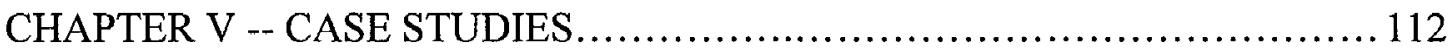

Case Study, School A...................................................... 113

Case Study, School B..................................................... 148

CHAPTER VI -. CROSS CASE ANALYSIS.............................. 178

CHAPTER VII -- CONCLUSIONS, IMPLICATIONS, AND FUTURE

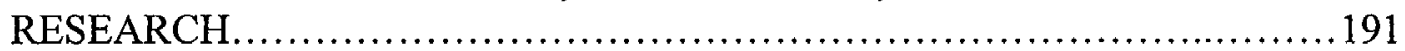

REFERENCES........................................................... 215

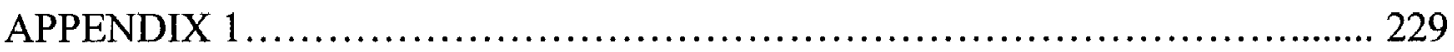

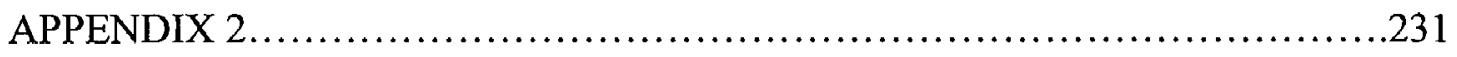

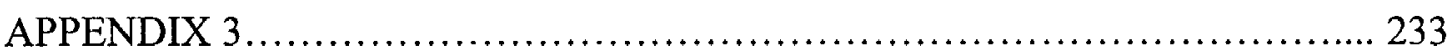

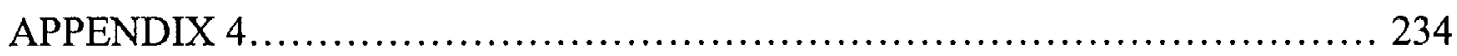

CURRICULUM VITAE ................................................. 236 


\section{LIST OF TABLES}

TABLE

PAGE

1. Chart Contrasting Educational Decision Making Based on Intuition or Convenience with Decision Making Based on Data...................91

2. Chart Contrasting Traditional Professional Development Sessions with Sessions of Lesson Study...............................................

3. Chart of responses to guiding questions following observations at School B.......106

4. Chart of responses to guiding questions following observations at School B.....108

5. Percentage of students achieving Novice, Apprentice, Proficient, or Distinguished performance levels on the 2008-2009 state assessment............................115

6. Percentage of students achieving Novice, Apprentice, Proficient, or Distinguished performance levels on the 2008-2009 state assessment. 


\section{CHAPTER I}

\section{INTRODUCTION}

This study examined how two schools used data for school and classroom improvement in the context of high stakes accountability mandated by No Child Left Behind. To frame this examination, I hypothesized that the work of improvement planning was mediated by the constructs of procedures and processes, materials and tools, and normative values that are present in each school. I approached this investigation using a sociocultural lens of distributed leadership.

This section will describe experiences that led me to this research, and the major constructs that are woven throughout the study. This section will conclude with a description of how the study is organized.

The Study and What Drew Me to This Topic

This section outlines major influences on my study. Past experiences and professional roles helped to guide my path. The elements of data use, sociocultural theory, mediated agency and distributed leadership, are common themes throughout this description.

Researcher

My study grew directly out of my experiences with a larger project which explored whole school reform through professional development using a distributed leadership model, Effective Schools for the 21st Century (ES21, Stringfield, et al., 2004; 
2010). The investigation was a three-year exploration of school improvement based on the past thirty-five years of school effectiveness and reform research.

During the process of this research, I observed participating teams engaging to build knowledge, plan reforms, and implement changes. The process paralleled a theoretical approach which is often encouraged for students. Although I had modeled and facilitated this process in my elementary students, researching the process for the ES21 study led me to its name: social construction. This concept is based on sociocultural theory that knowledge is shaped and mediated by social, cultural, and historical contexts which utilizes tools such as language, numeracy, or works of art. Vygotsky (cited in Daniels, 1996), and more recently, Cole \& Wertsch (2006) and Rogoff (1990) have contributed to this ideology. Recently, Spillane, Halverson \& Diamond (2001, 2004) extended the idea of social construction to describe distributed leadership in schools. The authors described leadership as being stretched across context, leaders, and followers. This provides a paradigm for thinking about how leaders behave within an organization. Under this model, as leaders construct change together, they then distribute its implementation among all stakeholders within the specific processes, tools, and norms that are the context components.

\section{Professional Experiences}

Using mediational tools. Looking back on my varied professional experiences, I realized how each shaped my understanding of how people work together to think, talk and plan for improvement. I spent fifteen years as a speech-language pathologist which gave me a solid foundation in the processes of data use and planning improvement strategies. My work was to facilitate advancing the language abilities and skills of young 
and old alike. As I engaged with clients to build or rehabilitate their communication skills, I quickly concluded that these skills were best acquired not by engaging in traditional lessons. Instead, learning was enhanced and embedded when utilizing a sociocultural perspective, using tools to mediate knowledge in authentic contexts (Rogoff, 1990; Tharp \& Gallimore, 1988; Wertsch, Tulviste, \& Hagstrom, 1993). Most of my years as a speech-language pathologist were in a public school setting. Those years were spent providing services to students, and facilitating student learning through language in the classroom. Based on these experiences I saw the strong connection between language as a mediational tool and outcomes. This realization was validated as I read that Bakhtin extended Vygotsky's perspective of language in that not only is language important in the sense that we have language, but perhaps even more importantly, in the sense that language can become so specified as to become part and parcel of what defines an a social system or an entity (Wertsch, Tulviste \& Hagstrom, 1993, p. 346). This was seen not only in classrooms, but also in the "teacher talk" heard as teachers discussed and planned together. It was through its use as a culturally relevant tool, that I saw activities within the context of normative values guide and mediate effective improvement that was constructed collaboratively with others. Besides language, I saw many other tools such as technology, protocols, rubrics and pacing guides used in efforts to generate performance outcomes.

Using distributed leadership. My studies at the University of Louisville not only focused on research, but also on certification for educational administration and leadership. The coursework for this practitioner's role, as well as the studies for my research interests, led me to the concept of distributed leadership (Spillane, Halverson, \& 
Diamond, 2004). My subsequent roles as instructional coach and elementary school principal, along with my work from the ES21 project, informed my perspective and practical application of this approach. These combined experiences gave me insight into how school leaders use data and distributed leadership to implement reform efforts.

While collecting data for the project, I saw teachers looking at student work and assessment results, and mutually constructing next steps through procedures and processes, materials and tools, and normative values and rules. They used grade group teams and partnering to divide responsibilities in learning, and provide support until they became independent. I heard detailed descriptions of how teachers viewed their current challenges, how they learned from professional development, and how they constructed together the strategies learned to meet the needs of their schools. These stories and narratives of experience (Clandinin \& Connelly, 2000) allowed me to "fathom human experiences and...illuminate the complexities endemic to the undertaking" (Wood, 2000, p. 2000), which guided my research toward qualitative methods. The role of researcher enlightened and expanded my knowledge as an administrator. Similarly, from my role in administration I found I was able to recognize, identify, and organize research based on concepts that I knew pertained to the planning process.

This experience helped me to understand that there is a difference in merely talking about a subject or mandating what needs to be done, and constructing work and ideas together by establishing normative values and using materials and tools in contextual activities. Utilizing the framework in this study of using mediational elements within a fluid relationship of following and leading is a logical application of my experiences, and is the heart of this dissertation. 
When change comes about interdependently and is distributed among participants, it has many benefits. This kind of change is organic and internal, as opposed to coerced change resulting from mandates imposed from a centralized authority. Greenleaf (1997) stated, "The trouble with coercive power is that it only strengthens resistance. And, if successful, its controlling effect lasts only as long as the force is strong. It is not organic. Only persuasion and consequent voluntary acceptance are organic" (pp. 55-56).

A distributed model of leadership lends itself to organic change. The acknowledgement and persuasion needed to bring about reform can be accomplished through a distributed model as colleagues engage in learning conversations, along with mediational tools in the context of the professional norms and relevant activities. This study examines change as it is socially constructed through mediating variables of procedures and processes, materials and tools, and norms and rules in the context of reform requiring data use.

It is essential that today's administrator stay informed about improvement processes, data use, and how to lead improvement. At the best, the relationship between administrator and researcher is a dynamic one, each role informing and building on the other. In these times of high stakes accountability, the role of researcher is inherent in the job of a school administrator. Although not usually framed in formal studies, a principal looks at data, analyzes trends, gathers evidence from teacher and student conversations and work, and makes decisions based on these data. Practitioners' work cannot be effectively designed, implemented, reviewed, and revised without monitoring, collecting data, and constructing next steps. When effectively executed, this is a seamless, continuous reciprocal process. Not only does effective work depend on being both 
researcher and practitioner; neither role can be successfully sustained without the other. The blending of both worlds leads to building greater competencies. The cohesive process of researcher and practitioner can no longer be considered an erudite quality reserved for the academic, but a necessary component of what it takes to lead.

Data use. The most consistent element in all of my professional experiences has been the use of data. Data collection was a daily event during my role as a speechlanguage pathologist. Analyzing and planning next steps from data constituted the major process for successful implementation of strategies. As an instructional coach, data were the primary strategy I used in whole school, grade group or vertical meetings and professional development sessions. These data came from a variety of sources such as school, district and state assessments and student work.

Materials and tools that helped guide this work came from district documents, core content guides, continuums, or pacing guides, as well as rubrics, and protocols. Although the use of data in improvement planning was far from a linear process, data helped my colleagues and me see the levels at which students were performing, and to plan measureable goals for improvement. In this role, I was able to see firsthand the benefits of data use, and also to see barriers to effective data use, such as timeliness, availability, and display of data.

Data continue to be the driving force behind the most basic and foundational decisions I make as an administrator. Instructional programs, interventions, schedules, and budget decisions are based on data. Data use has become a constant and pervasive element in how student achievement is measured, reported, analyzed, and how plans are created for next steps. 
Three other factors have influenced this paper. While working with Dr. Susan Lasky and Dr. Sam Stringfield on the ES21 study, I was introduced to the concept of qualitative research (Guba \& Lincoln, 1985). My previous research experience in my Master's program had been quantitative in nature, focusing on numerical data, but I found as a qualitative researcher I was able to approach investigation with a broader lens that allowed for nuance and richness sometimes neglected in quantitative studies (Miles \& Huberman, 1994). To achieve this, I used an inductive approach, keeping myself open to the unexpected or unintended consequences that investigatory research can yield.

The second factor was my presentation at the 2008 American Educational Research Association, An Exploration of Highly Effective Principals in "Low Performing" Schools. The paper investigated the work of principals at schools that alternated in and out of No Child Left Behind sanctions. The investigators involved in the ES21 project had all judged these principals to be highly effective in understanding and utilizing the distributed leadership model to effect change. My investigation of these principals' practices allowed me to apply excerpts of their conversation as evidence for their work in using data for improvement planning. The paper was qualitative and illustrated the many ways that the leaders engaged in the change process, and were actively involved in improvement planning, utilizing materials and tools during activities.

Additionally, I had the opportunity to contribute to the development of the matrix used in the ES21 project for proximal and distal outcomes. This matrix was created by Dr. Sue Lasky and Dr. Eugene Shaffer in order to describe the key elements of the reform intervention as they related to organizational features for analysis. Dr. Lasky guided further development of this document with me and two other graduate students by posing 
guiding and reflective questions. Both theoretical considerations and practical experience were factors that contributed to the construction of this matrix.

Approach to the Study

This study was grounded in qualitative investigation. Although there has been much recent interest in the field of education in utilizing experimental and quasiexperimental designs as described in Shadish, Cook, and Campbell (2002), not all research questions are best answered using this approach. Feuer, Towne, $\&$ Shavelson (2002) pointed out, "Judgments about scientific merit of a particular method can only be accomplished with respect to its ability to address the particular question at hand," and, "It is also true that some methods are better than others for particular purposes" (p. 7). Collecting qualitative data in the form of observations and interviews are a reliable way to document a school's activities.

Dr. Lasky was also instrumental in guiding my understanding of educational reform, standards-based education, and the impact of accountability on these efforts. Accountability has certainly accelerated the need for understanding and using data for improvement efforts. Datnow, Park, and Wohlstetter (2007) concluded that "building teacher capacity for effective data use seemed to go hand-in-hand with building instructional knowledge and skills."

\section{Organization of the Dissertation}

My study developed both inductively and deductively. I began with a "start list" (Yin, 1994) of constructs that were likely to be observed (formative data, summative data, other evidence, protocols, meetings). My work on the ES21 project exposed me to the planning and conversations that centered on the correlates of effective schools, 
including safe and orderly environment, high expectations, instructional leadership, clear and focused mission, opportunity to learn and student time on task, frequent monitoring of student progress, and home-school relationships (Lezotte, 1991). By hearing conversations that surrounded establishing these concepts in schools, I noticed common themes that were likely to emerge in this study.

The combination of data use for improvement planning through the sociocultural lens of distributed leadership and mediated agency in the context of federally mandates reform is the nexus of concepts that inform this paper. Chapter II reviews the literature related to data since 2000 , with a few comments on earlier literature. This review reveals the sequence of how data have become incorporated into the educational setting, barriers to data use, and identifies various uses of data. As well, this chapter examines sociocultural theory and looks at how policy influences data use and impacts the educational environment.

Chapter III explains why this paper and the questions to be answered are best addressed through a qualitative approach. Attempting to apply only quantitative analysis to this study would be both inadequate and inappropriate. A case study design is described and applied to the elements of this study. I also described the sample selection, instrument development, data collection and data analysis. Chapter IV describes the ES21 professional development sessions that were attended by the schools' teacher leaders. Case studies and a cross-case analysis of the two schools in this study are described in Chapter V, while conclusions, implications, and suggestions for future research are drawn in Chapter VI. 


\section{CHAPTER II}

\section{LITERATURE REVIEW}

The body of work calling for improvement in schoolwide planning and instructional practice in the current standards-based reform environment is extensive, and vital to achieve mandates imposed from the state and federal levels. Many studies conclude with the recommendation to advance teacher knowledge, practice, and organizational capacity, but relatively few studies have closely documented the process.

In the environment of high stakes testing accountability for increased student achievement, efforts to identify and bring about organizational, teacher, and individual student improvement are necessary. Pressure at the federal level with the No Child Left Behind Act (NCLB, 2001) only accelerated this accountability. Successful implementation of these changes is a complicated process, and documentation of these efforts is incumbent on educators and systems organizers. States, districts, and schools alike are searching for new approaches to bring about improvement, and as these reform initiatives are developed and attempted, systematic and rigorous investigation of their planning, implementation, and results are needed to help inform future practice. There has been little longitudinal, systematic investigation of complex interventions, and especially of specific subcomponents of reform efforts. This dissertation aims to add to the body of knowledge about the how of educational planning when guided by data and other evidence in an effort to improve classroom and whole school achievement 
outcomes within the context of NCLB. The purpose of this study is to examine how three organizational elements of distributed leadership shaped and mediated strategies for whole school reform as two schools planned for school and classroom improvement from data.

\section{Educational Reform}

This section offers a history of federal education policy since the publication of $A$ Nation at Risk (U.S. Department of Education [USDOE], 1983), as well as brief references to earlier cogent events leading to the issuance of the report. This sequence shows the evolution and influence of policy on the education system in the context of each era, and will close with notes on the significance of the study and research questions.

In November of 1963, President Lyndon Johnson announced his vision to build a "Great Society" which included the far-reaching "War on Poverty." Arguably, the most crucial element of this initiative was the promotion of educational opportunity. As part of this initiative, the Elementary and Secondary Education Act of 1965 (ESEA) funneled billions of federal dollars to schools and school districts (Local Educational Agencies, LEAs) to build capacity and flexibility in helping low-income families. Initiatives such as Head Start and other Title 1 programs were implemented (www.nclb.gov). Although ESEA was focused on advances at a grass roots level, it also impacted educational policy- making, and helped frame subsequent federal funding policies.

First, it signaled the switch from general federal aid to education towards categorical aid, and the tying of federal aid to national policy concerns such as poverty, defense or economic growth. Second, it addressed the religious conflict by linking federal aid to educational programs directly benefiting poor children in parochial schools, and not the institutions in which they enrolled. Third, the reliance on state departments of education to administer federal funds (promoted 
to avoid criticisms of federal control) resulted in an expansion of state bureaucracies and larger involvement of state governments in educational decision-making. (Spring, cited in Schugurensky, 2002, p. 1)

Thus, this Act created "for the first time, a partnership among federal, state, and local governments to address part of the larger national agenda...by targeting federal aid to poor students and schools" (Pattison \& Brukas, 2007, p. 1).

That expansion of the states' role in education continues today, feeling the mounting pressure to fulfill federal requirements. States such as Kentucky enacted legislated mandates impacting curriculum, funding, and governance in an effort to improve student outcomes (Kentucky Education Reform Act, KERA, 1990). This responsibility is passed down to districts, and ultimately to schools and classrooms where the daily challenge of achieving immediate improvement is felt.

In the early 1980s, Terrel Bell, Secretary of Education under President Ronald Reagan established the National Commission on Excellence in Education to investigate the widespread reports that America's educational system was on the decline. The Commission was formed, despite the preceding decade and a half of intense efforts to improve education, due to "the widespread public perception that something is seriously remiss in our educational system." (A Nation at Risk, 1983). This report attacked the then current progressive educational movement calling for a pressing need to reintroduce “cultural literacy" characterized by "facts, phrases, and texts," more reminiscent of classical Western European education.

During this same period, efforts were underway to discover and describe elements or characteristics of schools that were experiencing success regardless of students' family background or socioeconomic status (Lezotte, 1991). Reacting to a report written by 
James Coleman (1966) which stated that public schools could not overcome the disadvantages of poverty so that children can learn, Ron Edmonds set out to investigate schools that were successful in teaching low income students. Building on the work of Edmonds (1979a, 1979b), Lezotte and other researchers described seven correlates of effective schools which helped to define and identify the Effective Schools Movement. The correlates Lezotte described were:

1. Clear School Mission - In the effective school, there is a clearly articulated school mission through which the staff shares an understanding of and commitment to instructional goals, priorities, assessment procedures and accountability. Staff accepts responsibility for students' learning of the school's essential curricular goals.

2. High Expectations for Success - In the effective school, there is a climate of expectation in which the staff believe and demonstrate that all students can attain mastery of the essential content and school skills, and the staff also believe that they have the capability to help all students achieve that mastery.

3. Instructional Leadership - In the effective school, the principal acts as an instructional leader and effectively and persistently communicates that mission to the staff, parents, and students. The principal understands and applies the characteristics of instructional effectiveness in the management of the instructional program.

4. Frequent Monitoring of Student Progress - In the effective school, student academic progress is measured frequently. A variety of assessment procedures are used. The results of the assessments are used to improve individual student performance and also to improve the instructional program. 
5. Opportunity to Learn and Student Time on Task - In the effective school, teachers allocate a significant amount of classroom time to instruction in the essential content and skills. For a high percentage of this time students are engaged in whole class or large group, teacher-directed, planned learning activities.

6. Safe and Orderly Environment - In the effective school, there is an orderly, purposeful, businesslike atmosphere which is free from the threat of physical harm. The school climate is not oppressive and is conducive to teaching and learning.

7. Home - School Relations - In the effective school, parents understand and support the school's basic mission and are given the opportunity to play an important role in helping the school to achieve that mission (Association for Effective Schools, 1996).

As an outgrowth of the correlates for effective schools, educational philosophies began to change. Thinking began to shift from acceptance of failure for some students to the idea that all students could reach a prescribed standard or level of competence; and in fact, studies found that even those students labeled at-risk for failing had an opportunity to succeed (Rossi \& Stringfield, 1997). Elmore (2000) succinctly described the "new educational accountability" (p. 1) as:

...a deceptively simple logic: schools and school systems should be held accountable for their contributions to student learning. Society should communicate its expectations for what students should know and be able to do in the form of standards, both for what should be taught and for what students should be able to demonstrate about their learning. School administrators and policy makers, at the state, district, and school level, should regularly evaluate whether teachers are teaching what they are expected to teach and whether students can demonstrate what they are expected to learn. The fundamental unit of accountability should be the school, because that is the organizational unit where teaching and learning actually occurs. Evidence from evaluations of teaching and student performance should be used to improve teaching and learning and, ultimately, to allocate rewards and sanctions (Elmore, Abelman, et al., 1996).

Thus, the standards-based movement was underway. 
The standards-based movement essentially called for educators to ensure that all students demonstrate a minimum level of competence in the various content areas. Ravitch (as cited in Pattison \& Brukas, 2000) described the concept stating, "Standards can improve achievement by clearly defining what is to be taught and what kind of performance is expected" (p. 25). In the years following the establishment of standardsbased reform, K-12 education in the U.S. began to undergo significant change. Many states had their own versions of standards-based legislation. For example, Kentucky, Texas, and Massachusetts developed challenging standards for student outcomes demonstrated through newly created assessments. Other states' accountability requirements, however, were less rigorous. For example, the required proficiency score in some states was only 70 to 80 , and the length of time allowed for all states to reach proficiency ranged as far as 2020 (Rudalevige, 2005).

The Kentucky Education Reform Act of 1990 (KERA) was a watershed example of standards-based reform that had a major impact in Kentucky, and influenced legislation nationally. It ushered in a system of delineated benchmarks of learning, accompanied by indicators or subcomponents that students should demonstrate. Accountability under standards-based reform shifted away from blaming individual students, families, and social circumstances. Instead, it focused on schools and held them responsible for students' achievement (Massel, 2001).

There are many examples of programs and initiatives based on the principles of standards-based reform. One well-known initiative was led by Anthony Alvarado in New York's famed District 2. This effort focused on literacy and was founded on improving instructional practice through the professional development of teachers and principals. 
Although, initially, the purpose of this push was to improve instruction, it eventually came to "shift discernibly toward a more explicit emphasis on student performance, and toward a more explicit discussion of standards—-both standards of practice and student performance standards" (Elmore \& Burney, 1998, p. 8). The K -8 district showed substantial gains in student performance in literacy and spawned a second attempt at large-scale reform with Alvarado at the helm, this time in the San Diego City School District (Darling-Hammond, et al., 2005).

Other programs such as Success for All, America's Choice, the Coalition of Essential Schools, and Different Ways of Knowing, known as Comprehensive School Reform (CSR), also targeted schools with low-achieving students in high poverty contexts. All of these interventions promoted strategies for instruction and learning that were situated in contexts very close to where the learning takes place, in the school or classroom itself. Even though program design, dollars, and accountability may begin at the highest of levels of government, it is at the local level where change must happen.

\section{Current Political Context for Data Use}

While the standards-based movement is now commonplace, its "progress is far from uniform" (Lashway, 2001, p. 1), and even though the initiation of the standards movement of the 1980s yielded achievement increases on state tests, scores on the National Assessment of Educational Progress remained stubbornly flat from the 1970s through the 1990s. This led to the No Child Left Behind Act (NCLB), signed into law in 2001. NCLB dictated high stakes accountability for every school in the United States. This legislation called for improvement to be made by student achievement of prescribed standards, indicated by an Annual Yearly Progress index (AYP), targeting a score of 100 
by the year 2014. Schools failing to meet their yearly progress receive staged sanctions, which could ultimately involve state takeover and restructuring.

As a way for schools to demonstrate their progress, NCLB attached "additional urgency, particularly to the quest for learning from data that was implied, but not as explicit in earlier reforms; and placed emphasis on data ranging from assessment literacy, data management and use, statistical expertise, and systems thinking" (Lasky, Shaffer, \& Hopkins, 2007, p. 95). Since the requirements for student performance are attached to accountability, it is primarily at the school level that educators are under pressure to demonstrate constant improvement. Additionally, for all students to have access to high quality education, it is the organization, rather than just in individual teachers, that need to show improvement.

As overseers of local schools, districts are realizing the need to create systemic products, processes and structures across all schools to promote conditions described by the correlates. They are scrambling to align standards, curriculum, assessments, and professional development. Fundamental to these efforts is the ability for teachers and administrators to understand and use data, and realize how it can be used to inform change, but little has been documented detailing how evidence-based reforms are actually being planned, implemented, utilized, and supported at the school and classroom levels. Research has shown, however, that sustainability of reform is difficult, and in many cases, lost. (Teddlie \& Stringfield, 2007).

The passage of the No Child Left Behind Act of 2001 added urgency to the quest for learning and data. Never before in U.S. education have schools been required to increase standardized measurable outcomes in the way NCLB mandates. Under NCLB, 
schools are mandated to reach state defined proficiency levels for 100 percent of all students by the year 2014. Each year prior to that date, schools have a proficiency benchmark they are required to meet, showing progression toward the score of 100 percent. This is known as Annual Yearly Progress, and is composed of a subset of indicators based on content areas, and school factors such as gender, race, socioeconomic status, and special needs, to name a few.

Failure to meet the benchmarks places a school at risk for a staged set of sanctions ranging from making tutoring available for failing students to state takeover and restructuring. Reduction of federal funds can accompany these sanctions (NCLB, 2001). Likewise, schools have not previously been subject to regular public reporting of their rankings. The learning required for standards-based education in an ever-evolving high stakes accountability policy context is immense. This mandate has far-reaching effects impacting a multitude of people.

The mandates for improvement have been written into law, and the consequences of accountability rankings made clear. Yet little is actually known in the field of education about how long it takes to first create the conditions in schools that foster steady increases in student learning outcomes and sustain them over time, as required by yearly progress goals (Lasky, Schaffer, \& Hopkins, 2007). Tongeri \& Anderson (2003) found that in elementary schools, increases in student scores can occur within three years of introducing an improvement initiative, but there are many things that challenge this improvement. As examples, states have continued to revise their accountability systems, including their standards, assessments, data bases, Annual Yearly Progress expectations, 
and consequences for not meeting them. This means that school leaders, including classroom teachers, are aiming to meet moving targets, while scoring goals and ranking criteria change, as do the technologies used to meet their targets (Lasky, Shaffer, \& Hopkins, 2007).

\section{Interaction of Policy and Data}

There is an iterative dynamic between data and policy (Kowalski \& Lasley, 2008). The current political environment has influenced the uses of and the need for data, but conversely, data use influences policy and policymaking. Schools and teachers are graded based on empirical data as described in NCLB, and this influences states and districts to make decisions about "personnel decision, student IEP formation, and policy, curriculum, and resource allocation decisions driven by NCLB and other laws (Kowalski \& Lasley, 2008, p. 53). Coburn (2006) pointed out that although mandates may call for a certain empirical level of performance, policy does not enter a state, district, classroom or school in a vacuum. She uncovered differing conceptions of what constituted valid evidence among educators depending on factors such as intended use, historic influence, and environmental context such as work roles. District and top-level administrators were more likely to see data as valid if it displayed solid psychometric properties, while classroom teachers and building administrators included examples of student reasoning and thinking skills as evidence.

Noting the difficulties schools and teachers have in cleanly applying assessment data to a practical application of student learning and performance, Cromey (2000) outlined ways for policy to address some of the challenges. Cromey's suggestions included aligning all state-mandated assessments to the learning standards, setting clear 
learning standards, providing professional development so that teachers could see how curriculum and assessment can guide improvement planning, and investigating the face validity of standardized, large scale assessments. Clearly, the policy context of today has shaped the need for educators to understand and adopt decisions based on data.

\section{Change in Reform Processes}

When policymakers envision and legislate change in education, mandates pass through various domains of the system (Datnow, Lasky, Stringfield, \& Teddlie, 2006). Because this implementation is carried out in divergent climate and cultures, with multiple actors, and in a wide range of funding contexts, the change process is far from seamless. In fact, evidence showed that as policy is influenced by these factors, it is mediated and mutually adapted (Berman \& McLaughlin, 1978) to varying degrees. There are many approaches to studying how change occurs during reform processes as policies designed to effect the change are implemented.

Implementation of reform efforts is an arduous process (Supovitz \& Weinbaum, 2008). Shadish, Cook, \& Campbell (2002) commented on the difficulty of the implementation process, stating that results can be unreliable when "the intervention is not implemented properly, fully, or even at all" (p. 314). To study how change occurs in the reform process, I will look at policy; how it can be viewed from different perspectives, and used to achieve different outcomes.

The word policy usually conjures up a detached, rigid set of directions originating in some board room far removed from reality. While this may be the perception of "street level bureaucrats" those that study change, and those who have followed an original policy initiative through ideas, intentions, design, implementation, and evaluation know 
this perception to be far from reality (Berman \& McLaughlin, 1978; Weatherly \& Lipsky, 1977, cited in Elmore, 1979-1980). No matter what the form, content, or targets, policy targeting change is transformed from origin to implementation, as are its intended outcomes (Hall \& McGuinty, 1997; McLaughlin, 1987).

\section{Policy Perspectives}

There are many different ways to frame and understand how change occurs as policy moves through a system. There are also arrays of models that describe policy and the role it plays in change efforts. Some view policy from a narrow, focused perspective, while others see policy more broadly, with a less prescribed and constrained purpose. I will begin my description of policy from a rational perspective, and then move to examples that view policy in a more open and flexible framework.

Fullan (2004) and Earl, et al. (2001) viewed policy as a lever used to accomplish purposes. A lever is typically used as a device that moves an object at one end as force or pressure is applied at the opposite end. We see that as pressure falls onto policymakers, they create policy which is, in turn, used to create movement to achieve the prescribed outcomes of the policy.

Bascia and Hargreaves (2000) described how, for over a century, policy mandates have been viewed as a way to define, manage, and monitor the technical aspects of education. They described the view of some policymakers to be that if school programs, assessments, teaching responsibilities, and schedules are altered in a uniform way, teachers can act as technicians to ensure uniform results. This approach to change assumes the belief that educators have the knowledge and skills necessary to enact the 
mandated changes, or that they are either "unfocused, recalcitrant, lazy or unmotivated" (Earl \& LeMahieu, 1997, p. 158).

Spillane and Jennings (1997) saw policy as curriculum to promote learning. They drew parallels between teachers and pedagogy as an analogy to illustrate the importance of teaching policy "curriculum" to enhance coherence in learning goals. Levin, (1998), too, explored the possibility of policy as a learning tool, investigating mutual learning among six countries. He, ultimately, viewed the process as unsuccessful because it seemed that little mutual learning actually occurred. In fact, he likened the process more to "policy borrowing" instead of mutual learning, and depicted this type of policy making in medical terms, as an "epidemic" (p. 6).

McDonald \& Elmore (1987) described policy as an instrument that is forged for the purpose of translating ideas into tangible outcomes. They categorized policy into four types of instruments, and described the costs and benefits of each. Bascia (2001) also categorized policy as a blunt instrument used as a force for change, but rarely reaching its original objective. She described policy in terms of pendulum swings (opposing social concerns) and archeological digs (influences brought to bear by past policies).

Datnow, Lasky, Stringfield, and Teddlie (2006) viewed policy as ideas and values which are responsive to the current political and social context. This perspective sees policy mandates as:

an expression of peoples' values, beliefs, and political or moral purposes that are embedded in contexts of power, relationship, institutional and societal norms or conventions, and global economic and political movements that are unique to the time in which policies are generated (p. 95).

Finally, Hall and McGinty (1997) recognized that policy can result in a transformation of intentions. They contrasted conventional policy models, framed in 
rational sequenced stages, with a framework which infuses policy outcomes with process, citing Estes and Edmonds (1981), "the process becomes the policy outcome-that is, the outcome is generated in the process so that the policy is the process" (p. 81). Hall and McGinty went on to state that, "Policy is considered here as a transformation of intentions where policy content, practices, and consequences are generated in the dynamics across time and space. Policies are vehicles for the realization of intentions" (p. 81).

\section{Policy Implementation}

As policy is received at the site it becomes operationalized. As with policy perspectives, implementation, too, has its variation. Policy implementation has been conventionally described in a logical, sequenced fashion by Sabatier and Jenkins-Smith (cited in Hall \& McGuinty, 1997). These authors described stages of agenda setting, formulation, enactment, implementation, evaluation, and feedback. These stages appeared to follow an orderly and rational progression, focus on fidelity, and leave out any opportunity for refinement or adaptation as the process occurs.

Elmore (1979-1980) explained forward mapping, which begins at the apex of a hierarchical chart in the form of clear intent and outcomes. Implementation through this lens occurs in a rational, predictable, and consistent way toward a satisfactory end. This approach, likewise, assumed a rational response on the part of all stakeholders, and has an "implicit and unquestioned assumption that policymakers control the organizational, political, and technological processes that affect implementation" (p. 603).

Clune (1989) found three views of the ways curriculum policy is understood and received by schools in his study of curriculum policy in secondary education. The first, 
school as policy mediator, viewed the school as an active participant in the delivery system of curriculum policy, which included such subcomponents as "schoolwide planning, teacher training, and measurement of student performance" (p. 265) which takes place in individual schools. The second, school as policy critic, suggested that schools which fail to implement policy do so because the realities of school context render success unattainable, and thus, the policy should be discarded or reformed. The third perspective Clune found was the school was policy constructor. This view allowed for alternative policies to be generated at the school level, instead of serving only as agents of implementing imposed policies.

Coburn (2001) chronicled how people in school sites interact with policy to "shape, interpret, adapt, and even transform" policy. Teachers, as enactors of policy, formally and informally demonstrated acceptance or rejection of policy elements, as well as modifications or compromises of procedures, definitions, and/or technical aspects.

Devising policies that support educational change in particular ways requires a finely nuanced understanding of the conditions in which teaching and learning take place. (Berman \& McLaughlin, 1976; Coburn, 2001; Datnow, Borman, Stringifled, Overman \& Castellano, 2003; Hall \& McGinty, 1997; Lasky \& Datnow, 2006). Competing factions about the purpose and nature of schooling, and the enduring educational structures both augment and constrict policies as they are injected into the school environment. Nespor (cited in Bascia, 2001) suggested one way to bridge educational structures is to work across networks and human systems rather than emphasize organizational boundaries. This idea has also been detailed by Lasky (2001), and Lasky and Datnow (2006) in a typology of linkages across which resources and communication flow (or do not flow) 
between educational domains. From this we see how policies are mutually adapted and co-constructed as they journey through various human and structural stages of development and implementation to produce change. Bascia (2001) stated that, "policy, in short, is powerful, but practitioners weave a complicated web of possibilities" (p. 263).

Although policy can be defined from many different perspectives, this dissertation will use the term policy to mean a mechanism used to translate philosophical and ideological ideas into outcomes. Along a policy's journey from conception to implementation, mediating factors and contexts help to shape it into a tool that is bounded by the capacity of the organization. At the site level, people in organizations interpret and negotiate how it will (or can) enact policy, thus change is co-constructed by each domain, or by each level in a larger policy system. (Berman \& McLaughlin, 1987; Coburn, 2001; Datnow, Borman, Stringfield, Overman \& Castellano, 2003; Hall \& McGinty, 1997; Lasky \& Datnow, 2006; Levin, 1998). From this vantage point, change is not viewed as an outcome which is achieved by following a set of dicta that is followed in lock step. As we will see, even mandates, which carry an expectation of compliance (McDonald \& Elmore, 1987), are changed and modified along the way.

\section{Sociocultural Lens}

I use a sociocultural lens and mediated agency to study the ways elements of the Effective Schools for the $21^{\text {st }}$ Century intervention were implemented in participating schools and used for school and classroom improvement planning. Sociocultural theory has received increased attention in the last three decades, and has focused on how social environment, cultural tools, and interactions influence and shape cognitive functions and mediate outcomes. This body of work has explored issues of how concepts are 
understood, how they are developed and shaped through the use of tools and activities, how they are situated in everyday contexts and social interactions, and how they may be distributed across instruments and people.

Wertsch, Tulviste, and Hagstrom (1993) defined mediated agency as people "operating-with-mediational-means" (p. 349). When considering mediated agency in the context of school reform, high stakes accountability mandated in federal policy (NCLB) acts as a mediator as it ushers in new requirements for competencies in data use. Under this new framework, schools begin to understand, interpret, and implement their work differently as it is influenced and shaped by new language, technologies, and data systems that comprise the cultural and social environment of the educational system. Specifically, as new standards, curricula, and data analysis tools are created to meet federal requirements, teachers and administrators reshape their thoughts, ideas, and beliefs as they construct their work together. Thus, the outward social elements of policy for reform mediate and shape the inward, psychological and cognitive processes.

The idea that social, cultural, and historical context of humans was intimately connected to the way people learned and acted was introduced in the early twentieth century by Vygotsky, Leont'ev, and Luria (Cole \& Wertsch, 2006; John-Steiner \& Mahn, 2008). They specifically focused on tools and symbols within environments, and how they shaped or mediated knowledge. To explore this model of how people come to "know" something, Vygotsky maintained that cognitive function takes place on two levels: first on the intermental (or social) plane, and then on the intramental (or individual) plane. The intermental plane is the social interaction that occurs between people; while the intramental plane is the internal psychological cognitive processes that 
take place. Wertsch, Tulviste, and Hagstrom (1993) described this approach as intermental functioning which is a "socially shared process that is mastered and internalized to form intramental processes" (p. 340).

As educational tools such as analyses and technologies for data use are developed within the reform context, people can influence or cause change to happen as they interact with and act upon them. We see then how these cultural and social tools help to shape the agency of an individual or group. As standards, curricula, and data analysis tools are introduced, schools sense an urgency to align their own structures, procedures and resources to meet requirements. This alters the way in which they distribute roles and tasks across the school setting, and the ways in which an individual may act within the new context. Agency, then, is mediated by the larger context of reform and high stakes accountability.

Schools not only are influenced by external contexts, but they also help to shape reform. As they implement practices and strategies to meet mandates, they also develop operating procedures and processes, materials and tools, and normative values. These, too, act to shape outcomes and individual actions.

\section{Data Use Review}

This section will review recent literature on data use, barriers to its use, and the most common ways it is used for educational purposes.

Because NCLB mandated more rigorous standards and an accelerated timeframe compared to existing state legislation, states found themselves in immediate need of accountability tools such as assessments, knowledge about data and data warehousing systems, reporting systems, and the ability to train countless numbers of staff on these 
tools. These requirements put considerable strain on the state's fiscal resources, and impact funding that is available to achieve educational adequacy. To further complicate the issue, if schools do not make their required AYP, they stand to experience lowered federal funds. This fact, taken with the already greater demands placed on schools with high at-risk populations, places even more burden on educators at every level to find ways to improve student achievement, which, undoubtedly, compels improvement in instructional practice. Because of these stipulations, NCLB created conditions for new competencies in learning about and utilizing data to progress toward standards. It was soon obvious that a gap existed in what NCLB required and capacities in the field (data elements), including school and teacher-level capacity to understand, collect, and analyze data from state level achievement scores to classroom level assessments, and to plan for improvements in practice.

Data-based decisions in education have actually been made in this country as far back as 1949, when Taylor expressed the usefulness of data collection for instruction and curriculum (Burks, 1998). Since that time, educators have recognized the usefulness of data, and encouraged its use for improvement efforts. Before the turn of this century, teachers were urged to make improvements by examining existing district data (Johnson, 1997). The emphasis on data has now turned into a nonnegotiable requirement for educators, as described by Earl (2005, p. 6):

Not only are schools being judged using data, many of the reforms also assume or require a capacity on the part of schools and school leaders to use data internally to identify their priorities for change, to evaluate the impact of the decisions that they make to understand their students' academic standing to establish improvement plans and to monitor and assure progress (Herman \& Gibbons, 2001). 


\section{Barriers to Data Use}

Data warehouses and systems. By the year 2000, the need for data warehouses and data systems was apparent (Bernhardt, 2000), but it was still unclear exactly what type of data educators would need to aid them in instructional planning (Killion \& Bellamy, 2000). Croney, Van der Ploeg, and Mansini (2000) discussed the inability of educational data systems to be useful, and supported using data to guide decision making. Daniels and Johnson-Ferguson (2001) described the creation of a computer system to assess student progress during the entire school year, as opposed to waiting until the end of year assessments. In this way, educators could ask what could be done instead of resigning themselves to what had already happened. Four years later, Stringfield, Wayman, and Yakimowski (2004) found that there was a 17\% rate of growth in data use tools, but that the tools focused on administrative applications rather than the ability to make changes at the classroom and student levels.

Professional development/training. Even as NCLB was ushered onto the educational scene, there were admissions that,

Data systems currently exist in most educational institutions, and especially in public education systems, but the knowledge to use data to improve teaching and learning on macro levels (i.e., district, program, and school), and on micro levels (including classrooms and individual learner situations) is lacking (Gordon \& Bridglall, 2003, p.1)

As districts and schools felt the pressure for data use (Conrad \& Eller, 2003; Hardy, 2003; Holcomb, 1999), stakeholders began to herald the call for capacity and training at every level of education, but especially at the school level. Creighton (2001) stated, "until we begin to seriously evaluate and analyze the data that exist in our schools, our profession will continue to be scrutinized and questioned with regard to student achievements and quality teaching and learning" (p. 56). For this to happen, educators 
realized the need for training (Chen, Heritage, \& Lee, 2005; Choppin, 2002; Conrad \& Eller, 2003; Cromey, 2000; Datnow, Park \& Wohlstetner, 2007) to know how to interpret and apply data for improvement planning. Brunner, et al. (2005) examined New York City's public school systems efforts to use data in the decision making process. They described ongoing, unprecedented, and extensive professional development that was needed to build capacity for this work. Chrispeels, Castillo \& Brown (2000) investigated the work of California's leadership teams that had completed a one year professional development program. Training dealt with developing capacity to input data, interpreting data, looking for patterns and trends, analyzing problems, being conducted in the form of summer seminars, data retreats, training of central office personnel or hired experts, instructing school staff to conduct their own data analysis by training a select group of teachers, administrators training school staff, and even providing opportunities for teachers to design strategies for their own curricula (Datnow, Park, \& Wohlstetter, 2007; Dembowsky, Pane, Barney, \& Christina, 2005; Henke, 2005; Huffman \& Kalnin, 2003; Khanna, Trousdale, Penuel, \& Kell, 1999; Datnow, Park, \& Wohlstetter, 2007; Council of Chief State School Officers, 2001).

Need for local data. Since the inception of standards-based reform, states have been dealing with data on a large scale; however, schools soon felt the added pressure of accountability. As a result, schools became the appropriate unit of analysis for using data for educational reform, and even teachers themselves became the focus of data. Schools began to need data that was more relevant to their own sites, and even to their own classrooms. Around the beginning of 2000, many local sources (districts and schools) cited a need for adequate and relevant data warehouse systems, software, disaggregation 
tools (Creighton, 2001; Cromey, Van der Ploeg, \& Mansini, 2000; Daniels \& JohnsonFerguson, 2001), and those calls for better data access have continued (Dembowsky, Pane, Barney, \& Christinia, 2005).

Choppin (2002) studied six Milwaukee schools that attempted data use to inform decision making. He framed his study with four questions: (a) What are the data needs of schools? (b) How can quality and flow of data to schools be improved? (c) What level of data analysis is useful to schools? and (d) How can schools use data effectively to meet their needs? He found that all of the schools cited the lack of access to data. Another common problem was that the data were not aligned to be relevant at the school level. Not only did educators state that data needed to be local and aligned, they also needed data to be delivered at regular intervals, and at more frequent intervals than just annually. There was also a need for software that could process, collect, and analyze data. Choppin went on to report that all six teams faced problems at the school level due to a dearth of data, issues of technical capacity, and lack of personnel resources.

As educational systems began meeting the initial needs of developing (or purchasing) software systems and providing professional development or training, educators began to realize their needed for relevant, specific, local data; not just at the school level, but also at the classroom and, especially, at the student level (Chrispeels, Castillo, \& Brown, 2000; Cromey, VanderPloeg, \& Mansini, 2000; Datnow, Park. \& Wohlstetter, 2007; Dembowsky, Pane, Barney, \& Christinia, 2005). This student level data could be used not only for performance levels, but also to specify at what content and concept level each student was performing. In this way, gaps could be planned for intentionally, and specific, individual lessons can be planned for low performing students. 
Lack of access to data. Many researchers have found that educators lack access to appropriate data, or to a variety of data needed for classroom or school improvement (Choppin, 2002; Council of Chief State School Officers, 2001; Cromey, 2000; Cromey, Van der Ploeg, \& Mansini, 2000). Not only did schools want current data, but they also wanted historical data such as data from previous years, prior grades and scores. Current data that teachers found useful were attendance records, assessments, and discipline. Even the most basic district data showing student achievement was sometimes unavailable, yet schools were asked to collect their own data during the school year. When describing the environment for high stakes testing, Cromey, Van der Ploeg, and Mansini (2000) referred to the inability of most educational data systems to support the use of data to guide decisions.

Ingram, Seashore-Louis, and Schroeder (2004) found that schools oftentimes did not use the quantified data given them by the district, but preferred school/classroom data and anecdotal data. Even as recently as 2005, Dembowsky, Pane, Barney, and Christinia found that survey respondents indicated a lack of appropriate technology, which included computers and software, that could provide needed data. As a footnote to this, schools also cited poor formatting or visual representation of data to be a problem (Choppin, 2002; Council of Chief State School Officers, 2001). Additionally, the simple fact of whether or not data accurately reflect learning of standards was questioned. Herman (2005) found that because assessments did not cover all standards, teachers tend to focus on areas they expect to be assessed.

Conrad \& Eller (2003), Wayman, Stringfield \& Millard (2004), and Wayman, Stringfield \& Yakimowski (2004) called for districts to provide the necessary hardware 
and software, and for the capacity to import and export data to the appropriate recipients to report and set goals for improvement planning. As with any new initiative, there was also documentation of discomfort and unease with data use as well as long-held assumptions about it (Council of Chief State School Officers, 2001).

Need for alignment. A problem that seems to have persisted since the initial realization that data were needed to effectively meet goals set by standards-based education, was the need for alignment (Coburn \& Talbert, 2006; Cromey, VanderPloeg, \& Mansini, 2000; Datnow, Park, \& Wohlstetter, 2007; Dembowksy, Pane, Barney, \& Christinia, 2005; Doyle, 2003). These authors found that alignment was needed among the various educational domains such as assessment and achievement (Choppin, 2002), and especially in the area of curriculum and instruction. Standards, assessment, instructional planning, and instruction itself all were areas that needed to be aligned. Assessment needs to assess what is being taught, and instruction needs to focus on the standards that are to be assessed. Wayman, Midgley and Stringfield (2006) referred to this as calibration, that needs to occur from the top at the district level all the way to the classroom. The authors mentioned some of the components in this process as standards, definitions, learning goals, instruction, assessment, and provided some strategies for support.

Need for multiple sources of data. Literature spelling out the need to have multiple sources of data is abundant. (Bernhardt, 2000; Brunnet, et al., 2005; Council of Chief State School Officers, 2001; Jandris, 2001; Khanna, Trousdale, Penuel, \& Kell, 1999; Lachat, 2002; Lachat \& Smith, 2004; Levesque, Bradby \& Rossi, 1996; Massel, 2001; Rallis \& MacMullen, 2000). Instructional and schoolwide reform requires looking 
into many complex, dynamic components, as well as knowing immediate results and recognizing longitudinal trends. In order to perform tasks a varied as this, no one form or source of data will suffice. Choppin (2002) documented a common desire for quick access to a wide variety of both academic and behavioral data to allow teachers to track student grades and standardized scores, as well as information on attendance and discipline. Historical data and data collected from the current school year were seen as essential for making informed decisions. All of the teams in this study expressed their lack of access to data of this type.

Need for convenient, readable data. Not only do data need to be from multiple sources, literature also documented the need for data to be presented in a way that is convenient (Choppin, 2002; Council of Chief School Officers, 2001). Herman and Gribbons (2001) and Light, Wexler and Heinze (2004) also stated that a key factor in the ability to use and make inferences from data, is how the data are reported. For example, a graph can communicate a great deal of data in a clearer, more concise way that when using narrative description. Holcomb (1999) stated, "If a school portfolio isn't visually appealing, the task of engaging people in discussion of the data and its implications for planning and decision making will be that much more difficult" (p. 91). Lefee (2002) concurred when studying Avon Public Schools in Connecticut:

Like most school districts, Avon collected lots of information. But much of it was organized or reported in ways that rendered it hard to use or worse. "Data collection is a messy, messy business,"...It's done in different formats, sometimes electronically, sometimes on cards or paper. Often it's incomplete. Teachers collect it differently, and not everybody has the same access to it, which means not everybody is going to be on the same page (p.2).

Timeliness. Another difficulty found in data use was the idea of timeliness. Dembowsky, Pane, Barney, and Christina (2005) and Choppin (2002), stated that 
timeliness is a necessary element of data use; however, the ability of districts and schools to provide relevant and timely data are often poor, sometimes influenced by issues such as technical difficulties or datasets being (re)created. Often, especially true for summative assessments, teachers perceived that the data were too old to be useful. Also, much of the summative data were seen only as a confirmation of what the classroom teacher already knew, either from formative assessments, or from classroom performance (Wayman \& Stringfield, 2003)

Consensus on valid data. Educators also grapple with the issue of what constitutes valid data. Coburn (2006) described conflicts within school communities about the issues of whether objective, psychometric assessments, grade-level standards shown by districtlevel assessments, assessments that judge thinking and reasoning, or teachers' clinical judgment. Ingram, Seashore-Louis and Schroeder (2004) also addressed this conundrum. When investigating what data teachers used to analyze their own effectiveness, colleagues' effectiveness, and schoolwide effectiveness, the authors found there were an equal percentage of teachers that held strong beliefs about the need for anecdotal, experiential, or intuitive data as there was for systematic data. Only $15 \%$ reported using both systematic and non-systematic data. Young (2006) described four case studies that looked at grade level efforts to meet expectations for data. The study documented that each of the four schools used different data to achieve the goal of instructional improvement.

Uses of Data

Strategies for improvement planning. Improving teaching and learning has come to be the implicit purpose for current data use. The elements that comprise this process 
have been described by many authors (Council of Chief State School Officers, 2001; Cromey, VanderPloeg, \& Mansini, 2000; Datnow, Park, \& Wohlstetter, 2007). What these authors found was that improvement began with collaborative conversations or by asking guiding questions, such as: Where are our students currently performing? Are there any gaps among students? What are we doing to address our weaknesses? Are they working? In fact, Cushman (1999), and Datnow, Park, and Wohlstetter (2007) stressed the importance of asking questions to explore and set goals with data.

Besides framing data work with questions, other frequently noted strategies for school improvement were looking at demographic data, tracking student performance, and using, or in some cases, creating benchmark assessments so teachers could see how students progress at frequent intervals. Armstrong and Anthes (2001) documented that schools that compared their scores to other schools with like demographics but higher scores, were highly motivated to improve teaching and learning for their own students. Brunner, et al. (2005) stated that teachers even used data given from a specialized program (Grow Report) to align relevant professional development sessions. This helped them to become more knowledgeable about how to improve their instruction in areas of student need.

Coburn (2006) posited that teachers viewed data as something that can inform them about what students know and what strategies students use. This understanding can then help teachers to better fit their instruction to learner needs. Many references were made to the general process of data being used to inform best practices, using data for improvement of instructional strategies, planning lessons from data, addressing achievement gaps, informing teacher practice, or for informing next steps (Armstrong \& 
Anthes, 2001; Brunner, et al., 2005; Cromey, Van der Ploeg \& Mansini, 2000; Datnow, Park, \& Wohlstetter, 2007; Earl, 2005; Herman, 2005; Protheroe, 2001).

Tracking student progress. Another common practice of data disaggregation to improve student performance is to track student progress. Armstrong and Anthes (2001) found that districts using data to make decisions saw improvement in curriculum, instructional strategies, and overall student outcomes. Common practices among six school districts investigated included setting benchmarks for students to achieve, and then tracking their performance at regular intervals. This data were then used to develop new instructional strategies for those students missing the benchmark. Brunner, et al. (2005) investigated uses of The Grow Report $\odot$ and found that teachers used this data tool to monitor their students' performance and make adjustments such as assigning students to groups, differentiating or individualizing instruction, and even as documentation to support creation of Individual Education Plans. In 2005, Pennsylvania did not have a statewide data analysis system that could adequately track student data. As a result, not only could they not keep an eye on students' academic performance, but there was also no access to information such as demographics, mobility rates, and records.

Cross-site visits for schools with like data. Data have also been useful in motivating low-performing schools to higher achievement. Copland (2003) described the use of design studios, where a school that heavily engaged in an improvement effort invited other schools to come and observe their practices. In turn, the visitors go back to their schools to discuss ways they could implement what they had seen. This practice, initiated by teachers, was seen as an authentic professional learning community, extending beyond a directive of an administrator. Datnow, Park, and Wohlstetter (2007) 
also found that decisions based on data that was shared across schools produced positive benefits in planning school improvements.

Dedicated coaches for data management. The way data were received, managed, and distributed was found to take many different forms. Feldman and Tung (2001) documented the use of an external coach who worked with teachers in whole school reform, in academic teams, and weekly meetings with administrators. One of the core practices identified to effect change in schools was for coaches to help in data-based inquiry and data based decision making. The authors stated a wide range of activities that encompassed work around data. Examples included looking at student work samples in writing and developing new instructional strategies, as well as being the person who collected the data from teachers. Teachers viewed the coaches' work to have an influence on change in instruction and in the classroom. Schools that utilized a dedicated coach, expert, data analyst, or point person to collect, manage, organize, analyze, distribute and discuss data are documented in other studies (Armstrong \& Anthes, 2001; Feldman \& Tung, 2002; Herman \& Gribbons, 2001: Killion \& Bellamy, 2000; Lachat \& Smith, 2004; Noyce, Penny, \& Traver, 2000).

Using data for at-risk identification. Identifying at-risk students is one of the primary uses of data analysis. In fact, advancing struggling students to proficient levels is at the heart of NCLB. Scores from annual state testing indicate not only whole school indices (AYP), but also disaggregate the standing of each student for reading, math, and selected other content areas according to grade level. Chen, Heritage and Lee (2005) argued that monitoring annual scores, alone, will not narrow the achievement gap, but rather "continual monitoring and interpretation of performance so that students who risk 
not meeting standards can be identified early and steps can be taken to provide additional support." (p. 311). Data will continue to play an ever-important role in teasing out what places a child at risk and when they are at risk. Stringfield and Land (2002) stated that "the sheer abundance of potential risk factors now makes possible the classification of nearly every student as at-risk at some point during his or her school life" (p. 3).

Teacher views of data. If data are to be used to effect change, they must end up in the hands of teachers. Coburn (2006) extended the typical empirical image of data when she spoke about evidence use. She found conflicting views of what constitutes data and evidence of student learning. One area of disagreement was the degree to which teachers' possessed a unique ability to make connections between instruction and student responses. Her study found the teachers' clinical judgment was seen as the most valid source of evidence. Some districts also call for students to participate in their own data analysis, goal setting, and instructional planning (Brunner, et al., 2005; Cromey, Van der Ploeg, \& Mansini, 2000, Stiggins, 2008).

\section{Other Evidence}

Most people think of the word "data" as referring to evidence that involves statistical analysis, randomized studies, and controlled circumstances used for the purposes of investigating or exploring hypotheses. There is, however, much more to be said about data and the gathering of evidence. Schön (cited in Kowalski, 2008) discussed how evidence is also acquired through in-use theories or action theories. These theories are constructed through educators' daily practice based on their own observations and experiences. 
Whitehurst (2007) contrasted empirical evidence with professional wisdom, composed of educators' experience and the consensus views of teachers. He put forth that education currently relies more heavily on professional wisdom than on empirical research, and showed graphically that the field of education lags behind other social science fields in gold standard research. He emphasized, however, that both experimental data and professional wisdom are jointly needed. Empirical evidence aids education in eliminating trendy approaches, investigating competing approaches, and expanding knowledge in the field. Whitehurst posited that professional wisdom also plays a role in adapting results to local contexts, and in applying action theories in areas where empirical research is lacking.

Mayer (2003) contended that not only are empirical data needed in educational research, but also that systematic observations in natural contexts are "acceptable sources of evidence... as long as they inform a particular recommendation for practice" (p. 3). Kowalski (2008) concurred, recognizing that evidence such as objective; consistent observation reports and document analysis constitute data.

There have been some studies which documented processes in which schools investigated and planned instructional improvement (Datnow, Park, \& Wohlstetter, 2007; Dembowsky, Pane, Burney, \& Christinia, 2005; Earl \& Katz, 2005; ), using data and other evidence, but few have captured specific conversations, verbalized thought process, and interactions as they relate to the activities, norms, and tools used to construct instructional improvement planning. This paper is concerned with which data teachers find useful to analyze, how it helps them delineate problems, and what processes, tools, and norms are utilized to aid in the planning for instructional improvement; as well what 
strategies, conversations, and tasks are used to move student performance to higher levels.

\section{Growing Complexity}

When looking chronologically at research on data use, one can see that it is becoming more complex over time. When educators first began realizing the benefits of data, there were calls for data warehouses and systems that would make assessment results available at the school level. As these requirements began to be met, educators began to question what types of data were useful, and the purpose of numerical "scores." Soon classroom teachers began to call for systems that could not only report, but disaggregate data in ways that were readable and relevant to their own students. Not only did teachers realize the need for multiple sources of data, but they required that the data be immediate or at least timely enough for them to interpret and use results in next steps planning.

As educators have become more sophisticated in using and understanding data, they are now realizing that not all data are created equal. For instance, summative or annual data are assessment of learning that tells what a student has already learned, while benchmark data are useful for providing snapshots of how a whole school, grade group or classroom is performing. Conversely, summative or benchmark data do not hold the same value as formative data to inform instructional planning at the classroom level. Formative data taken by teachers at the classroom level, such as anecdotal notes, checklists, exit slips help to inform teachers about daily student understanding of content. Armed with this information, teachers then can make specific diagnostic determinations and plan effective next steps, such as differentiated instruction, reteaching, regrouping of students 
or whole group instruction. (Stiggins, 2006; Stiggins, 2008; Stiggins \& Chappuis, 2008).

The most current and refined research on data use and making informed decisions from data, calls for tight alignment of educational standards, analysis of performance assessments and formative assessments (Ainsworth, 2009; DuFour \& Eaker, 1998; DuFour, DuFour, Eaker, \& Karhanek, 2006; DuFour, Eaker, \& Many, 2006). With these cohesive elements in place, data can be a powerful tool in painting an accurate picture of student performance, providing a compelling tool for accurate planning, and helping to create policy that is challenging, yet with attainable goals.

\section{Distributed Leadership}

Even though No Child Left Behind implicitly requires educators to have competencies with data, it nowhere mandates or describes the how of this process, or the way in which these competencies can be reached. Assumed in the federal requirements for proficiency based on data-driven results is the idea that once confronted by the empirical evidence, schools will analyze these results and use that information for improvement in schoolwide or classroom practices, leading to increased student achievement in order to meet AYP requirements.

There is research that links the role of distributed leadership to developing capacities for implementing school reforms. This sociocultural leadership approach provides insight on how schools establish normative routines, tools, and structures (Chrispeels, 2004; Spillane, 2005) that can be key in creating and developing knowledge, skills, and practice for change.

Copland (2003) found that for school improvement to be successful, there must be a collective effort, "dependent not on the actions of singular visionary individuals, but 
rather on a set of functions or qualities shared across a much broader segment of schools community" (p. 2). Chrispeels (2004) also recognized that leadership is distributed is an "emergent property" that is seen as people combine their individual expertise to bring about change which could not be effected by one person alone (p. 5). She emphasized that distributed leadership was connected to teachers' capabilities, citing DarlingHammond, Bullmaster, and Cobb (1995),

teacher leadership is inextricably connected to teacher learning; that teacher leadership can be embedded in tasks and roles that do not create artificial, imposed, formal hierarchies, and that such approaches may lead to greater profession-wide leadership as the 'normal role' of teacher(s) (p. 87).

Chrispeels (2004) also explored how teachers came together to problem-solve and plan improvement through activities that were not necessarily part of a hierarchical system, but that, instead, grew out of an interdependent relationship of socially constructing work together in grade-level teams. One important finding from her six years of researching leadership teams was that principals found ways to work together with teachers in ways that distributed leadership when they learned how to interpret data together.

Just as Hutchins (1995a, 1995b) theorized that learning goes beyond individuals to include tools and instruments, Spillane, Halverson, and Diamond (2004) extended the idea that activities and tasks can be distributed interdependently among individuals or teams of individuals. They described a distributed perspective of working, stretched across the interactions between leaders, followers, and situation, to be most effective for leading schools in capacity for innovation. In constructing this framework, the authors theorized that "leadership involves mobilizing school personnel and clients to notice, face, and take on the tasks of changing instruction as well as harnessing and mobilizing 
the resources needed to support the transformation of teaching and learning" (p.12). This speaks to external processes that construct the practice of leadership. The interactions that are constructed in situations also help to constitute the situation due to the interdependent nature of this leadership dynamic (Elmore, 2000; Leithwood, SeashoreLouis, Anderson, \& Wahlstrom, 2004; Spillane, Halverson, \& Diamond, 2004; Spillane, 2005).

Leadership has been explored through many different lenses in recent decades, focusing on leader styles, characteristics of leaders, and activities or daily operations of leaders. In all these examples the unit of analysis was the leader, or in school terms, the principal. Spillane, Halverson, and Diamond (2004) contrasted distributed leadership with the traditional hierarchical models that view the administrator as the expert at the top, who directs and doles out responsibilities to the staff. Rather, they described leadership as being distributed across principal, teacher leaders, followers, and context (or situation), making the appropriate unit of analysis the school rather than, solely, the administrator.

By including followers as a component of leadership, the authors acknowledged the power of those who are lead to influence outcomes. Sergiovanni (1992) asserted that, "when followership and leadership are joined, the traditional hierarchy of the school is upset" (p, 71). Followership, then becomes a constitutive element of leadership. This brings up the conceptual notion that leadership and followership can be interchangeable roles for an individual, depending on the situation at hand to determine which role is taken. Thus, leadership is not seen as a static position, but a fluid dynamic in an organization. As well, by incorporating the environment as an element of leadership, 
Spillane, Halverson, and Diamond (2004) gave significance to the interactive nature of actors, artifacts, and situation.

\section{Proximal Outcomes}

Whole school reforms are complex and multi-faceted. Understanding what elements of a complex reform are adapted or implemented in the early stages and throughout a reform must happen if researchers are going to draw conclusions about a reform affecting change. Both "intent to treat" and "treatment on treatment" (or said another way, what the intervention intended to do, and what was actually implemented on the ground) need to be considered when investigating reform efforts (Shaddish, Cook \& Campbell, 2005). With a complex reform such as ES21, one needs a way to break down the study of change by subcomponents of the intervention over time. Therefore, investigating proximal outcomes becomes important to understanding what changes occurred in the use of new tools, enacting new norms, and new procedures and processes.

Anson, et al. (1991) discussed proximal outcomes in The Comer School Development Program. Although the ultimate desired outcome of this program was increased student achievement, the authors recognized the underlying foundations of promoting teacher-student relationships, normative values of trust and respect, and affirming students' individuality as proximal, yet necessary elements of this reform effort. Likewise, when investigating mentoring programs, Karcher, Kuperminc, Portwood, Sipe and Taylor (2006) described outcomes in terms of proximal, enabling, and distal. Proximal outcomes were those outcomes that were the immediate results of activities engaged in by the participants. The authors found that these proximal outcomes "may serve as mediators or moderators of program effects on distal outcomes" (p. 716). 
Since it is not known how long it takes to create school environments and conditions for sustainable reform, programs that do not recognize proximal outcomes as part of this process, may prematurely judge a reform effort to be unsuccessful.

\section{Mediated Agency}

I use distributed leadership, as described above, and mediated agency to anchor this study. In a sociocultural context, mediated agency refers to people (individuals, communities, or organizations) operating-with-mediational-means (Wertsch, Tulviste, \& Hagstrom, 1993). As we have seen, mediational means can include those attributed to Vygotsky's work such as language, works of art, maps, and numeracy. As sociocultural theory has developed, we have also seen that new technologies such as cockpit instrument panels and computers qualify as mediators.

Just as leadership encompasses more than the individual, bringing about organizational improvement also involves more than individual agency. To summarize from above, Rogoff (1990), Tharp and Gallimore (1998), Vygotsky (1962), and Wertsch, Tulviste, and Hagstrom (1993) identified and described sociocultural terms wherein priority was given to cultural tools and the social contexts in which the learning takes place. These tools and contexts were not viewed simply as activities and settings, but they served as factors that actually shaped how something was perceived and acted on. As well, humans formed beliefs, understandings, and values, and carried out actions that were constituted of cultural, historical and social structures.

Within the school setting, improvement interventions then become mediated by contexts such as policy, standards, state and district procedures, and mandated outcomes. In the current educational climate, all of these contexts require competencies in using and 
applying data. As change is implemented, practices change, capacity for data use increases, and change is constructed, or mediated, in the interactions of individuals engaging in activities within these contexts, as well as within the assumptions and beliefs of individuals. Done collectively, a school becomes a community that amounts to more than the aggregate of individuals. Rather, it becomes interconnected and interdependent in nature, functioning as a cohesive unit, and serving as the appropriate unit of analysis to explore how change is mediated through a system.

\section{Framework for Analysis}

Halverson, Grigg, Prichet and Thomas (2005) described distributed leadership as a system of practice that relies on artifacts, which they defined as programs, procedures, and policies. They emphasized identification of key tasks and structures that schools used to share tasks among people and across these artifacts. These structures took various forms, such as subject area groups, grade groups, or whole school meetings. These structures were for the purpose of creating a flow from evidence to classroom teacher.

Wayman, Midgley, and Stringfield (2006) used the terminology of activities and materials. They illustrated the term activities with examples of common grading among teachers, and analyzing data to find strengths and weaknesses prior to planning. They referred to shared materials as a way teams distribute information across actors. As well, Timperley (2005) stated that contracts (in the form of mandates or imposed policy), "do not stand independent of a set of interactions surrounding them, and their interactions are strongly influenced by beliefs about how to achieve the outcomes" (p. 146). She spoke of project tools, structures, activities, processes, and routines when framing the discussion of how schools worked toward improvement in a distributed way. 
In a seminal discussion of distributed leadership Spillane, Halverson and Diamond (2004), and Halverson (2006) stated that school leadership is best understood through tasks around artifacts. They also posited that when analyzing distributed leadership in schools, the framework needs to include more than just identification and analyzing of these tasks, but to also look at the way the tasks are acted out. This involves more than just listing out daily practices, but also analysis needs to include the assumptions, beliefs, and experiences.

As described, multiple terminologies are used in literature to describe distributed leadership key constructs. As part of the Effective Schools for the $21^{\text {st }}$ Century project, a framework was developed that allowed participants to "think, talk, and work with colleagues in their schools and across the project in ways that furthered system-wide learning" (Lasky, Schaffer \& Hopkins, 2008, p. 99). This framework included the organizational scaffolds of "activities as structures for investigating and talking about data, tools such as technology or materials for developing expertise with new language, practices and processes; and norms or rules for collegial interactions that focus on school improvement" (Lasky, Schaffer \& Hopkins, 2008. p. 99). During my work as researcher on the project, I realized that this framework could be extended as a way to analyze how leadership was distributed as teachers and administrators worked with data for school improvement. This framework encompassed the various elements of the intervention system, core elements of the professional development, and how constructs of distributed leadership could be reflected in proximal and distal outcomes (see Appendix 2). The framework in Appendix 2 was developed by Dr. Sue Lasky, assisted by Dr. Gene Schaffer, myself, and two other graduate students. It was based on current literature, 
several iterations of discussions around research, and professional experiences. The framework was built around three organizational scaffolds that shape and distribute implementation of reform efforts. These are: (a) operating procedures and processes as structures for developing school capacity in the areas of evidence-based planning and data use to inform instruction; (b) materials and tools such as technology or materials for developing expertise with new language, practices, and processes; and (c) norms and rules for collegial interactions that focus on school. These key constructs of distributed leadership are core organizational conditions that can mediate and scaffold learning, and reform implementation in schools. They will serve as anchors that will drive my analysis for this paper, along with data use in the current context of high stakes accountability.

Two core elements of the matrix were of interest to this study. They were: (a) Physical environment supports and reflects a Highly Reliable Learning Organization with Distributed Leadership, and (b) Valid evidence and student data from multiple sources inform best practice in whole school Standard Operating Procedures, Staff Performance, and Classroom Teaching. Investigating proximal and distal outcomes of how data are used for improvement planning using a distributed leadership model is also considered in this dissertation.

\section{Conceptual Framework}

The model presented in Figure 1 (p. 52) guided this research. In this model, No Child Left Behind is the context that drives the need for improvement planning. Federal mandates issued in this document place rigorous demands on schools for increased student performance. These new accountability standards created a need for teachers and 
administrators to develop a wide range of skills in data use, including analyzing, interpreting, and reporting data.

To achieve these skills, individuals must also develop abilities to read data in various formats and from multiple sources, become familiar with data warehouse and reporting systems, and develop statistical competencies. People in schools also must learn to think together as an organizational unit to use data most effectively (Earl \& Timperley, 2007). As this capacity is built, teachers and schools can more successfully use data to examine instructional practices and plan ways to improve them to raise student achievement.

Improvement planning provides the opportunity to use and analyze data and other evidence to determine student performance. Given this information, educators can explore pathways for action and make revisions to their instruction. These revisions may be manifested in ways such as reteaching, differentiated learning, creating assessments for learning, student (re)grouping, Lesson Study, revising curriculum, or a variety of techniques and methods to best fit the need at hand.

ES21 was an intervention using professional development with distributed leadership as the vehicle to develop capacity for data use in schools. The three constructs of distributed leadership that were developed during the ES21 project (see Appendix 2) are the mediating variables that influence the outcome of improvement planning.

For my analysis, I use a sociocultural epistemological lens and highlight the three organizational scaffolds that created the conditions for people to think, talk, and work with colleagues in their schools in ways that furthered their learning and intervention implementation, and extend the scaffolds as an analysis tool for distributed leadership. 
These scaffolds are: (a) operating procedures and processes, (b) materials and tools, and (c) norms and rules (Lasky, Shaffer \& Hopkins, 2008; Spillane, Halverson \& Diamond, 2004; Wertsch, Tulviste \& Hagstrom, 1993). In reality, these constructs are interconnected and interdependent; yet each can be foregrounded systematically for analysis.

Operating procedures and processes are structures such as various types of schools meetings, activities such as data analysis, creating rubrics, or examining student work, and practices such as peer observations. These procedures and processes serve to develop capacity for data use and evidence-based planning to inform instruction.

Materials and tools are resources such as technology, reports, protocols, or rubrics used for developing expertise with new practices, processes, and language. These materials and tools are shaped by the context and needs at hand, and also help to shape the context and process itself.

Norms are the tacit beliefs that in essence govern behaviors, whereas rules are explicit guidelines and policies. These norms can be described as standard operating procedure for schools, or "just the way things are around here." Even though leadership that is routinely distributed in schools can be considered a normative value in itself, a more specific description of this process will be examined.

Lastly, a major feature of this framework is its iterative nature. Each component of this framework serves to inform other components throughout the process. 


\section{NCLB Context}

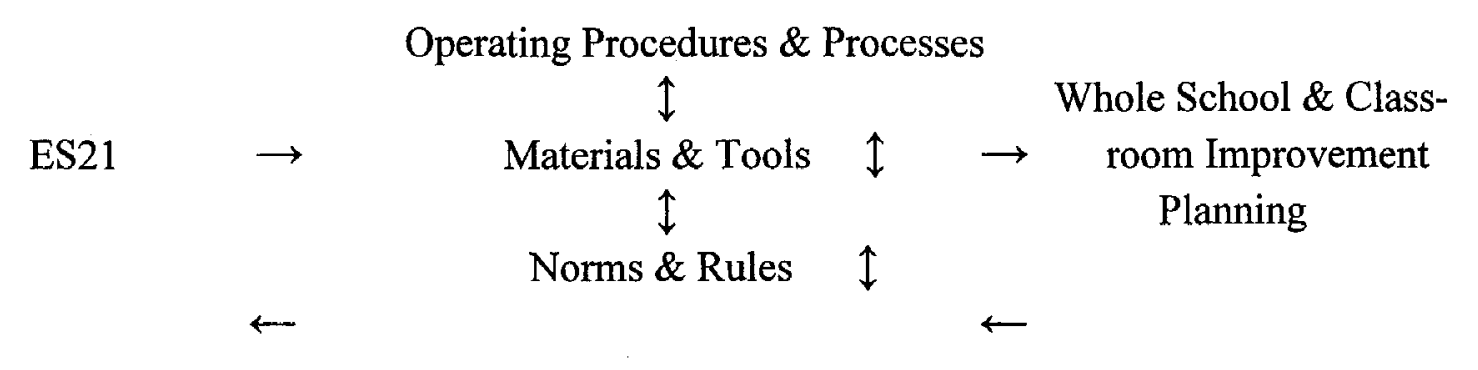

Figure 1. School and classroom planning driven by ES21 strategies as mediated by three organizational scaffolds in the context of NCLB.

Significance of the Study

The primary significance of this study is to explore how two core components of a complex intervention were implemented over time. Investigating these core components of distributed leadership for data use, and organizing them using the key constructs of operating procedures and processes, materials/tools, and norms/rules, will help to inform how the reform effort moved through the educational system, and how relationships and interactions between people, products, and environment continue to seek best practices for improvement. Findings can also add to the body of literature about how distributed leadership is operationalized, and to influence the creation of realistic and achievable policy goals.

\section{Research Questions}

The following questions guided the investigation and framed the data collected and analyzed.

Questions:

1. What elements of ES21 are evidenced in teachers' talk, and procedures and processes related to data use for improvement planning over time? 
2. What elements of ES21 are evidenced in teachers' talk, and materials and tools related to data use for improvement planning over time?

3. What elements of ES21 are evidenced in teachers' talk, and norms and rules related to data use for improvement planning over time? 


\section{CHAPTER III}

\section{METHODOLOGY}

This section explains the methodology that was used to guide this study.

Qualitative data were collected and analyzed in this investigation, and are described here. The section ends with ethical considerations.

\section{Study Within a Study}

This study had its origins in work done on a larger study, Effective Schools for the $21^{\text {st }}$ Century (ES21). Dr. Sam Stringfield was the principal investigator for the study funded by the Olin Foundation. Dr. Sue Lasky served as co-principal investigator. ES21 was a three-year, longitudinal, experimental, mixed method study that investigated a school effects intervention. The study involved 34 schools from the states of North Carolina, South Carolina, California, and Kentucky. Seventeen experimental schools received the intervention utilizing a distributed leadership model for implementing strategies learned during research-based professional development. The goals of this study were to (a) study and document the extent to which research-based school intervention strategies were successfully implemented, and to explore school-level factors that would predict successful implementation, (b) document the relationships between school-level implementation and effects on students' outcome gains, (c) document the effect of the school level intervention on behaviors of teachers in the classroom, and (d) explore contextual factors at the school, district, and state levels, and the extents to which 
these contextual-level factors affect intervention implementation, outcomes, and sustainability/institutionalization (Stringfield \& Lasky, 2005).

This study was rooted in research conducted on effective schools, highly reliable organizations, and co-construction. Prior to Lezotte's work which delineated the Correlates of Effective Schools (1991), research was already beginning to explore characteristics that were present in schools experiencing success regardless of students' family background or socioeconomic status. Characteristics that defined these schools received much attention in the 1980s (Good \& Brophy, 1986; Purkey \& Smith, 1983; Ralph \& Fennesssey, 1983; Rowan, Bossert, \& Dwyer, 1983, cited in Stringfield \& Teddlie, 1991a).

Between 1981 and 1992, Stringfield and Teddlie (1988, 1991a, 1991b) researched school effectiveness in urban, suburban, and rural schools in the Louisiana School Effectiveness Study. The study was conducted in five phases with a variety of findings which included the fact that both teachers and schools could "strongly influence achievement" (Stringfield \& Teddlie, 1998, p. 44). They also found that:

(1) student perception of positive academic climate, (2) principals' sense of school efficacy, (3) family commitment to education, (4) student sense of longterm educational achievement, and (5) absence of a negative school climate were associated with achievement, which showed that "what schools do can dramatically affect student achievement, regardless of socioeconomic status" (p. 44).

During the course of the study, connections to high reliability organizations (LaPorte \& Consolini, 1991) began to be made. Stringfield (1995, 1998; Datnow \& Stringfield, 2000) described conditions that existed in these organizations and that could be applied to schools. Highly reliable organizations operate on the premise that every task 
must be performed with accuracy each and every time. He summarized (Datnow \& Stringfield, 2000) that a school could be considered "highly reliable when:

1. A finite set of clear goals, shared at all organizational levels.

2. A shared belief across the levels that failure to achieve those goals would be disastrous.

3. An ongoing alertness to surprises or lapses. Small failures that can cascade into major academic problems must be monitored carefully.

4. The building and maintenance of powerful database. These databases are (a) relevant to core goals, (b) rich in triangulation on key dimensions, (c) real-time available (i.e., before failures cascade), and (d) regularly cross-checked by multiple, concerned groups.

5. The extension of formal, logical decision analysis as far as extant knowledge allows. Many regularly repeating tasks become standard operating procedures.

6. Initiatives that identify flaws in standard operating procedures, and honor the flaw finders.

Highly reliable organizations characteristically engage in decision making at high levels, which requires:

7. Extensive recruiting.

8. Constant, targeted training and retraining.

9. Serious performance evaluations. In HROs, monitoring is mutual, without counterproductive loss of overall autonomy and confidence. This is achievable because the goals are clear and widely shared. HROs do not engage in one-way monitoring for its own sake. 
10. Because time is the enemy of reliability, HROs are hierarchically structured. However, during times of peak activity, HROs display a second layer of behavior that emphasizes collegial decision making, regardless of position.

11. Clear valuing of the organization by their supervising organization(s). All work to maintain active, respectful communication.

12. Short-term efficiency takes a back seat to very high reliability" (pp. 186-187). Reform efforts that were based on Effective Schools Research coupled with principles from Highly Reliable Organizations, have been implemented within specific educational contexts in Wales. Research studies indicated that the schools there showed positive results, and continued to show gains four and five years after intervention efforts ended (Stringfield, Reynolds, \& Schaffer, 2008).

Datnow and Stringfield (2000) stated that, "For schools to become HROs requires well-focused coordination among key groups within a school, district, and state;" however they also pointed out that "a host of normative and political shifts [are present in reform] that the HRO literature does not fully illuminate, yet are clearly endemic to the process" (p. 187). Datnow, Hubbard, and Mehan (1998) described efforts to coordinate these key groups within local contexts as co-construction.

Datnow and Stringfield (2000) argued that schools utilizing an outside reform design need cooperation and collaboration among the design team, educators, and policy makers to successfully implement, much less sustain, the effort. It is through this work together that the effort becomes co-constructed. This includes each aspect of the reform, from the beginning stages of finding a good fit between the school and the intervention when selecting a program (adoption), to implementation, to sustainability. When 
improvement efforts integrate these key players and elements over time, they all shape the way the work is done, and the success or failure of the effort.

The ES21 study, based on these principles, was an experimental, randomized field trial. Thirty-four schools participated; seventeen experimental and seventeen control. Schools were matched for socioeconomic populations with other schools in the same districts. The experimental schools served a high proportion of at-risk students, and had been inconsistent in meeting their Annual Yearly Progress (AYP) goals for No Child Left Behind. The experimental schools were asked to select teacher leaders to attend the professional development sessions along with their principals. Both schools chose one representative from each grade group (K-5) to be on the teacher leader team for ES21. A distributed leadership model was used to implement the strategies learned during the professional development sessions as the leaders returned to their own schools.

The professional development curriculum was based on school effects research as well as research grounded in highly reliable organizations, and included:

- Refinements in the Grade Level Teaming process and extensions of the Strengths-based Change Model (Chrispeels \& Andrews, 2007; Chrispeels \& colleagues, 2000; Chrispeels \& Gonzalez, 2007)

- A focus on students' productive work-(Clare \& Aschbacheri, 2001)

- A deepening use of Lesson Study (Lewis, 1995)

- A focus on Extended Instructional Time, including effective Homework (Cooper \& Valentine, 2001)

- Organizational development based on High Reliability Organizations (HROs) and High Reliability Schools, especially extensions of Standard Operating Procedures and the gathering/efficient storage/analysis of data to inform instructional decision making (Stringfield, 1997).

- The importance of Critical Friends (Bambino, 2002; Coalition of Essential Schools, 2006; Cushman, 1998). 
- Making productive use of the reality of co-construction of school reform (Datnow, Hubbard, \& Mehan, 2002; Datnow \& Stringfield, 2000)

Professional development sessions were held in each school district at least four times each year at outside centralized locations. In addition, each of the three years included a cross-site summit, which all experimental schools attended. The first year's summit was located in Atlanta, and was attended by principals and district personnel. The following two sessions, held in San Diego, California, and Charlotte, North Carolina, were attended by both administrators and leadership teams from each school. These sessions were designed to share and review experiences and progress, and to collaborate toward goal-setting and problem-solving in a collegial manner (Stringfield, 2006).

Data for This Study

Data for this dissertation were in part collected during my work as a Graduate student research assistant for the project. A year after the study ended, I collected data from two of the experimental schools. Both schools were close in proximity, and had volunteered to be in the larger study knowing there would be a random assignment. Also, the administrators agreed for data collection to take place in their schools. All teachers in these schools were invited to participate in interviews with me. This invitation was extended during whole school staff meetings, and in grade group or job embedded professional development sessions. As well, I asked school administrators to refer teachers that would likely be interested in being interviewed. School administrators were interviewed before and/or after each observation. 
Methodology Rationale

This was a qualitative study using data collection of observations, interviews, and document analysis. Qualitative methodology requires data collection that is "up close and personal." Observations of actions, listening to conversations, asking questions, and collecting documents as they happen allowed for a closeness to people and places that was needed to answer the questions posed in this investigation.

The larger study was a longitudinal, random assignment, mixed-method study (Tashakkori \& Teddlie, 1998). As Mayer (2003) contended, research should be issuedriven instead of doctrine-driven that relies heavily on ideologies and beliefs about one research method or another. Rather, he stated that:

...researchers should select research methods that can test hypotheses or answer research questions. Thus, researchers should be able to choose from a variety of methods ranging from controlled experiments to observational studies, and to choose from a variety of dependent measures ranging from quantitative to qualitative. In my opinion, it makes sense to use a range of methods and measures that all converge on understanding (p. 362).

Thomas (2004) posited that not all data have equal value relative to a hypothesis, question, or decision. For information to be counted as evidence, it must be relevant and plausible. There must also be a determination of whether the data gathered are sufficient. The data gathered must be considered in light of other information, or "corroborating evidence" (p. 4). As well, valuable evidence is based on its veracity; and is evidence free of significant error or influenced by strong beliefs or ideological perspectives. Mayer (2003) summarized this by stating that the relationship between data and the problem being addressed is what should determine the method(s) that are used to produce the data rather than by ideology or preference. 
To illustrate, Edwanger (cited in Boaler, 2008) described in detail a single student's misconceptions of mathematical concepts. This study greatly impacted the field, not because Edwanger:

showed through trials that one [methodological] approach led to such behaviors and another did not, but because he was able to provide the detail and the texture in his analysis that enabled people to see and understand the link between the teaching approach experienced and the mathematical thinking he developed. (p. 592)

The author went further to contend that despite the commonly held belief that qualitative studies are not generalizable, they actually can be because they provide the "depth of observation and analysis that enables readers to understand a connection or phenomenon clearly and judge its applicability to other cases" (p. 592).

\section{Case Study Design}

This dissertation used an exploratory study case design (Cresswell, 2005; Yin, 1994). Cresswell (2005) stated that case study design is appropriate to study a group of people engaged in activities over time. The case study may also represent a process where the researcher seeks an in-depth understanding of the case, or in this case, two research sites.

Case study differs from other approaches to research because it allows the investigator to study a current phenomenon in context (Yin, 1994). Experimental and quasi-experimental research seeks to eliminate context so that a phenomenon can be studied in isolation (Shadish, Cook \& Campbell, 2002). Also, while a survey may attempt to explain context, it is seen as removed from actual occurrences. Likewise, conducting historical research involves context, but does not allow for contemporary data collection. 
Case study, which is considered a type of ethnology, also differs from other ethnologic approaches because it proposes a theory prior to data collection. For instance, grounded theory allows a theory to develop after the data have been collected. For this dissertation, I proposed that the school level constructs of procedures and processes, materials and tools, and normative values would mediate how schools plan together. Theorizing prior to collecting my data was a strong indicator that case study design was the appropriate research method. As well, comparative analysis of the two schools in this study necessitated a case study design to analyze both schools separately, and to conduct a cross-case analysis. Case study design also derives benefit from previous theories that guide data collection and analysis.

Other technical characteristics of case study design arise given that context and phenomena often blend together, making them difficult to distinguish individually. Because of this, the researcher must realize that there will be other variables discovered in the investigation that may not be of particular interest for the study at hand, while recognizing the need (and having planned for) collecting multiple sources of evidence for triangulation. The blending of context and phenomena could almost be a tacit assumption. The intricate and multifaceted daily interactions that comprise the "phenomena" of school planning are made up of a complexity of variables. Some of these variables directly relate to the planning processes (such as scheduling, funding, and student performance), while others impact the process in a more peripheral way (personalities of teachers, availability of resources, physical location of classrooms). Just from composing this extemporaneous list of variables, it was easy to see that not all of them were pertinent to my study. 
Case study design allowed me the opportunity to conduct research "on the ground" for the events I am investigating, relying on observations, interviews, and documents to create a narrative analysis of the ways that people come to understand and act upon daily situations (Miles \& Huberman, 1994). In this way, I was able to obtain a very personal picture of what happened in the schools in my study.

My case study design was holistic, marked by a single unit of analysis. The unit of analysis was "schools"; specifically, two schools that had participated in the ES21 project. Summarizing briefly from the literature review, this unit of analysis was chosen over a singular leader because the school is the primary place where change occurs (Spillane, Halverson \& Diamond, 2004). Even though the focus of this study was "schools" as a unit, I also looked at distinct multi-level factors, such as grade levels, vertical teams, or even individual teachers and administrators. This allowed me to foreground specific elements for discussion, and to look systematically at how leadership was distributed across various elements that constitute a school as a whole.

Because there was more than one school, this case study was a multiple-case design. By collecting data from more than one school, comparative analysis can be conducted to investigate similarities and differences. Multiple case studies are considered more robust than single case studies. (Yin, 1994). When collecting and analyzing data, I operated under the same methodological framework for all schools.

Drawing heavily from sociocultural theory and a distributed leadership framework helped to guide what points of data I collected, and the lens through which I structured my study. Taking all of the unique features of case study under consideration, 
this design was the best and most logical choice for the purpose and questions in this paper.

\section{Checking for Researcher Bias}

Because I am currently an elementary school administrator conducting similar activities in my own school, $\mathrm{I}$ had to consider and examine the possibility of personal bias. Even though all schools in this particular district engage in school planning, the processes carried out by each individual school can differ. Because I was a researcher on the ES21 project prior to commencement of this study, I had already seen a variation in the ways that the different schools approached their planning process. This was also true in regard to my own school compared to the schools in this study. Realizing the individualistic nature of context in each school under consideration in this study helped to eliminate and/or significantly reduce any predisposition or bias toward data collection and analyses.

Also relevant to this point is that when conducting data collection and analyses, I was careful to look at each school independently. While all schools have many characteristics in common, each has its own distinguishing features and "personalities." Cresswell (2005) cautioned that research should be legitimate, evaluating each context in terms of "participants' lives, historical and cultural influences and the interactive forces of race, gender, and class" (p. 437). 


\section{Qualitative Data}

In this section I discuss the qualitative data collected in this study. The sample for the study will be described followed by descriptions of data collection and analysis. This section will end with limitations of the study and ethical considerations.

Qualitative methods, as discussed above, can give depth, context, texture, and nuance to answering the proposed questions. Observations of planning sessions; interviews with principals and teachers; document analysis of protocols, rubrics, district, school, and classroom assessments; researchers' field notes and reflective journal served as data. Most of the data were collected as part of the ES21 study. Follow-up interviews in each school were performed following the completion of that project, and under IRB approval for this paper.

\section{Sample Selection}

The sites. Research was conducted in two urban elementary schools with low and/or low-to-mid socioeconomic (SES) levels. The schools had not consistently met their AYP goals over the last six years. The sample was purposive and based on convenience. The schools had volunteered to be included in the ES21 study prior to the selection process, and were subsequently randomly assigned to the experimental group. The schools were chosen for this study because they received the intervention strategies over the years of 2005 - 2008 during ES21, and because they were in close geographical proximity which provided easy access for data collection. In their last session together in the ES21 intervention process, these schools observed and planned together for the upcoming school year. Their conversations together were documented and served as a springboard to the data collected in this study. 
Participants. Participants included administrators and teachers from two elementary schools that had been involved in the ES21 project. All of the participants were in the same school district. The number of participants who were available for this study varied between the two schools due to the unique daily operations and schedules in each school. In School A, seven teachers and one administrator were interviewed. Four of the teachers and the administrator had served on the ES21 leadership team, while three of the teachers had not. In School B, five interviews were conducted. The administrator and two teacher leaders from this school had participated in ES21, but the remaining two teachers had not.

\section{Instrument Development}

The interviews. The interviews were semi-structured and open-ended. They were developed to guide toward the constructs in my research questions, drawing somewhat from my own experiences with teachers and administrators relating to data use, and from the many hours of data collection on the ES21 project. The "start list" (Miles and Huberman, 1994) of constructs included questions not only about behaviors, but also allowed for comments on beliefs and attitudes about data use in schools.

When I began to design the protocol for interviewing I wanted to be sure that I emphasized the use of data in its various forms and ways they were used. After reviewing the final draft of several iterations, I found that I had overemphasized questions to establish the use of data without probing issues that related to my mediating variables. I saw that I needed to be more methodical in the organization and language of my questions to be sure I included the constructs of procedures and processes, materials and

tools, and norms and rules. Approaching the questions from a more systematic, organized 
perspective, I was able to establish data use within the context of asking questions about the variables.

I decided to structure my interview questions to be open-ended. This allowed the respondents not only to answer, but to comment on their answers, providing comments and even opinions. When I worded my questions I was careful not to embed assumptions. For example, before questions asking about specific tools and materials, I would lead with a broad, open-ended question about the various ways data were presented. That allowed me to follow up with questions about displays, charts, rubrics, etc. Respondents were allowed to expound on their answers, providing illustrations and examples.

Another issue that I considered was how to document the interviews. For some short, more informal interviews, I have used real-time transcription. While this certainly reduces the amount of time involved in transcribing, I felt there were too many negative factors to use this approach for my dissertation. For instance, the presence of a computer is a physical barrier between the interview and respondent. Even the extraneous noise of keystrokes can be a distraction. Also, sometimes precise words and language are lost in an attempt to keep pace with the respondent's speaking fluency. As well, I wanted to establish a personal, face-to-face atmosphere to encourage a sense of affinity and trust.

Inherent in interviewing is that the respondents need to have some degree of trust in the interviewer. Respondents were being asked to be honest and open, sometimes revealing closely held thoughts and ideas. The likelihood of this happening is much reduced, if not nil, when the interview is not able to establish a sense of trustworthiness. Because I have been involved in the ES21 project for two years prior to this study, I was familiar to most respondents. They had seen me work as a researcher as they attended 
professional development sessions and cross-site visits. Although I am not personally close to any of those interviewed, I feel that I have established a rapport and a sense of professionalism with them.

\section{Data Collection}

In qualitative research data collection is a circular process. As Thomas (2003) described, both inductive and deductive reasoning inform each other during the process of a qualitative study, and set up a cycle during the process. Whether starting from an inductive or deductive framework, both lenses are necessary during the course of the investigation.

This study used data collected as part of the larger study from the years 2005 to 2008. There was an interview that was conducted in the spring of 2007, which created the initial thought process and inspiration for this study. Data were collected in 2008 as part of the larger project, and continued in 2009 and 2010 as part of this study.

The observations. Observations were conducted at two cross site sessions attended by all 17 experimental schools, a cross-school session attended by both schools in the study, and six other observations for the two schools in this study. Both schools had received the experimental intervention strategies over the three years of the project.

The two cross-site sessions for all 17 experimental schools were conducted so participants could learn, think, and talk together about implementation, strategies and planning of the intervention. The cross-school professional development session for the schools in this district was designed for the schools to learn from each other and plan together in the winter of the 2008 school year. The purpose of this meeting was to 
explore, learn from instructional and environmental strategies, and give feedback to the host school.

In the spring of 2008 , the schools attended their last professional development session, and were observed in planning sessions to implement some of the strategies that were presented. Along with observations from this planning session in May, 2008, two other school observations were conducted in October and December of 2008. During these observations, a staff meeting focusing on peer observations and feedback, and job embedded professional development sessions analyzing a video of reading instruction were conducted.

In the fall of 2009 , School A was observed as they began constructing their improvement plans after receiving No Child Left Behind AYP scores and state assessment results. Third through fifth grade students in this state had been assessed during the previous school year in reading and math. Fourth graders were also assessed in science, and fifth graders were also assessed in social studies and on-demand writing. The schools then used this data to set annual goals and objectives as well as the strategies to achieve them.

Each school met in various forums of staff meetings (utilizing both whole group and horizontal groups) or job embedded professional development sessions. The forum chosen for each school was based on the principal's judgment as the best way to accomplish the purpose for the meetings. Each principal described the work they were doing in the various sessions. During part of all of these sessions, the teachers and administrators used data and other evidence to plan classroom and whole school improvement. Observations of these sessions were conducted by recording notes and 
some conversations during the various meetings. Either on site transcriptions or transcriptions of the recorded events served as documents for analysis.

The interviews. Interviews were conducted during the winter of 2010 with each principal, leadership team members, teachers, and the lead professional developer of the project. Interviews with the principals and a sample of teachers serving on the leadership teams explored what, if any, aspects of the ES21 intervention strategies were still being used, and how they were implemented. The interviews ranged from approximately 20 to 30 minutes, and were conducted before or after observations, and/or at the end of the study, and were recorded or transcribed. These interviews served to clarify or expand on issues or situations that were not readily known to the investigator. Interviews with the lead professional developer were conducted to answer questions about ES21 content he had presented to school staff, and to get his impressions on what the principals and leadership teams had implemented in the schools, as well as what challenges they faced.

The documents. The documentation collected from schools included protocols, rubrics, district, school demographic information as well as school, district, and statewide assessment documents. The ES21 professional development session power points and materials were also collected. Of special importance were the sessions on establishing and integrating leadership, conducting lesson study, and sessions relating to analyzing and planning from assessments. Documents were collected on an ongoing basis throughout the course of the study as they were used.

\section{Data Analyses}

I used a social anthropology approach for my data analysis. Miles and Huberman (1994) described this approach to analysis for studies that are 
interested in the behavioral regularities in everyday situations: language use, artifacts, rituals, relationships...As Van Maanen (1979) put it, the prime analytic task is to "uncover and explicate the ways in which people in particular [work] settings come to understand, account for, take action, and otherwise manage their day-to-day situation.' This 'uncovering' and 'explicating' is typically based on successive observations and interviews, which are reviewed analytically to guide the next move in the field (p. 8).

I saw many similarities between my investigation and the characteristics of this approach. I explored day-to-day operations of schools using observations and interviews along with document analysis. The successive nature of this approach allowed for data analysis and data collection to inform each other during the process. As part of my analysis I also used the systematic devices of a Partially Ordered Meta-Matrix and a Content Analytic Summary Table to assist in coding and displaying evidence.

One of the decisions I had to make regarding data analyses was whether or not to use computerized programs to search for keywords to code. I had previously done coding by hand and found the process very authentic. It allowed me to build knowledge about each piece of data to build a complete picture of this study. As well, when coding by hand, I could see that a single passage or "chunk" of data could be relevant to more than one code. When coding the evidence, I used open coding, and began by developing codes that correlated to the constructs of processes/procedures, materials/tools, and norms/rules. For transcribed materials, I read for cohesive "chunks" of narrative that were relative to my "start list". They were then coded by hand and later arranged into displays of a Partially Ordered Meta-Matrix and a Content Ordered Display.

All data were coded using a Partially Ordered Meta Matrix that categorized findings by descriptors according to each site. This tool allowed the data to be standardized into the same units for analysis. It also helped to synthesize the data, 
reducing them into fewer sets to explore the various relationships and establishing common terms and language (Miles \& Huberman, 1994). At first, different matrices were assembled for each school; then later iterations were developed for across school analysis. The data were coded for operating processes/procedures, materials/tools, and norms/rules.

Data were also organized into a Content Ordered Display. This display helped me to focus on the content of the cases regardless of the case it came from. It allowed me to look at how often certain of the mediating variables occurred and to look for trends and unique characteristics of data use across the schools.

The observations. Observations were recorded using a digital or manual recorder, and/or transcription. Field notes were also taken from actual conversations and events in the meeting sessions. Because data collection and data analysis inform each other, the observations served to provide new information for interview questions, or to rephrase or clarify them. Observation data were coded by hand beginning with the "start list" and analyzed for themes for each school and categorized according to the display tables. After this process was completed for one school, the same process was completed for the other schools. Patterns, similarities and differences were explored within schools and across the schools.

The interviews. All interviews were transcribed from a digital or manual recorder, or on-site transcription, and were arranged chronologically by school. Following transcription, I coded the interviews by hand and arranged them by schools. Each school's interview analysis was begun from the "start list" with new codes added as they emerged. The data were then analyzed using the Partially Ordered Meta-Matrix and the 
Content and the Content Analytic Summary Table. Codes were analyzed for themes. These themes were explored both within and across schools to look for patterns of similarities and differences emerged.

The documents. Documents were collected from the ES21 project sessions including session handouts, protocols, and power points. Documents from each school were collected as I visited them for observations and interviews. The documents were arranged by schools, coded by hand by school, and arranged on the display tables to search for patterns. They were also described by their use, such as assessment tools, reporting tools, or supporting documents.

\section{Limitations of the Study}

This study has some limits inherent in qualitative research. Even though literature refers to the researcher being an "instrument" during investigation (Guba \& Lincoln, 1985), what the researcher records (for example in notes) and how it is interpreted is, no doubt, framed by his/her inherent persona and life experiences. As a school administrator also engaging in the same type work that I am investigating, I bring my own interpretations and frame of reference to this project.

There is also the risk of influencing any actions or outcomes of what is being observed by the very fact that the observer is present. This phenomenon is known as reactivity (Maxwell, 1997). This author explained, however, that trying to completely eliminate the researcher's effect is not a meaningful goal in qualitative research, but understanding how the participants might be influenced is more important.

As well, the site selections for this study came from a larger study. Thus, these schools had already shown willingness to be included in ongoing research, and so may 
not be representative of schools chosen at random, independent of any other investigation. Another limitation is that the sample of schools was small, as were the administrators and teachers that were interviewed. As well, the teachers agreed or volunteered to be interviewed, which in itself is a subset of teachers at each school. All of these factors limit the generalizability of this study.

\section{Ethical Considerations}

This study followed the procedures outlined by the University of Louisville Institutional Review Board. Since researchers have an obligation to the participants of a study to respect the possibility of risks, I completed the human subjects' protections certification, as required by the University. All participants were informed about the purpose of the research and given the option not to participate, either in observation or in interviews.

The observation and interview processes were structured or semi-structured. All interview questions were related only to the purpose of the study and to the research questions. Participants were informed that observations, interview responses, and documents obtained during the study were kept in confidence, and would not be subsequently revealed. Data have been stored in a safe location, and audiotapes will be destroyed after three years. 


\section{CHAPTER IV}

\section{PROFESSIONAL DEVELOPMENT}

The Effective Schools for the $21^{\text {st }}$ Century intervention utilized distributed leadership as the vehicle to implement intervention strategies at the sites. The developer of the professional development sessions described this distributed leadership in terms of an operating procedure:

Well, the delivery system [italics added], in the sense of how do we get this out to the teachers, is one piece in that we run this program with leadership teams identified by principals in schools, and these leadership teams represent a wide array of people from the individual schools. They are [a] cascade model to deliver back to the different folks at the school to the grade level teams and however the school designs that.

One difficulty of this system over time proved to be that team leaders changed from year to year, which made continuity of knowledge, ideas, and implementation challenging. Nevertheless, both schools maintained teams consisting of the administrator and teacher leaders over the three years of the project.

The sessions were spread over three years, and were designed to give the participants both theoretical knowledge and practical skills that would establish and sustain highly effective schools. There were some initial setbacks regarding the materials for the professional development curriculum. The developers had been assured that materials were available and suitable for the upcoming sessions. As plans continued, it became apparent that the existing materials were either unavailable or insufficient for the project. As a result, materials had to be created specifically for the ES21 project, with 
only a rough outline of the sessions completed at the end of the year long planning period. Refinements of the materials continued over the three year course of the project to tailor materials for the sessions and the individual schools or districts..

The curriculum was research-based with foundations in the Correlates for Effective Schools (Lezotte, 1991). The sessions were designed to give teacher leaders strategies they could take back to their schools for implementation with the purpose of (a) developing procedures and processes based on the correlates, (b) aligning resources so that work based on the correlates could occur, and (c) creating and developing structures that enabled people to build skills to achieve the goals of the correlates. Over the course of the program, the developer of the professional development sessions worked with the participants to assess school-level strengths and challenge areas.

As stated, the effective schools correlates provided the foundation for the intervention, but other resources supported the intervention. They were:

- From rhetoric to real: The BEST approach to comprehensive school reform

- Chrispeels \& Daly's (2005) strength-based approach to professional development

- Highly Reliable Organizations (Stringfield, 1995; Stringfield, Reynolds, \& Schaffer, 2008)

- Data warehousing and presentation software systems to improve classroom teaching (e.g., Wayman, Stringfield, \& Yakimowski, 2004)

- Reliable co-construction of school reform (Datnow \& Stringfield, 2000); and

- Review of the most recent research on school effects (Teddlie \& Reynolds, 2000) 
The practices taught in the professional development session were tightly linked to the work from high reliability organizations. Strategies such as the multiple "layers" of structures (such as horizontal grade groups and vertical groups), and re-rostering of students originate from ideas proposed in high reliability organizations. As work on the professional development component progressed, feedback by the principals and teachers helped to modify, and to some extent tailor, the materials and activities. Components were dropped, added, or modified accordingly. As the ES21 professional development team became familiar with each district and school, plans and materials were created to accommodate their needs. This exemplified co-construction of reform efforts among colleagues that was specifically tailored to each school's needs and capacities.

A powerful result of co-constructed work is not only that it is intentional, but that it becomes relevant to teachers and staff at individual schools. The procedures and processes, materials and tools that are developed, and the norms and rules that are set become relevant to school needs, and also to the strengths and capacities in each school. As these capacities are identified and exercised through implementation, it provided opportunity to increase capacity among individual teachers and as a whole school as they worked to become more highly reliable organizations.

\section{Year 1}

The content for Year 1 was successfully covered during the planned sessions. Teacher leaders and principals from both schools attended the sessions. Also, the Director of Research for the two schools in this study appointed a liaison to attend the professional development training. Both schools met together in six district-level sessions throughout the $2005-2006$ school year. Even though several accommodations had to be made for 
alternate session dates as conflicts arose, the first-year content was completed. These sessions introduced and grounded the participants in the effective schools correlates, and worked to establish and develop teacher leadership teams in both schools. The content also focused on each school creating a focused mission, understanding of high-quality teaching, and understanding data. Following the sessions, the leadership team returned to their schools to train their school faculty and staff.

In addition to the district-level training, there was one cross-site session that included principals and central administrators for all 16 experimental schools, although the liaison for the two schools in this study was not in attendance. This meeting was held in Atlanta over three days during the summer. The content for this session was to review Year 1 activities, and to reinforce understanding of the correlates and the processes involved. The participants also looked forward and planned for Year 2, which focused on increasing the principals' participation in the intervention, and goal setting in each school between the principal and leadership team. Another important part of this session was to continue the shared learning between the districts and states in this project. Day 1

The first day of Year 1 laid the groundwork for coming sessions. The seven effective school correlates were introduced and an acronym was created to remember

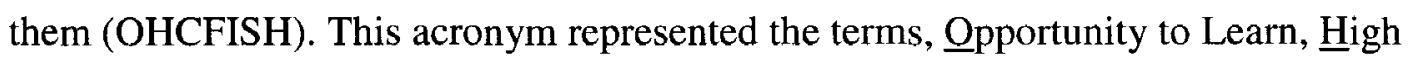

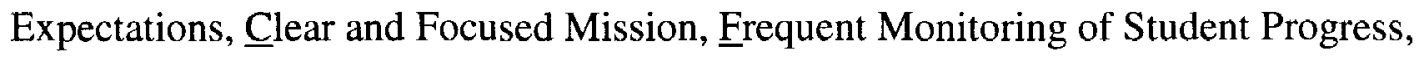
Instructional Leadership, $\underline{\text { Safe }}$ and Orderly Environment, and Home-School Relationships. Teachers began to build their leadership skills by considering their strengths based on personality types. The teachers saw this as an approach to assuming or 
apportioning tasks for themselves and in their respective schools. This activity was used to develop a bond and a sense of teamwork. This session was also designed to be a highefficiency model for conducting meetings.

The purpose of the session was to help the leadership teams develop skills to be strong collaborative leaders, especially in four major areas:

- Setting Direction

- Developing People

- Designing the Organization for Success, and

- Leading for Social Justice

During the session, each team leader assumed a role, performing specific tasks of facilitator, recorder, process observer, or timekeeper. The session ended with the leadership teams constructed an ACE goal for their school (achievable, challenging, exciting, measurable, and focused on student learning).

Day 2

Day 2 began to focus on the theme of Developing People. In the first activity, the leadership team (LT) was asked to grade the effectiveness of a lesson, using the letters AF. After viewing a video of the lesson, the LT broke into grade level groups and established the criteria for the grade. Following this, they went back to their original groups and charted the themes that arose.

To parallel this activity, each participant was given a copy of the article Five Standards of Effective Teaching, by the Center for Research on Education, Diversity and Excellence (CREDE). The groups used a jigsaw format to present the information and 
were encouraged to observe the likenesses between the five standards and the criteria they created for the lesson that was presented.

The next activity involved a second video which was designed to focus on positive aspects of interpersonal relationships. The participants chose a partner from their team and interviewed each other, using an interview protocol that was provided. Insights about each person were recorded on a summary sheet. All participants then gathered to hear an exciting story or a quote they had heard from their respective partners about powerful teaching. Major themes and common themes were charted and posted by each team. Following this, the teams engaged in a "field trip" activity to share their findings.

To incorporate and align the information from the three activities (grading the lesson, comparing the five standards to their own criteria, and peer interviews) the groups were asked to agree on three to five themes or ideas. They were asked to list these ideas on chart paper and to come up with a symbol or a metaphor that represented them.

Next, the leadership teams were asked to create "Provocative Propositions." These are positive, present tense statements that should be: (a) based on collective history, (b) stretch the status quo, (c) suggest real possibilities, (d) provoke action, (e) guide team learning, and (f) challenge assumptions. Examples of Provocative Propositions were mentioned, and the teams then shared their work, offering feedback to each other. They were then given a chance to modify their statements.

The session was closed by a discussion of how the participants could share the knowledge they had gained from this day with their schools. A final slide, designed to focus on positive leadership language, was presented:

5 Words: You did a good job. 
4 Words: What do you think?

3 Words: $\quad$ Can I help?

2 Words: Thank you.

1 Word: We

Day 3

Day 3 began with reflection by teacher leaders completing guiding questions. The next two activities were designed to investigate qualities or descriptors of leadership. The teams were asked to give Likert responses on a scantron sheet, responding to 32 leadership team descriptors. They also were asked to rank 23 aspects of leadership as it was functioning for them at that time. These activities were created to help the participants see their progress over the course of the workshops.

The theme for Day 3 was Designing the Organization for Success. After the LTs assigned the roles of recorder, facilitator, timekeeper, and observer, they created an organizational chart that reflected their school. Information on the charts included school committees, flow of information, flow of money, and other elements that affected the workings of their schools, including the LT itself. Following this activity, the participants had a discussion of school committees, thinking about how to utilize them more effectively, and aligning them with the Effective School Correlates. A sample for reorganizing a school organizational chart was provided.

Next, the leadership teams were given the article, Beyond Testing: The 7 Disciplines for Strengthening Instruction (Wagner, 2003). Participants were encouraged to read the article independently and highlight selections that were meaningful to them. Then, as a team, they completed a rubric for their district for each of the seven 
disciplines, ranking them from "not yet started" to "well established." They also listed evidence to support their judgments.

To build on this and previous activities for Day 3, the participants took the organizational charts they had constructed earlier, and discussed what they had learned about organizational coherence. Following this discussion, the leadership teams created a new chart they felt could optimize their school's effectiveness. All of the teams were invited to look at each other's charts and offer feedback.

To conclude, the teams developed an action plan for their schools. They also shared this with the other participants. Looking ahead to the next session, Day 4, the LTs were asked to conduct "Powerful Teaching" interviews with their colleagues, and to bring their class rosters. At this time, parent and staff surveys were distributed.

Day 4

For a brief review of Day 3, the participants engaged in activities that focused on decision making and guidelines for effective meetings. Participants practiced these skills as they met over a team journey map created by each team. This map illustrated their journey toward the goals they set for their schools. The participants then engaged in three activities over the course of the day to help them practice the guidelines for effective meetings.

The first activity was designed to process the interviews that the participants had conducted with their colleagues about powerful teaching. They identified common themes, talked about how they related to their ACE goals, and shared with the whole group. 
For the second activity, the leadership teams used their class rosters to identify one student who was not quite achieving proficiency. The teams were introduced to rerostering, which is a tool used to focus on each child by planning appropriate instruction and interventions. The groups then were asked to rewrite their rosters, ranking the students in order of highest to lowest student achievement. At first, the students' rankings were based on one source of data, but after the rankings were created, other sources of data were considered as substantiation.

Following lunch, the focus shifted to perceptual data. The participants used perceptual data as they recorded strengths and concerns, along with supporting evidence, for each of the correlates.

In the third activity, the LTs worked in pairs and summarized the perceptual data they had aligned with the correlates. Each pair analyzed two correlates, shared their findings, and picked one or two that could support the team's ACE goal. The teams were asked to teach the re-rostering strategy to one grade level at their school and to record their observations. They were given time to discuss and decide what, when, where, and how they would share the information they had learned on this day with their colleagues. Day 5

Day 5 began with information on effective grade level meetings. Challenges included a lack of time for grade level teachers to met, lack of training for effective meetings, isolation of teachers, and the untapped resource of teacher knowledge.

Next, information from two studies was presented on the benefits of teachers' interaction. The studies were conducted in a California school district with a student population of 16,000 students. Data for this study consisted of surveys, focus groups, and 
observations, and were collected by the Center for Educational Leadership and Effective Schools at Santa Barbara.

The first study investigated teachers' perceptions of what grade level structures and processes contributed to grade level meetings that impact teacher and student learning. Results revealed that regular grade level meetings, quarterly vertical meetings, grade level meetings that have a focus aligned with school goals, alternating roles for members, and creating an agenda and taking minutes for each meeting were elements that facilitated learning. Also, the study found that highly effective grade level meetings were characterized by annual goals, using protocols, positive group interactions, group facilitation training, and team building strategies. Finally, this study found that norms which facilitated learning were encouragement of divergent views, recognition of members' uniqueness, open expression of concerns and ideas, and seeking to understand others.

The second study explored what work teachers did on grade level teams to support student learning, and how it influenced the generation of knowledge. Investigation of the first question found that the work teachers did that supported student learning was: sharing, discussing, reflecting, interaction around objects, creation of objects, and observation. The concept of moving from independent to interdependent work was discussed along with these strategies.

The types of knowledge that were generated were found to be: content knowledge, pedagogical knowledge, pedagogical content knowledge, knowledge of students, and knowledge of self. The participants discussed all of these findings and discussed implications for their own practice. 
The next part of Day 5 emphasized student work and focused on evidence to describe strengths, errors, and standards. Following this analysis, the teacher leaders were asked to make inferences about a student, and then shift their emphasis to themselves as teachers. They, then, discussed ideas and strategies to move the student to the next level, using the personal pronoun "I." After this focus on student work based on evidence, the focus shifted to lesson quality and alignment. Working in pairs, participants evaluated a lesson using a rubric from CRESST (National Center for Research on Evaluation, Standards, \& Student Testing) with indicators of cognitive challenge, clarity of goals, clarity of grading criteria, alignment of learning goals and task, alignment of learning goals and grading criteria, and overall quality of assignments.

The leadership teams were then asked to bring work to the next session. They were to interview a proficient student as well as a student approaching proficiency following a lesson. They were to ask:

- What were you supposed to do?

- What did you learn and how do you know?

- What did I do that helped you learn?

- Explain how you were graded.

The participants were then given time to decide where, when, how and what to share with their schools from today's session.

Day 6

Day 6 of the first year of ES21 began with a review and reflection of each previous session, reviewing the role of the leadership teams, and setting the agenda for this day. The first activity was to review the student interviews the teacher leaders had 
conducted at their own schools. The purpose of the interviews was for teachers to understand how their knowledge of student perceptions of lessons can inform lesson planning and instruction. Teachers shared two or three themes and discussed how the data they collected from the interviews might influence lesson development. Following this, they aligned these findings with their ACE goals.

Next, the focus continued with the third component of training designed to build strong collaborative leadership, Designing the Organization for Success. This component helped to develop structures and processes to foster trust, coherence, shared leadership, organizational learning, and flexibility. The teams completed a continuum survey exploring organizational relationships, and then tabulated the results from four of the questions. They discussed the similarities and differences in their groups, and were asked to provide evidence to support their rating. A group discussion was then held to discuss how the team had achieved their current level of implementation, how they would move to the next level, and how they would transition the entrance or exiting of new members.

Following lunch on Day 6, the teams focused on Setting Direction. Teams revisited and built on their ACE goal as they engaged in discussions with the other participants to hear their experiences and knowledge. They engaged in a jigsaw to review the work they had done so far:

- Correlates of Effective Schools

- Five Standards for Effective Teaching

- Strengths-Based Reflective Inquiry Interview Process

- 7 Disciplines for Strengthening Instruction

- School Organization 
- Re-rostering and Use of Data (Perceptual/Achievement)

- Atlas Protocol for Reviewing Student Work

- CRESST Rubric for Lesson Quality

Team members reviewed their journey map, and added to it. The journey map displayed highlights of the team's learning and growth as it went through the first year's sessions. It also was a tool for sharing their experiences with their own school communities. Participants traced their learning and activities throughout Days $1-6$ and highlighted meaningful "nuggets" through drawings and symbols. They planned next steps for achieving their ACE goals and shared this information with others, while listening to their feedback.

The teams then reconvened to discuss the feedback they had received for the next steps toward their ACE goals, and modified steps as they felt necessary. As the teams concluded their first year together, they were encouraged to continue adding to their journey maps and action steps during their school year, and were instructed that they would begin Year 2 by reviewing the progress and evidence during the implementation of their plans.

\section{Year 2}

Year 2 was conducted during the $2006-2007$ school year, and consisted of four sessions. These sessions emphasized the use of data when analyzing student work. The topics of lesson study and homework to enhance student performance were also discussed. 
Day 1

After a period of time for the participants to visit and become reacquainted with each other after the summer break, the participants engaged in a review of the project. The purpose of ES21 and its unique elements were discussed. Also, the participants established where they were in implementing the ES21 elements. This was accomplished with an activity called Chronology Mapping. Not only did this activity allow each school to map where they were, each school was able to see where other schools were, and new members to the leadership teams were brought up to date.

The teams also reviewed the acronym OHCFISH and the Effective School Correlates that align with each letter: Opportunity to Learn and Time on Task, High Expectations, Clear School Mission, Frequent Monitoring, Instructional Leadership, $\underline{\text { Safe }}$

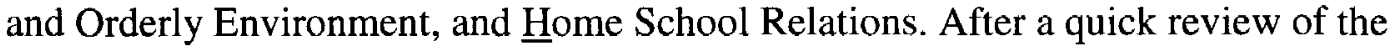
previous year's professional development content, the teams each selected roles for each member, and discussed the four purposes of the leadership teams: Setting Direction, Developing People, Designing the Organization for Success, and Leading for Social Justice.

Using data for school and student improvement was one of the major components of Year 2, and was introduced on Day 1. The presenter explained that using student data when looking at student work ensured that the schools needs would be met, essential knowledge could be gained to become an Effective School, grade leaders would learn strategies for disseminating to colleagues, and that student learning would be enhanced. This discussion led into the introduction of data-driven decision making. Indicators of selected sources of data were: (a) timeliness, (b) workshop evaluations, (c) Effective 
Schools surveys, (d) principal's summer survey, (e) school visits, (f) school data (standardized tests, attendance, Annual Yearly Progress data, and state data). These indicators were then linked to the Effective School Correlates to show how the use of data contributes to making a school effective. Next, two cycles for decision making were introduced and discussed. The components differed in terminology for the two cycles, but emphasized a process for decision making. The first cycle for decisions based on data included:

- Collect and organize data

- Analyze data patterns

- Pose hypotheses

- Develop improvement goals

- Design specific strategies

- Define evaluation criteria

- Make the commitment

The second cycle was similar in process and in content, but listed the following components:

- Setting the vision

- Collecting and Analyzing Data

- Identifying Challenges

- Action Planning

- Annual Assessment

The teams then discussed how to use data in their respective schools. Before returning to the ES21 project sessions for Year 2, the teams had been asked to bring three types of 
data with them. The first one was a piece of student writing that was representative of their current classrooms. They were also to bring interviews from two or three students, described as "one-legged" interviews. This term indicated the very brief nature of the interview process; very quick, almost "on the fly" or "one-legged." The teachers were to ask, (a) What school lesson do you remember most? (b) What makes a lesson interesting to you? and (c) If you were teaching, what assignments would you give students for homework? For the third type of data, teachers were to pick the most meaningful assessment they had for their class and/or school.

These three types of data represented three different data sources. The student writing and student interviews were classroom-level data sources. These data were used to offer insights in student thinking, ideas, opinions, or feelings. The student responses helped teachers plan lessons in ways that students prefer, and targeting learning styles for certain students. The data for the most meaningful assessment could be considered classroom, district, or even state data. Other types of data discussed were standardized tests, attendance data, discipline reports, free and reduced lunch, teacher turnover, and meeting agendas.

Further discussion emphasized that for data to be used effectively, they should be disaggregated and an item analysis conducted. Other topics included additional sources of data that could be useful to improve instruction, and effective use of data. An example of data use was shown in the form of a data road map. A chart was presented contrasting decision making based on intuition or convenience and decisions based on data. 
Table 1

Chart contrasting educational decision making based on intuition or convenience with decision making based on data

Decision Making Based on Intuition or Convenience

Data-Driven Decision Making

Tradition

Scattered staff development programs as

an improvement

Budgetary decisions based on prior

practice, priority programs

Staff assignments based on interest and

availability

Reports to the community about school

events

Goal-setting by board members,

administrators, or teachers based on

votes, favorite initiatives, or fads

Staff meetings that focus on operations

and the dissemination of information

Parent communication via twice-a-year

conferences at elementary "open houses"

and newsletters
Focused staff development programs

Strategy to address documented problems/ needs

Budget allocations to programs based on

data-informed needs

Staff assignments based on skills needed

as indicated by the data

Organized factual reports to the

community about the learning progress of

students

Goal-setting based on data about problems

and possible explanations

Staff meetings that focus on strategies and issues raised by the local schools' data

Regular parent communication regarding

the progress of their children 
Grading systems based on each teacher's

criteria of completed work and

participation

Periodic administrative team meetings

focused solely on operations
Grading systems based on common

criteria for student performance that reports progress on the standards as well as work skills

Administrative team meetings that focus on measured progress toward data-based improvement goals

Next, Atlas Protocols were established for student work. Sample student work was distributed while each team reminded themselves of their existing norms. One of the teacher leaders from each team described the assignment that produced the student work. Teachers had the chance to ask clarifying questions while the presenting teacher listened without comment and recorded comments on a four-column chart. To conclude this activity, the team reflected on the protocol process.

Day 2

Day 2 began by setting the agenda and reviewing the importance of establishing norms. Team jobs and responsibilities of facilitator, recorder, process observer, timekeeper, and historian were established. The purpose and goals of ES21 professional development for the leadership teams were reviewed. The purpose and goal of the program were reviewed, along with two other elements which were: (a) the key focus areas of Setting Direction, Developing People, Designing the Organization for Success and Leading for Social Justice; and (b) the iterative nature of data-based inquiry.

The first new element introduced for Day 2 emphasized the benefits of collaborative work. Quotes and statistics were given that showed how work done through 
observation and sharing could benefit students. An activity designed to engage in work in a format called a vertical slice was completed. This activity asked the participants to suspend their own personal judgment while they only made observations. Following this, they were to share their observations in small groups, and reflect on questions that this process raised for themselves. After this experience, the idea of employing protocols for discussions was introduced. A protocol was defined as consisting of agreed upon guidelines for a conversation. By understanding and agreeing to this structure, the presenter explained that people are enabled to have a certain kind of conversation that people are not in the habit of having. Protocols were also described as vehicles for building the skills and necessary for collaborative work and building trust by doing substantive work together. Further, protocols were described as creating a structure to make it safe to ask challenging questions of others.

From this description of protocols, the presenter asked the teams to work in vertical slices to complete an activity where the participants observed or read a piece of work in silence, responded to what they saw along with giving evidence to support the observation, ask questions that their observation raised. Notes were taken for the team by the facilitator. Next, the facilitator asked the group to look at the evidence given for the activity, as well as what areas of strength could be used to build on, and to make decisions about where instruction should be focused next time.

The next topic presented to the leadership teams was on Research Lessons, or Lesson Study. Five elements of a research lesson were delineated: (a) the actual classroom lesson with students, watched by other teachers; (b) that it was planned for a long time, collaboratively, (c) that it brought to life a goal or vision of education; (d) that 
it was recorded (video and audio), accompanied by student work; and, (e) that it was discussed by faculty and sometimes outside commentators. It was pointed out that when a teacher acts as a researcher, it provides him/her an opportunity to research his/her own understanding about the way their students think (Lewis, Perry, Hurd, \& O'Connel, 2006). As well, it was stated that lesson study is a vehicle to examine content and pedagogy.

A vital question that the team leaders had to consider was whether or not Lesson Study would work at their schools. To explore this possibility, the participants engaged in a jigsaw activity to read the article, Lesson Study Comes of Age in North America (Lewis, Perry, Hurd, \& O'Connell, 2006). Following this activity, the participants were shown a chart with the different phases of Lesson Study: the planning phase, the research lesson, and the post-lesson activities. The planning phase included discussing long term goals for students' academic, social, and ethical development; choosing content area and unit; discussing learning goals for the content area, unit, and lesson; and planning lesson(s) that foster long-term goals and lesson unit goals.

The research lesson phase was shown to be the actual classroom lesson where the attending teachers study student thinking, learning, engagement, and behavior, etc. The post-lesson activities included discussion of the lesson focusing on evidence of whether the lesson promoted the long-term goals and lesson/unit goals, and consolidating learning where the teachers write a report that includes the lesson plan, data, and summary of the discussion. Following this, the teachers refine and reteach the lesson if desired. Alternately, a new focus of study could be selected at this point. 
The teams were then given the opportunity to plan a Lesson Study for their schools. They were first encouraged to choose a Lesson Study theme, thinking about the question they had used for their vertical slice activity, and what they learned about the students from that activity. In this activity, the participants identified the gap between the ideal qualities they established for their students and the actual performance of the students based on evidence. Following this, the team leaders discussed what would occur as they observed the planned lesson. The benefits to lesson observations included the opportunities to see how students think and learn; to think deeply about long-term goals for students; thinking about goals related to specific content areas, units, lessons, and instruction; planning lessons that bring both short- and long-term goals to life; deepen subject matter knowledge; develop instructional knowledge; and build capacity for collegial learning.

The participants then planned a specific lesson, giving the title of the lesson, deciding the grade level for the lesson, the length of time for the lesson, and establishing the performance objectives. The teams were encouraged to consider the works of Bloom's taxonomy (Bloom, 1956), McTighe and Wiggins Understanding Cycle (Wiggins \& McTighe, 1998), and William's taxonomy (Williams, 1993). To help in the design process, the teacher leaders were exposed to the idea of backward design steps, where the first step in the planning process was to identify the desired outcomes, determine acceptable evidence, and plan learning experiences and instruction. Concluding information for this day contrasted traditional professional development with sessions of Lesson Study, as follows: 
Table 2

Chart contrasting traditional professional development sessions with sessions of Lesson Study

Professional Development

Traditional

Research Lessons

Begins with answer

Driven by experts

Communication: Trainer to Teachers

Relationship hierarchical

Research informs practice
Begins with question

Driven by participants

Communication: Among Teachers

Relationship reciprocal

Practice is research

Before going home, the teams made additions to their journey maps describing where they had been and where they were going as a team. They were instructed to have open discussions with grade level teams at their schools regarding the vertical slice format and Lesson Study. They also were encouraged to share their journey maps with their entire school faculties and other interested school communities.

Day 3

Day 3 began with participants sharing their accomplishments since the last session. They also shared future plans, and engaged in an item analysis of classrooms to lead into in-depth examination of how to look at student work in a vertical slice. Structured steps that described the process of conducting a vertical slice were:

- Decide on the purpose for conducting the slice. This could be a specific question or the investigation of a certain day's work. 
- Refine the purpose into a guiding question.

- Decide a sampling strategy. In most cases, the sampling strategy should be broadly distributed across grade levels, males/females, socioeconomic levels, etc.

- Identify the methods of the slice. Some methods mentioned were student work on paper, and other evidence like artwork, photos, videotapes, or student journals.

- Decide the duration of the slice, usually one day but could possibly be work done over two or three days,

- Arrange the logistics. Deciding who will collect the work and when, obtaining parental permissions, removing identifying names, and copying the work for all participants were some of the items that need to be managed.

- Decide how to interrogate the slice. Discussion may be facilitated or enhanced by the use of protocols.

Before lunch, the participants reviewed the elements of Lesson Study, concluding with questions to facilitate planning a research lesson.

Following the lunch break, the participants engaged in a new topic of Designing Homework. This session began with questions for teachers: (a) What do students gain from the homework you assign? (b) What might parents gain from the homework you assign? and (c) What do you learn from the student's product? Other questions created for teachers to ask themselves about designing homework were asked: (a) Can students work independently? (b) What can students do when they don't understand the work?(c) 
What product will you want from them? (d) How will you fit the homework into your lesson or unit? and (e) How long will it take them to do the homework?

Teams were given a state reading standard and asked to design a homework lesson. After creating the lesson, the teachers were asked to check their homework assignment against the questions previously introduced. Further examination of their assignment occurred when the participants engaged in a step-back consultancy exercise. This allowed other participants to look at the assignment and ask questions for clarification, comment on the assignment, and suggest changes they might make for their own classrooms or schools.

Information from research done on the topic of homework was shared with the teams. Some of the facts were:

1. Seventy percent of studies indicate students who do homework had higher achievement scores than those who did not.

2. The 10 minute rule seems to be effective for students.

3. Parents help establish the value and importance of homework by taking an interest and establish a place and time for homework.

To conclude this day, two graphs presented interesting facts about homework. First, a comparison graph was presented on the percentage of students who spend more than two hours of homework per day. In descending order the countries were France, Taiwan, Korea, United States, and Canada for both 9-year-olds and 13-year-olds. A second graph showed the percentage of 13-year-olds who spend more than four hours a week on mathematics and science. For math, the countries were: Soviet Union, Korea, Taiwan, France, United States, Canada, Hungary, in descending order ranging from 34 hours to 10 
hours. For science, the countries ranked: Soviet Union, Hungary, Taiwan, Korea, United States, Canada, and France.

Two tables were also displayed showing the percentage of nine-year-olds reporting hours spent on homework daily by country. An interesting statistic here was those students who reported spending no time at all on daily homework. In descending order, the countries were: Canada-29\%, USA-20\%, Israel-4\%, Slovenia-4\%, Ireland-2\%, Korea-2\%, and Taiwan-2\%. The second table showed the percentage of nine-year-olds reporting hours spent on mathematics and science homework weekly by country. The countries of students spending four or more hours, in descending order were: Spain, Hungary, Israel, Korea, Slovenia, Ireland and Taiwan (tie), USA, and Canada. Day 4

As Day 4 began, the participants were invited to engage in an activity to get reacquainted with each other and talk about their experiences since the last session. The agenda was set for the day and included both review of previous content, as well as new information. The first activity for the participants was to go on a "ghost walk." The teachers engaged in this activity to reflect on classroom environments. This activity also served as an introduction to peer observations. This activity helped to focus on evidence instead of evaluation, to give the school a snapshot of its efforts, and to shed some light on the consistency and rigor of instruction.

The activity was structured to have the participants visit a classroom at their own grade level when the students were not present. For 15 minutes, the teachers walked around silently and documented evidence that fit into the Effective School Correlates. When the teams concluded their walks, they created a wall chart that had the correlates 
across the top. The teachers filled in the chart with examples from each classroom (or a line drawn if an area was not observed). The number of classrooms with evidence for each correlate was tallied. Questions for consideration were then presented:

- What is easy to observe in all classrooms?

- What is consistent across all classrooms?

- What do we do well?

- What might be areas that we can improve?

- Are there classrooms that are particularly successful at any of the elements of the program?

- What seems important to you that was not included in the chart?

- Are there some subjects that are more observed than others?

- Does the grade level impact what is exhibited or how it is exhibited? Does it matter?

- Do you see differences between leadership team members and other members of the faculty?

- Walk around and look at the other charts. Are there similarities/differences? Is there anything you can learn from their charts?

- As a group, write up at least three major conclusions and possible actions based on your observations and conclusions.

The ghost walk was linked to highly reliable principles. The presenter pointed out that the walks were one way to monitor the school's environment on specific elements of effective schools, and that the documentation of a majority of the classrooms would give a report on consistency of the school on the essential elements of effective schools. 
The last part of Day 4 centered on Critical Friends. Through this activity, the participants learned to work collegially with peers on issues of teachers and student learning. It was pointed out that, historically, some teachers have worked in isolation. To work collaboratively, teachers need to develop skills such as peer observation, examination of and analysis of student work, giving effective feedback, and creating new knowledge together.

A Critical Friends group was described as consisting of 8 to 12 teachers and administrators who agree to work regularly together to define and produce improved student achievement. They also develop shared norms and values, engage in reflective dialogue, give each other feedback on their work, and hold each other accountable. The group can serve as an instructional leadership team, or as a grade level team. The group examines their own classroom work, and looks at the link between classroom activity and learning standards. When a Critical Friends group works effectively, there should be an immediate transfer from the classroom to the group and back again as teachers revise their work based on the feedback they get from peers, and try out the modifications in their classrooms. The presenter stated that a ghost walk is a good first step in the process of peer or collegial observation. Day 4 ended with participants talking about plans they had for the summer, and also planning for next year's ES21 sessions.

\section{Year 3}

Day 1

Year 3 began with welcoming the schools back from their summer break. An opening activity enlisted both reflection and anticipation for the leadership teams. They were to write about their most enjoyable summer moment, and then write one positive 
event they wanted for their school in the upcoming year. Following this, an agenda for the day was displayed on a power point that included looking back at previous content, and introducing the topics of Critical Friends and Highly Reliable Organizations. The roles of facilitator, recorder, timekeeper, historian/artist, and process observer were assigned, and the team norms were established. Questions guiding the work of establishing norms were: (a) How do we treat each other? (b) How do we treat ideas? (c) How do we make decisions? and (d) How do we make sure everyone is heard?

As participants began reflecting over the past two years, they focused on the elements of:

- Vertical Slices

- Chronology Mapping of Current Status (Journey Maps)

- CRESST - A revisiting of analysis of student work with an eye to taking this process down to the grade level team for the evaluation of student learning

- Data-Wise Process - a model for the continuous use of data to improve instruction

- Highly Reliable Organizations Overview

- Team Roles

- Planning in Grade Level Teams

- Decision Making in Teams

- Data Usage

- Highly Reliable Organizations Implementation

- Lesson Study

- Homework 
- Critical Friends Overview

- The Planning of Year 3

Participants were then asked to extend their journey maps based on what their conversations and observations of their reflections.

The first major topic of this session was Critical Friends. This element of the professional development was focused on enhancing school coherence and effectiveness. The topic was revisited by an illustration of a student who had been given a homework assignment of finding words that began with "W." He had turned in a picture of a family, thinking that it was an example of his wish. However, his teacher put an " $\mathrm{X}$ " on the homework, informing him that he had not found a "w" word. He attempted to explain, but the teacher had moved on.

The questions were then asked, "Have you ever been so rushed that you missed the opportunity to unpack a student's wrong answer?" and "How can working together help us read our students' cues accurately to support their learning and development?" The illustration was used as a way for teachers to see the value of listening to feedback. Furthermore, it served to show that giving constructive feedback was essential for the growth and understanding that leads to improvement. The concept of Critical Friends was then extended to structuring cross-school visits by the various teams.

Specific guidelines were given for receiving and giving feedback. When giving feedback, some points were: (a) find out and respond to the receivers' concerns, (b) speak for yourself only, (c) don't evaluate, and (d) help the receiver figure out what to do with your feedback. When receiving feedback, the listener was encouraged to: (a) Be specific 
about the feedback you want, (b) Be open to feedback, (c) Clarify and check your understanding, and (d) Share your reaction to the feedback.

Five connections between Critical Friends and Highly Reliable Organizations were elaborated. Critical Friends can be useful in assuring a highly reliable school by offering a process that monitors school and classrooms in an environment that is safe and effective. By using Critical Friends, standard operating procedures are developed across classrooms. It also encourages teachers to identify flaws and the process honors the flaw finders. As well, constant training results from this process. Finally, the mutual nature of Critical Friends assures reliability of this model for rigorous performance evaluation.

The teams were then asked to complete a carousel activity. This strategy was designed to get a great deal of feedback from a large number of people in a short period of time. Chart paper was divided into four quarters with labels in each one: (a) clarifying questions, (b) probing questions, (c) recommendations, and (d) resources. These elements were used as part of the feedback process for Critical Friends.

The session was closed by each leadership team reflecting on how these techniques could benefit their schools, and how it would fit into the overall direction of their schools. Schools were encouraged to design cross-school visits, and develop a discussion group based on the observations. A final reflection on data and data use asked questions about what data were available to the teams, which sources of data they were using, and what next steps would be. The teams were also asked to consider how data influenced their instruction, organization, curriculum, and assessment, as they considered the ways they currently used data. 
Day 2

Day 2 was the first of two cross-site visits between the four experimental schools in this district. It was held at School B, and began with introductions from the principal. She also gave a summary of school demographics and welcomed all participants. Following her comments, the teacher leaders were divided up into groups, given an overview of the day, and planned the group activities.

During the morning, the groups, which consisted of one member from each of the four schools, engaged in five rounds of observations of classrooms, meetings, and activities as they walked around the school. Each round of observations lasted approximately 25 - 30 minutes, and focused on:

- Classroom and School Climate

- Instruction Observation

- Classroom Interaction

- Student Work

Besides the instruction being delivered in the classrooms, the groups also had the opportunity to observe a second grade, and at a later time, a first grade job embedded PD on math.

Following the five rounds of observations and lunch, the participants gathered to discuss their findings. They recorded and charted their data on cards that asked: (a) What was important? (b) What recommendations would you give? (c) What do you want to know? and (d) What will you take home and use in your own school? A sampling of responses follows: 
Table 3

Chart of responses to guiding questions following observations at school B

Guiding Questions $\quad$ Leadership Team Observations

The math PD was focused, covered lots of content;

focused/intentional/purposeful.

What was important?

Students that were not in guided reading groups were still engaged on computer or reading with another adult.

Clear expectations have been taught.

The first grade teacher had great organization.

PD for teachers for respecting students using verbal and body language

What recommendations

Have common class rules/expectations

would you give?

Post proficient work

Teachers may want to use popsicle sticks to draw names out (randomly) vs. students raising hands

Index and open response questions average high.

Have you blind scored work for quality control on open response scoring?

What do you want to know? Who are the extra people in the upper grades?

How many teachers does it take to have reading all at one time? 
Some classrooms have the day's objectives posted, others don't. Is this a schoolwide requirement or a choice?

How you utilize staff

Reading block with no interruptions

What will you take home? Used a timer for transition time

Breaking down quarterly assessments to identify strengths within each grade level

This information was then synthesized to paint a picture of what they saw. The big ideas that were charted for School B included: (a) procedures are obviously in place, (b) the principal leadership trickles to the rest of the school, (c) student academic achievement is celebrated, (d) higher academic expectations were observed, (e) learning objectives were posted or stated in many rooms, and (f) evidence of good use of academic time.

The participants also completed an exit inventory to get an overall impression of the school that was an integrated picture of daily activities, as well as the extent to which it was using ES21 principles in its every day work. The school was ranked on a seven point scale by each school, including the host school. The results of the survey were compiled, charted, and discussed.

The principal then made some remarks that supported or commented on the findings for the day. The staff talked about changes that these findings could bring about for their school, and the possibilities for next steps for school wide and classroom improvement. Also, the PD model, itself, was discussed to explore any improvements 
that could improve the process. Suggestions were made to shorten the length of time for each observation, as well as reducing the amount of people making up each team. The observation teams were made up of five participants, which the principal felt overcrowded the classrooms.

Day 3

Day 3 was the second of the two cross-site visits, and was held at School A. To begin this session, the principal welcomed the visitors and gave demographic information about the school. She also mentioned that she had not told the staff too much about the cross-site visit because she did not want them to "put on a dog and pony show." The professional development facilitator then presented the directions for the walkthroughs and the schedule for the day. The process was the same for five rounds of observations as the participants walked through the school. They were to answer the same questions used at School B, and a sampling of responses is as follows:

Table 4

Chart of responses to guiding questions following observations at school $B$

What was important?

Student work is everywhere!

Students were engaged and on task.

Nice probing questions leading to hands-on activities

Expectations/consequences posted in each room

Share writing rubric with students and allow them to

What recommendations evaluate each others' work 
Do all classrooms use science modules?

What do you want to know?
Would you consider departmentalizing in $4^{\text {th }}$ and $5^{\text {th }}$ grades?

How did you group your students for math centers?

Lots of graphic organizers with clear purpose for each one; pictures for ESL

What will you take home? All rooms had a well established routine; it was standard through each room.

Use of PVC pipes for fluency practice; novelty and motivational

The afternoon session that followed the observations, again followed the same procedure as the previous cross-site visit. The big ideas for School A included: (a) students were engaged using appropriate voice levels, (b) students were doing hands-on work, (c) need more consistency in literacy centers, (d) lots of expectations posted and stated, (e) lots of positive interactions, and (f) every class needs to have objective posted and stated.

The participants completed the exit inventory as they had previously done. The results were compiled, charted, and discussed to give feedback. The principal thanked 
everyone for their participation and helping them learn more about their school, and the session was dismissed.

Day 4

The purpose of Day 4, which was the very last ES21 session, was to revisit the data from the cross site visits. The professional development facilitator explained that in those visits, there was a lot of information created in a variety of categories. In this session, the participants reorganized the data to make them more meaningful for the two host schools. After the data were analyzed and reorganized, the facilitator explained that they would draw on elements of ES21 in ways that would help to create each School Improvement Plan.

The group separated into teams with the participants from each school representing a team. The roles of facilitator, recorder, timekeeper, and process observer were assigned. The facilitator offered a model for data analysis that the schools could use as they looked at their own classrooms or whole school. By incorporating this model into their work, schools could go forward using data in their daily work.

The first activity involved planning future goals. The participants were asked to think about their plans and goals for the next school year. They anticipated their AYP data, and discussed ways they could manage the mandates that were coming from the federal level in No Child Left Behind. The teams were then given the same categories (Classroom and School Climate, Instruction, Classroom Interaction, and Student Work) they had used for their observations in the cross-site visits. They were asked to use these four categories and place the each of the Correlates of Effective Schools into at least one of the categories. Next, the schools added one more category called the Emerging 
Category. This category was designed so the schools could identify something they felt was important to include in the planning for next year, but that did not fit neatly into any of the existing categories. Then the facilitator handed out the data from the previous cross-site sessions. As the teams went through this data, they organized them under one of the four categories, which also contained at least one element of the correlates. They also could use the Emerging Category if they wished.

This exercise was intentionally designed to get the schools to look at data. As they sifted through the data, they began to organize their thoughts on what was important for the next school year. For each category, the schools then wrote down the major ideas to focus on. From this point, the discussion centered on how to take the results back to their respective schools and talk to the teachers about their work. The presenter reminded the participants that this was a way to take qualitative work and organize it in a way to be of value. This type of action research created an iterative loop that allowed the schools to observe what was going on, and how they could improve on it. It also gave the teams support for the decisions they made regarding the School Improvement Plan as they looked forward. The session came to a close and team members were excused. The principals were asked to write exit slips and summaries of how they planned to use their data for improvement as they looked to the next year. 


\section{CHAPTER V}

\section{CASE STUDIES}

Chapter V consists of two case studies from School A and School B which were part of the ES21 intervention project. This chapter begins with a description of the state and district context that applied to both schools, and proceeds through the evidence collected for each school.

\section{Description of the State and District Context for Both Schools}

The state assessment system entered an interim phase in its accountability standards in 2008-2009. The state legislature made numerous changes to the entire testing process, and created a three-year interim period with a new state assessment program to begin in 2012. During the interim, the focus on the accountability index and individual growth charts were suspended, but the assessment continued to measure student performance and categorized student performance by Novice, Apprentice, Proficient, and Distinguished, and determined if NCLB goals were met.

The Superintendent was in his third year of service to the county. His major initiatives for elementary schools included Math Investigations II, the use of formative assessment, decreasing teacher/pupil ratio, providing nurses in schools, and Care for Kids, which emphasizes social and emotional learning in conjunction with academic success. An inquiry-based approach to learning was also promoted. 
Instructional supports included content area resource teachers who provided curricular expertise and support to schools. The district also constructed benchmark assessments for reading, math, science, and social studies, which are given three times per year. These benchmarks were generally predictive of NCLB scores, and the data from them could be analyzed in many ways, including by NCLB subgroup.

The schools were operating in the first year of a new student assignment plan. In June 2007, the Supreme Court issued a decision that stated the district could no longer assign students to schools based on race. As a result, the district created an alternate plan based on: (a) the percentage of minority students in the elementary residential area, (b) the median household income per household member in the elementary residential area, and (c) the educational attainment of adults age 25 and over in the elementary residential area. With this information, the district required each school to serve a diverse population to fulfill a ratio of between $15 \%$ and $50 \%$ of students that came from challenged areas.

\section{Case Study, School A}

School A was one of 90 elementary schools in this urban school district and among the four schools who participated in the ES21 project. At the time of this study, the latest published information listed the student population at 497 students. Of that number, none were classified as English as Second Language students, and $81.7 \%$ were classified as Free and Reduced Lunch, which qualified the school for Title 1 funding. Spending per student was $\$ 9,698$. The ethnic makeup of the school was: $60.2 \%$ White, 27.6\% African American, and 11.3\% Other. The latest published attendance rate was $94.1 \%$, and the pupil to teacher ratio was $15.0 \%$. The school had 3.5 Exceptional Child 
Education units and one Head Start classroom. The mobility rate for $2008-2009$ was $12.88 \%$, and $9.92 \%$ for $2009-2010$.

There were 37 teachers at School A, and each one was fell into the category of "Highly Qualified" as described by NCLB. The faculty was also supported by an inhouse resource teacher, a literacy leader provided by the district two days per week, and Every 1 Reads volunteers.

The educational levels of the staff were as follows: 1 Doctorate degree, 12 Master's Degrees plus 30 credit hours, four Master's Degrees plus 15 credit hours, 10 Master's Degrees, three Bachelor's Degrees plus 15 credit hours, 6 Bachelor's Degrees, and 2 Emergency Bachelor of Arts Degrees. Of these staff members, $11 \%$ were AfricanAmerican females, $11 \%$ were classified as Other Male, and $78 \%$ were classified as Other Female. Teacher attendance was $94.0 \%$, and teacher retention was $90.9 \%$.

The priorities of the Comprehensive School Improvement Plan include: (a) improving student performance in literacy and math, (b) implementing Care for Kids, (c) integrating technology, (d) equity, and (e) increasing parental involvement. Their SiteBased Decision Making Committee was made up of one administrator, three teachers, two parents, and one member described as "Other."

The instructional programs for School A included a five block reading program, and a new math curriculum which was introduced during the 2008-2009 school year, and a hands-on, inquiry approach in science and math. The school provided Extended School Services to struggling students for reading and math, and offered extra-curricular programs such as Band and Orchestra, and Computer classes. 
The results of the state assessment for School A for the 2008-2009 school year were as follows:

Table 5

Percentage of students achieving Novice, Apprentice, Proficient, or Distinguished performance levels on the 2008-2009 state assessment

\begin{tabular}{lcccc} 
Content Area & \% Novice & \% Apprentice & \% Proficient & \% Distinguished \\
\hline Reading & 21.43 & 33.08 & 41.35 & 4.14 \\
Math & 27.82 & 33.46 & 29.70 & 9.02 \\
Science & 29.63 & 38.27 & 25.93 & 6.17 \\
Social Studies & 20.48 & 49.40 & 25.30 & 4.82 \\
$\begin{array}{l}\text { Writing On- } \\
\text { Demand }\end{array}$ & 10.84 & 51.81 & 33.73 & 3.61 \\
\hline
\end{tabular}

No Child Left Behind results indicated that $45.49 \%$ of students were Proficient or Distinguished in reading, and $38.72 \%$ of students were Proficient or Distinguished in math. The school did not achieve AYP in 2007-2008 or in 2008-2009, but did reach the target in 2006-2007.

\section{Implementation}

As School A teacher leaders took the information they learned in the ES21 professional development sessions, they worked with classroom teachers and support staff to implement the strategies. As stated previously, this investigation focuses on efforts related using data for whole school and classroom improvement planning. Procedures and Processes: Meeting Formats 
The procedures and processes that were in place at School A included structures, such as meeting formats, procedures that promoted collaborative and reciprocal learning for the staff and students, and processes to focus on improving student outcomes.

The meeting formats that were both observed and reported were:

- Leadership Team Meetings

- Staff Meetings

- Horizontal (Grade Group) Meetings

- Cross Grade Meetings

- Vertical Team Meetings

- Job Embedded Professional Development

- Committee Meetings

- Cross School Meetings

Leadership Teams. School A had team leaders prior to ES21, and they were chosen by the administrator. After the first year in the study, the administrator retired and the school hired a new administrator. This administrator was initially unsure about ES21 and some of the teacher leaders, but the leadership team met with her and convinced her that they wanted to continue with the project with the existing team.

As it turned out, the administrator relied heavily on ES21 as a familiar approach to leading her school, and gained a good degree of emotional support from it as well. She had spent twenty-two years in middle schools where it was customary for mid-level management teams, or teacher leaders, to be used to distribute work. She reported that in her experience, middle school teachers were eager to assume teacher leader positions and responsibilities, and her knowledge of this process gave her a recognizable vehicle to 
implement her work. It also allowed her to use her prior knowledge to encourage and implement leadership in her own school.

The ES21 leadership team was structured so that one teacher leader from each grade level was chosen to represent their respective grade groups (with content leaders added later). Initially, the leadership team's function was to relay communication between the administrator and the other teachers on their team. As time progressed, the principal encouraged them to take more responsibility in the vision, planning, and monitoring of the work that was done as a whole school.

In the beginning I used them just for distributing information, you know, between myself and the staff and their team. I think...from my perception, it was more of a name only, that there wasn't the responsibility that was attached to it, or I don't know that the expectation hadn't been there, but they just hadn't accepted that responsibility...[E]very grade level had a team, I mean had a team leader. I added the department heads, because I thought if we're talking instructional leadership, duh, it would make sense to have those people involved, too...And then as we would go to these meetings [ES21], we found more and more responsibilities which they could take. Taking responsibility for the instruction of others, or making some of those decisions wasn't easy, and still doesn't come easy for them... I just tried to turn more and more responsibilities over to them.

The teachers' views of the leadership team also reflected growth in their role.

They definitely saw themselves as part of a communication system, but as ES21

progressed, they realized their own power to affect decisions and to help guide the school on a global basis. At the end of the second year, a member of the leadership team reflected:

At first, we didn't have a clue why we were there. We just knew our school was on the border line, we had a high poverty rate, and so on. ES21 took a survey of why we thought we were there, what was our mission, why were we teaching what we're teaching, what did we focus on in our teaching? Then we learned how to use a leadership team to help guide the school... [such as] how do you make change sustainable, like if we lose our principal. Our first principal did leave, and then the new principal didn't know what ES 21 was all about... The principal at first wanted to change the team leaders. I said, 'No, we've got ES21 and we 
signed for a three year commitment.' It took a while for the principal to say ok, a lapse in time to get the principal on board [to keep the same team leaders]. In ES21, we have learned to look at everybody's talents and let each person serve there. For example, if someone's good at technology, we use their talents in that way, if they're good at writing, we use them for writing. We intentionally look for talent.

One interesting observation made by the principal was that, at first, teachers were timid about accepting a leadership role. Their shyness was not because they did not want to do the work, but because they were unsure about how they would be judged by their peers. The implication was that peers would view this as an arrogant or conceited move, and therefore, might be socially rejected. As the principal guided the team over the course of the ES21 project, this feeling faded and was replaced with a focus on the work instead of on themselves.

I know ES21 is going to end soon, but I just hate to see it end. Our school has turned around 160 degrees. So much of that is because we talked about climate, teacher attitudes, [and] camaraderie. It has made a world of difference. Now we all want the same things for our kids. At the beginning of this year, when our principal told us we were $7^{\text {th }}$ from the bottom, tears just rolled down my face. But our school is so different now, you can see the kids learning and I know our scores are going to be improved...our school met for a whole weekend last summer, and we decided what we wanted our school to be and to look like. All that came from ES21.

As the teachers began to understand and demonstrate mid-level management responsibilities, they saw both whole school and personal rewards. This progression of leadership demonstrated a significant shift in culture and climate.

The leadership team met monthly They also usually met prior to ES21 sessions to prepare for the next meeting, and also following the session to discuss implementation in their school. Aside from attending the ES21 sessions, their work was to discuss and plan the school's work for the year, to provide communication between the principal and their 
grade group members, and to design activities for the staff during the course of the school year.

Cross-Site Meetings. The leadership team from School A participated in all three cross-site meetings for ES21. The first meeting was held in Atlanta, Georgia. The purpose of this meeting was for district liaisons and principals to come together to gain an understanding of the correlates and necessary processes for the program. A review of Year 1 activities and preparation for Year 2 also took place. The goals of this session included increased participation in the intervention, and goal setting that was coordinated between each district, principal, and leadership team. The cross-site format was also used for the schools to be able to share their learning across districts and states.

The second cross-site meeting was held in San Diego, California. District liaisons, principals, and leadership teams from all 17 schools attended this session, with the exception of the liaison from School A's district. Since the participating schools had been engaging in the same work, and since they had the chance to get to know each other the year before, this session was an active engagement in sharing experiences, and collaborating in work to analyze and plan school work.

The third and final cross-site session was held in Charlotte, North Carolina. Following two years of work together, the participants met to continue their collaborative efforts for reform in their schools, to discuss sustainability for the intervention, to reflect, and share common experiences.

Cross-School Visits. As a result of the cross-site visits, the two schools that are the subject of this study followed up with a smaller version of the cross-site meetings. They decided to open up their schools to each other for the purpose of gaining insight and 
feedback as they made observations about each other's schools. Each school took one day to visit the other school to observe the environment, instruction and culture. Following the observations, the administrator, leadership team, and teachers met in a faculty meeting with the leadership team from the other school to hear their feedback. Although this was a somewhat uneasy process at times, it was viewed as a valuable experience: As one teacher put it:

Now, we took some of the strategies that we saw, we took those back...to our regular grade team and I shared it with our ECE team because we did see some good strategies used in the classroom. [W] hen we were the school they came to visit, we took what they gave us and tried to improve it. You know, that was kind of hard. It was kind of eye opening as [to] just what they really saw, you know.

Staff Meetings. Staff meetings occurred on Tuesday, and involved all certified teaching staff, including special area teachers and ECE teachers. Occasionally, classified employees, such as instructional assistants, attended when information pertained to them. Agendas for the staff meetings were posted or sent to the teacher via e-mail at least 24 hours beforehand. This served two purposes. Teachers knew what was to be discussed, what work to bring, or how to prepare. Also, sending the agenda out prior to the meeting allowed teachers to give feedback to the principal on other items they felt should be added.

The staff meetings began with the principal addressing the staff, and stating the items to be covered, referring to the agenda items written on a white board. Horizontal groups were the format most often used in staff meetings, although at times vertical teams were planned. Less frequently, teachers sat randomly, depending on the items to be covered. Staff meetings were the format for analyzing state assessments, and discussing next steps and strategies for improvement to be included in their School Improvement Plan. Other activities for staff meetings included re-rostering of students, and forming 
learning groups with common needs. Special education teachers, the instructional coach, and retired teachers also formed focus groups that could benefit from their services. Sometimes, students were distributed into appropriate reading groups across the grade levels.

Staff meetings were also used to analyze, discuss, and plan next steps from CCAs. Although CCAs for reading were only conducted in the third, fourth, and fifth grades, teachers from all levels participated in the process. The primary teachers were included because, "we look to see what we can do if the scores weren't what we wanted, what component we could hit so that they're ready in third grade." Student work samples were also brought to staff meetings for scoring and/or analysis, as well as for conveying general information to the staff.

Vertical Teams. At the beginning of the year when the staff came together to analyze their performance from the previous year, the principal arranged the staff into a vertical "slice" to look at the results from their state assessment. The results for the 20082009 school year indicated that the school had met 11 out of 15 No Child Left Behind goals, missing targeted performance for all subgroups in reading (all students, AfricanAmerican, free and reduced lunch, and students with disabilities). All subgroups reached the target for math, but only white students met the goal for both reading and math. The index for Annual Yearly Progress was 12.5 points under the goal.

Each vertical team consisted of a kindergarten, first grade, second grade, third grade, fourth grade, fifth grade, special area (either PE, Art, Library, or Computer) and ECE teacher. Each team then received certain content sections of the assessment (math, science, reading, etc.) to analyze. They compared the school performance to district and 
state performance, and examined their performance by NCLB standards. This format was chosen to promote the idea that all grades contribute to student performance, not just specific grades that are tested in a certain year. Following the data analysis, the faculty discussed strategies that needed to be emphasized or in place to help meet their goals.

Other times teachers met in vertical groups to address certain schoolwide needs. The school formed three committees focusing on culture, professional development and parent involvement. Each grade group, a special area teacher, and an ECE teacher were represented on each committee, which met monthly to address concerns.

Cross Grade Groups. Another format the teachers used was a cross-grade arrangement, which is a limited type of vertical design. A number of times during the school year, the teachers engaged in peer observations, and utilized this arrangement. These walkthroughs were designed to have teachers from one grade group go to other grade groups. For example, first grade teachers observed second grade teachers, second grade teachers observed third grade teachers, etc. So that the fifth grade teachers could also participate in this activity, the principal arranged for them to visit a nearby middle school. In this way, fifth grade teachers could inform their students not only about academic expectations for middle school, but for equally important issues such as rituals, routines, and culture. On subsequent walkthroughs, teachers visited lower grade levels, and also visited a grade level of their own choosing. This format was chosen to align work tightly with student performance as it related not only to their grade level, but also with adjacent grade levels. Future staff meetings or job embedded professional development sessions focused on work to implement strategies resulting from these findings. 
Another example of cross-grade meetings was designed to meet the needs of students struggling in reading. The principal used a whole school staff meeting to intentionally form reading groups, with adjacent grades collaborating with each other. This meeting took place at the beginning of the year, after teachers had a few weeks to firmly establish the reading levels of their students. The principal had teachers bring current student reading levels to the staff meeting, and roster the students from highest to lowest by grade level. Then, as a grade group, they formed reading groups, regardless of whose room they were in. In this way, teaching could be very specific, intentionally targeting needed skills for students with similar needs. As well, reading groups were more cohesive because the students in each group were in need of the same level of instruction.

The data were also examined for outliers; those students who were significantly above or below the other students in their grade level. At this point, teachers from those grade levels were consulted as to how these students could be served. In some cases, the teachers from the alternate grade levels offered to include the students in their reading groups. In other cases, materials and strategies were discussed to best meet the needs of the students. One second grade teacher commented:

...like I said, one of the things with that first grade teacher and I did...instead of having five to six reading groups, I was able to cut that to three because she was able to group some of mine with hers and then hers [I grouped hers with mine], so that has made a huge difference

Grade Groups. The staff met in grade groups twice weekly. One of the meetings using this format was job embedded PD sessions. These sessions were usually for the purpose of looking at student work and planning next steps. The principal, instructional coach, or literacy resource teacher typically led these meetings where Core Content 
Assessments (CCAs), in reading, math, and science, and other student work was

examined. Also, student writing samples were scored and discussed in this setting. Along with job embedded professional development sessions, grade groups also met together without an administrator to discuss findings from job embedded PD sessions, plan next steps, or discuss other classroom issues. These meetings usually occurred before or after school, or during the daily planning period the teachers had.

\section{Procedures and Processes: Activities}

School A engaged in many procedures and processes as they implemented the ES 21 strategies for data use that included data analysis for whole school, grade level, crossgrade level, and classroom level planning. Strategies growing out of this work included re-rostering of students, "sharing" students, and planning next steps.

Data Analysis. One theme pertaining to data use that was frequently repeated was that student performance was continually analyzed. The outcome measures ranged from statistical, standardized scores to formative assessment to anecdotal notes. Teachers commented not only on the frequency of analyzing student work, but also on the depth of the analysis.

I feel like that's all we do is look at data, and meet, and plan next steps!

I just feel like we analyze everything. That's what we do here, we analyze everything. You can see the colors are up there, too [for coding]. Everything we do, any type of assessment...I guess to analyze it, to drive your instruction to see what you need to either redo or move on.

Well, we are sitting in a type of war room, sort of. We're sitting in a room where everything on the walls monitor student progress, in reading especially. So on the walls of this room, we've taken the data, we've leveled, put the children in Tier I, Tier II, Tier III, and they're all listed on the wall. They're all charted, there's charts so all the students' progress is being monitored, charted, recorded, and they take that information to form everything from reading groups to special services help, and so we are data-driven, so to speak. 
Whole School Activities. The state assessment was analyzed at least yearly. The faculty met as a whole staff to divide up the document for an in-depth look at each content area. The analysis included a comparison of the school to district and state outcomes, as well as discussion of the school's performance for Annual Yearly Progress, as reported for No Child Left Behind.

The school also engaged in district benchmarks for reading, math, and science, and/or social studies known as CCAs. This work was analyzed in job embedded PD sessions with rubrics provided by the district. Student writing was also analyzed during these meetings with a district-provided rubric. The scores for the content areas of reading, math, science and social studies were entered on a software system, CASCADE, used as a district tool to monitor student performance, and as a way for school administrators to compare their school performance to the targeted index and to other schools in the district.

Grade Level Activities. CCAs were also an important instrument at the grade level. This was used as a significant source of information that informed teachers about how their students were performing, and to point to a likely score on the state assessment. These assessments were given three times each year, and gave teachers information on how each student performed, as well as information about their class as a whole. Both intermediate (fourth and fifth grade) teachers and primary (kindergarten through third) teachers used CCAs for math and science. Reading CCAs were only designed by the district to be given to third through fifth grades. From this information, teachers could see which questions were most frequently missed, which content areas (multiple choice or open response) were most challenging, and the percentage of students who missed each 
questions. This was a valuable tool in grade level meetings for planning strategies to reteach the content, considering different strategies or ways of learning, or to plan small focus groups among students.

Another process the teachers used to help specifically with reading was the Developmental Reading Assessment (DRA). This assessment was given in all grades to each student individually, and gave teachers information about the skills of decoding, fluency, and comprehension. This process resulted in information that helped teachers to collaborate with their grade group to form reading groups, share strategies, and share students.

The Dynamic Indicators of Basic Early Literacy Skills (DIBELS) assessment was given to kindergarten through second grade students. This examination was administered to provide teachers with information on how students performed in the area of phonics and letter naming skills. The results were used in much the same way as the CCAs and DRAs and were helpful in the intentional planning of individual student needs.

Classroom Level Activities. Just as the three aforementioned assessments provided valuable information for grade level work, they also allowed individual classroom teachers to analyze, plan, and implement work in their classrooms. In using these results, teachers often paired students, formed table groups, and/or targeted individual students for support.

One important, but more recent procedure for data analysis was formative assessment. Teachers explained and gave examples of formative assessments they used, and explained their value:

I give...formative assessments to see how many of my kids grasp certain concepts, and if I see there's too many kids that haven't understood what I have 
taught them, I would just reteach it, but, of course, I would have to reteach it in a different way because they didn't get it the first time. So I would come up with a different strategy to get them to understand whatever concept that it was for them to get what I needed them to get. I do a lot of, we do a lot of assessing in our class, more formative than summative, I guess, just to keep track of their understanding.

This type of assessment was only talked about at the classroom level, although peer observations could also be viewed as a type of schoolwide formative assessment.

Strategies Resulting from Data Analysis. Several primary strategies resulted from School A's commitment to data use. Among them is re-rostering of students, or in NCLB language, placing students into "tiers." Tier III students were those student scoring Novice on the state assessment, and who were performing more than one grade level below standard expectations. Tier II students were also below grade level, but fall into the range up to one grade level behind. Tier I students were those students who are performing on grade level or above. As each teacher rosters his/her students in rank order, the school can see how its students are performing on a global level, and also can be intentional in their school and classroom planning. The most visible evidence of this process was seen in School A's Data Room, which was where student results were charted for each content area. This is the room where job embedded sessions were held. Another strategy which flowed directly from this process was that of sharing students. As mentioned above, students at this school were often shared among teachers. All students had a homeroom teacher and were in that room for the majority of the day. The homeroom teacher was the teacher of record and oversaw the instruction for that student. At times, a student would perform significantly higher or lower than the peers in his/her homeroom. Through detailed analysis of student work, a decision was sometimes made to send him/her to another teacher to receive the teaching he/she needs. At other 
times, the teacher decided to pull a small group of her own if he/she has more than one student at roughly the same level. This strategy was not only used for range of performance levels, but also sometimes for specialized content. When one teacher was especially effective in teaching a specific subject or skill, students were rearranged or shared to take advantage of this opportunity.

A third process that resulted from data analysis was planning next steps. Teachers referred to this as a collaborative process among teachers, designed to improve student performance. Teachers explained that planning next steps is an ongoing process that occurs on an individual, group and whole school basis. One teacher stated, "I feel like that's just something we do on a daily basis, and then on a weekly basis it's more formal and we meet in here [data room] and we bounce ideas off each other." As grade groups met together they reported their planning ideas to the principal, "Well, we do provide [the principal], when we have a team meeting that's not embedded PD, then we do provide her with what we went over and next steps and that."

When discussing how her school responded to the state assessment results, one teacher explained that gaps may be seen in content areas or in specific methods of student response:

[A]s far as the [state assessment] is concerned... We'll be asked about ideas, what are some of the ideas that we can do to improve on this particular [content] area, or we'll try to figure out, brainstorm ideas as to how or why our students were less successful in multiple choice as opposed to open response or vice versa, so in that aspect we do.

Deciding which step is needed next for individual students, how to present it, and how to measure outcomes, was something the teachers described as a constant searching 
to achieve best results. The ongoing dialogue and consideration of best meeting

individual needs was described:

Well, I will say that because most of the kindergarten and first grade teachers are on the same level [same floor] and we're diagonal from each other that we often know what is happening in each other's classrooms. We talk a lot. We see each other more frequently, so we discuss, "Look at this. What should we do here?..Is this going to work for you? Will this help?..I used to teach second grade here so I am a little bit familiar with second grade needs so I kind of push toward that.

\section{Summary}

The variety of meeting formats and activities School A used described how work was distributed across procedures and processes. The descriptions also reveal that these procedures and processes are interconnected with the materials and tools, and norms and rules. Procedures and processes were not, and could not, be conducted in a vacuum, and were inextricably interwoven with the other two elements of the framework: materials and tools, and norms and rules.

The above descriptions also tell a story of co-construction. As the schools fine tuned their work together they made decisions regarding what meeting formats would be utilized and for what purpose, what work was important for their school and classrooms, and what strategies and activities would best address their needs as they interpreted data. Their implementation was also co-constructed among colleagues as they met individual student needs, regardless of who was the teacher of record.

In this way, School A also demonstrated progress toward high reliability work as they established a finite set of clear goals, and analyzed data from their databases. These procedures and processes had become a standard way of operating to prevent failures in student achievement. 


\section{Materials/Tools}

School A used a variety of materials and tools that shaped their work with data. These tools consisted of assessments ranging from standardized state mandated tests to teacher-made and formative assessments. Rubrics and protocols were also used with regularity to help guide their work.

Assessments. As School A used data for planning improvement, the employed a wide range of instruments to help them achieve their goals. Beginning from the state level and continuing to the classroom level, the assessments were:

- State Assessments

- Core Content for Assessment in reading, math, science, social studies (District)

- DIBELS (District)

- DRA (School)

- T-Pro (School)

- Rigby Reading Levels (School)

- On-Demand writing (School)

- Teacher-made tests (Classroom)

- Formative assessment (Classroom)

Besides assessments, other materials such as rubrics, spreadsheets, and technology were also used for improvement planning from data.

State Assessments. These tools were created for different purposes and for different populations of students. For example, the state assessment was designed for only third, fourth, and fifth grade students, and was administered only once, toward the 
close of the school year. This assessment tested content in the areas of reading, math, science, social studies, and Writing. Third, fourth, and fifth grades were all assessed in reading and math. Along with reading and math, fourth grade was assessed in science, and fifth grade was assessed in social studies and in on-demand writing.

District Benchmarks. The CCAs were created for specific grade groups in specific content areas. These assessments were made and distributed to schools by district personnel, and were the primary common benchmark used among all elementary schools. All grade levels took the CCAs in math and science, while only the fifth grade took the CCA in social studies. The CCA in reading was given to third, fourth, and fifth grade students. These benchmark assessments were administered three times per year in each content area.

The DIBELS assessment was used in kindergarten and first grades. Also, one subsection of this test was given to second graders in the 2009-2010 school year. The DIBELS was given three times during the year, in the fall, winter, and spring. This was another instrument that helped primary teachers establish reading levels, reading groups, and determine progress. As mentioned earlier, this instrument gave specific information on phonologic awareness, knowledge of the alphabet and letters, fluency, vocabulary and comprehension, which allowed reading instruction to be specifically tailored.

School Assessments. All students' reading levels were evidenced by a DRA score and by Rigby reading levels. Rigby was the reading curriculum that was used by the school, and while the Rigby reading levels were not actually an assessment, these levels were correlated with DRA scores, and reflected the movement students made through the curriculum. These scores were the major factor in determining reading groups and 
documenting reading progress, although other factors such as formative assessment also influenced this process. DRA scores were obtained three times per year, in the fall, winter, and at the end of the year. The final scores were also carried over to next year, so the incoming teacher would have a good idea of student performance and could quickly begin reading instruction for each child.

The T-Pro (Test of Primary Reading Outcomes) was an assessment given two times per year that provided information on student performance, with diagnostic measures to indicate areas of strength and weakness for students.

The content area of writing was monitored through a series of On-Demand prompts, which were scored and analyzed for grade-appropriate skills. These prompts were given throughout the year, and monitored for progress and areas of need.

Classroom Assessments. Although often less formal, classroom assessments are those instruments that are closest to the daily work and performance of students. These assessments were found in the prescriptive form of a paper and pencil teacher-made exams, as well as in informal documentation such as exit slips, checklists, or anecdotal notes.

This school attended a professional development session in the fall which focused on formative assessment and its value in moving students. The administrator also followed up at the school level by discussing formative assessment in a staff meeting, and provided a hand-out on different types of formative assessments.

Rubrics and Spreadsheets. Many of the rubrics used at School A reflected the assessments that were given, especially at the state and district levels. The district provided a Red Flag Analysis rubric to analyze the state assessment. This document was 
designed to get very detailed information on how the school performed in each content area. Specific page numbers were listed that correlated with information from each content area. Teachers and the administrator looked at each area to examine the school scores, and compare them to the district and state scores. For the 2008-2009 school year, trend data could also be viewed, showing how the school had performed in the previous year so that comparisons could be made. Observations related to performance other than content were also possible, such as how the students performed on multiple choice items and open response items. Even more specifically, information such as how many students entered no response for multiple choice, and open response ratings of zero through four (indicating unacceptable, or no, response through a distinguished response) were given for each content area and grade level. The Red Flag Analysis tool was meant to analyze scores as a whole school, and not for individual student scores. Those scores were provided to each teacher, as well as sent by the district to parents.

Perhaps the most important tool that School A had in place was their data room. This was a regular size classroom that was also used for job embedded PD sessions. There was a conference table with eight chairs, along with a desk with assorted other more comfortable chairs and a sofa. Along three of the walls were charts and posters that completely covered top third of the walls, resembling a giant spreadsheet. Students were listed by alphabetical order under their teacher's name. There was a chart for each teacher for the content areas of reading, and math, as well as a chart for science and social studies for those grades that were assessed in those areas. The instructional coach was responsible for charting the scores as they were reported on CASCADE. After scores were charted, they were color coded to reflect performance levels: green for proficient or 
distinguished, yellow for apprentice, and red for novice. As new scores became available they were charted in a longitudinal design so that movement could be seen at a glance. As charts reflected progress, student names were moved on the charts that displayed the tiers of all third, fourth, and fifth grade students. A quick look across tier charts easily told the story of student performance. Although not a one to one correspondence, CASCADE scores from CCAs were reported to have an $85 \%$ correlation to KCCT results. Because job embedded PD sessions were conducted in this room, discussions of student performance and next steps were a natural and frequent topic of conversation.

Rubrics for analyzing the open response section of the CCAs were also provided by the district. The rubric listed the required elements for acceptable student responses. The rubric further detailed what would characterize a response that would receive the highest mark of four. For example, a CCA about the life of Daniel Boone asked the reader to: (a) Identify one thing that was probably true about him, and (b) One thing that was probably not true about him. For the student to receive the highest mark of four, the rubric explained:

Student completely answers Part a by clearly identifying ONE thing that is probably true about Daniel. For Part b, the student clearly identifies ONE thing that is probably NOT true about Daniel. The identification and details the student gives show that he/she COMPLETELY understands the question and how to answer it. (Printed with permission.)

The document continued through what would characterize a response that would receive a zero (response is completely wrong or has nothing to do with the question) or a "B" (blank or no response). The rubric also gave "look fors" as examples of what information was provided in the passage:

For Part A: What is probably true about Daniel 1. Daniel helped to build a road west to Kentucky called the Wilderness Road 
2. Daniel was one of the finest people to live in Kentucky.

3. Daniel is famous for being a good hunter.

4. Daniel had a large family.

These documents were created to help standardize scoring across teachers and also across schools in the district. As another safeguard, School A also conducted "blind scoring" activities, where they graded CCAs without knowing whose student they were, or even who the student was. After this activity, the scores were compared to the scores the homeroom teacher had given, and comparisons were made to analyze any significant differences in outcomes.

One important rubric that was used frequently was a very simple document made by the principal after collaboration with the leadership team. As discussed earlier, teachers engaged in several walkthroughs throughout the year, each one with a different purpose, but each using the same rubric. The administrator explained her reasoning for developing the rubric, which only had three items: one thing that they saw that they liked, one thing they saw that they had a question about, and what they learned.

I think the visits were good. I think classroom teachers can get in that classroom and close that door and they don't have to see anything else, and I think any time they can go and see what's going on in someplace else, first of all, usually it will validate what they're doing, and then they can get ideas. And, it may validate it in a positive way, or it may validate it in a not positive way, but anyway they can do that.

She went on further to tie it directly to the work they had done in ES21 when they had visited other schools and classrooms in other states:

So I think us getting the chance to do that, I think that us sitting, the schools sitting there and talking, about how leadership worked in each building was a good opportunity for them. It was good because, and they were, it wasn't just a bunch of teachers, necessarily, it was a bunch of leaders in the building talking. They had some credibility. 
And I do feel like that was the turning point. I feel like those ghost walks, when we did that, I do feel like that was the turning point. Who I think about, I think about one of the team members who's not here any longer, she's at another school now. I remember her eyes just getting so big, and then one team member who was not here today and didn't get to talk to you, his eyes, just realizing what goes on, and then from there, we went to where we did daytime visits in each other's classes, which I tried my first year here, and they did it, but it was more of a compliant thing, and they didn't want to, and they just did it because, yeah, and they didn't get it, and so, we had those discussions out there [ES21 cross-site sessions]. Then the leadership team kind of helped figure out what these visits should look like, and I call them Pride Walks, 'cause we're the Lions and so we called them Pride Walks, and what these Pride Walks should look like. And then like, this past summer, like last year I had them do it every month. I had them do it the first Wednesday of the month.

Another document that was created in the school was a rubric that came from the fifth grade teachers. The district had implemented a new report card that was very different from what had been used in previous years. This report card had both Performance and Progress indicators. The Performance codes were listed as A (Excellent), B (Good), C (Satisfactory), D (Poor), and U (Unsatisfactory), typical of marks earned by students as they completed assignments and assessments. Along with these "grades," the report card also required that Progress also be indicated by a 4, 3, 2, 1 , or N/A. The numbers reflected student work in the following way:

4 - Work that is produced independently and is consistently above grade-level expectations for this period

3 - Work meets grade level expectations for this grading period

2 - Work shows progress but does not meet grade-level expectations for this period

1 - Work shows little or no progress and does not meet grade level expectations for this period

N/A - Not taught this six weeks

Because of the complexity of determining the combination of performance and progress, the fifth grade teachers felt the need to collaborate on how they understood the document and align the process by which they would assign grades: 
Well, I guess because of the way the report cards are changed, each grade came up with a certain rubric on how we grade the students' work, how we measure their work. It's not really graded anymore, but how we measure their work, because they have performance codes and whatever else, academic, I should say that. It's all confusing, but we did sit down as a team and then as a school and come up with a standardized way they everyone is going to grade so that all third grade grades will kind of look the same, or will be judged the same, and all fourth grade will look the same and so forth.

The Classroom Instructional Framework (CIF) was a document that was used for multiple purposes. This rubric was designed by the district as a walkthrough document for administrators as they watched formal lessons, and for everyday observations. The major components of this rubric were: (a) student engagement, (b) fostering a connection through establishing an anticipatory set (c) deepening understanding utilizing guided practice, and (d) making meaning through closing activities or independent practice. Each of these components was observed for both teaching practice and the learning culture in the classroom. At School A, as the principal and leadership team thought about what they wanted to accomplish in their own walkthroughs, they incorporated the CIF in this process. One of the teachers even mistakenly referred to their walkthroughs as by this name, which at the least showed her awareness of the intentionality and purpose of the document.

We have a walk-through and it has a special name, CIF, and she's [the principal] going to be mad at me because I have no idea what it stands for [laughs], but... [i]t's walkthroughs where we get to choose any teacher, and sometimes she will tell us to choose a grade level, or choose a grade level below or choose a grade level up, and the fifth graders get to go over to middle school or whatever, just to see where you need to be for the next year, or see what the kids did last year, or maybe just see what they're doing in a different grade period, so we discuss [our observations] either in a job embedded PD or in a staff meeting we go through the look-fors, and how can you help, or how can that person help you.

Technology. Multiple sources of technology were mentioned by teachers. The first one was an on-line strength-based assessment that the principal required of one member 
of the leadership team. She was a recent addition, replacing a retired teacher. This followed discussion of strength-based leadership in staff meeting, where the principal was encouraging everyone to focus on the things they did well. This value of using a strengths-based approach to leadership was heard in another teacher's discussion of how it served her needs:

I think it gives you an idea of, when you know you need something specific of where you go for whatever reason you might need. Like, say [Susan] does things like A, B, C. She's very direct...So, I would know, ok, if I really want the answer to this question, or whatever it is, I need to go see [Susan] to find out A, B, C.

Besides this on-line assessment, School A also used technology in the form of Smart technology to be used with their computer tablets, or SmartBoards. Of special note were hand-held remotes that the students could use for test-taking. The results could be seen immediately by both students and adults, with a variety of different ways to organize and display the data.

The most widely used tool for technology was the CASCADE system. This software tool was utilized by all teachers and administrators. Scores for CCAs, and DIBELS were entered through an on-line process. Results were immediately available to both teachers and administrators, as well as to district personnel. Individual student responses were scored and given a percentage for multiple choice and open response items. An aggregate score was given based on the outcome levels of distinguished, proficient, apprentice, or novice. As well, the percentage of students scoring in each of these areas was seen.

This system also had administrator tools which displayed how the whole school was performing in each content area. There were a variety of choices and filters so that the information could be arranged to display almost any area of interest. For example, 
each grade level could be viewed separately, and NCLB subgroups, such as AfricanAmerican or free and reduced lunch students, were displayed to compare to targeted scores. As the school year progressed, results from this software tool helped teachers decide the movement, rostering, and tiering of students. Teachers at School A were very familiar with this instrument and the information available to them after reporting student responses.

It gives you an itemized list of what each student has gotten correct or incorrect. It gives you the percentage, and index of the success rate of your class. It automatically categorizes your students into Proficient, Distinguished, Novice categories, so you can automatically find that out. It automatically gives you a grade and a breakdown of everything, according to the test you gave.

Two other sources of technology that was used daily were SuccessMaker and Earobics. SuccessMaker, a computer program for reading and math, presented content that was tailored to each students' instructional level as they progressed through the lessons. Detailed reports of progress, time spent, answer attempts versus correct answers, etc, were used for monitoring. Earobics is a reading intervention that emphasizes phonics and decoding skills, that was used in the primary grades.

Other Materials. Other materials were mentioned by teachers as being tools that they considered a part of the school correlates. The school had two examples of what they were doing to be explicit about their high expectation for students. As a result of their visit to a school in North Carolina during a cross-site visit, they observed a school saying a school pledge. School A had a poster that reflected their expectations for students that was called "Be Lions to Success: Be Safe, Be Kind, Be Respectful, Be Responsible, Be Your Best and Help the Rest." To reinforce this among the students, this was recited each day after the announcements, and was the last thing students did each morning 
before they began classroom work. There were also posters displaying language and vocabulary for high expectations among the staff and students along the walls.

One other type of material or tool that fell directly in line with the Effective School Correlates and the ES21 professional development sessions, were the Homeside Family Activities that each teacher sent home with students once a week, or every other week. These activities aligned tightly with the ES21 Home-School Relationship PD, and are part of the district's Care for Kids initiative. The Homeside Activities are designed to support conversations between students and their families to establish home/school connections.

\section{Summary}

The materials and tools used by School A came from multiple sources that ran the gamut from the federally required state assessments, to teacher-made tests, and formative assessments. Again, co-construction was evident, especially as the school collaborated to create unique instruments for the entire school, specific grade groups, or individual classrooms. For example, the teachers from this school attended professional development on formative assessment, and together discussed what it looked like, and how to use it effectively in the classroom. Rubrics and spreadsheets were created to be used across grade levels, which not only provided consistency in the school, it also built a common language and a tacit understanding of practice in the school. (Although outside the scope of this discussion, it could be argued that co-construction of state and district assessments also took place, as the designers of those instruments analyzed and reviewed student responses and performance levels from previous test administrations.) 


\section{Norms/Rules}

School A demonstrated norms and rules that served as underlying, unspoken foundations for their work with data. The norms and rules that were evidenced at School A helped to shape data use and improvement planning through tacit beliefs and standard operating procedures that were part of their daily way of doing things. The norms were not automatically recognized by the participants who interviewed, because as processes and procedures, and materials and tools became part of their everyday routines, they were no longer explicit to the user. As one teacher explained, 'I don't say, 'Wow!' because we just do that...I feel like that's just something we do on a daily basis." Another participant stated, "I didn't think of it that way!" after realizing that their practice of collaborating to look at data for planning was an unspoken assumption of their work.

Distributed Leadership. Although the leadership at School A can be seen as distributed across the elements in my conceptual framework, the fact that it was distributed came to be an implicit way of operating, and is worthy of note. During interviews, no teacher ever identified the term "distributed leadership" as an element of their work, but their descriptions were rich in describing how the leadership team worked, and how materials and tools were collaboratively created and used. What was also evident was how each of these elements worked interdependently among the staff. No process and procedure, or material and tools were spoken of as being used or created in isolation. All of the work, especially the work with data, was interactive, collaborative, and interdependent across the school.

Open Environment. It was clear that the principal had worked hard to implement an environment of openness at the school. She knew full well the temptation for teachers 
to remain isolated, "I think classroom teachers can get in that classroom and close that door, and they don't have to see anything else." She initially met with some resistance when she first asked teachers to observe each other, realizing that they "didn't get it" and were just going through the motions. Also the fact that she required teachers to meet at least three times each week (in a staff meeting, a grade group meeting, and job embedded PD) to discuss matters around student performance and instructional planning showed the importance she placed on collaboration and open dialogue.

One of the norms at School A is that classrooms have open doors. They were visited by peer teachers, visiting administrators and teachers, and by ES21 personnel. Teachers spoke about having others in their classrooms as a normal routine that was unchallenged. They realized that for the school to understand its students, and plan for growth, they needed to observe what was happening throughout the school. Not only did they realize it, but the leadership team planned for it to be that way. In the days before school began each, year, the leadership team met to discuss the work for the upcoming year. One of the topics of conversation was the walkthroughs that would be done during the year. The open environment, coupled with collaborative work, established normative values for professional, collegial efforts toward reform. Because norms are integral to how (or if) strategies for reform become implemented, they are also part of what distributes the work (or not) across the other elements of procedures and processes, and materials and tools. In School A, the norm of an open environment helped teachers to value peer observations and feedback.

Peer Observations. As mentioned above, teachers took it for granted that observing peers was part and parcel of their work. An interesting part of the way peer 
observations were conducted at this school was that each walkthrough had a different purpose. The first time, teachers were asked to observe teachers in the grade level above them so they could see what the expectations were for their students during the next year. Another time, the teachers were asked to observe the classrooms one grade below them so they could see how the students were learning at that grade level. On yet another visit, teachers were allowed to pick a teacher that they admired or respected. Another time, teachers were asked to pick a teacher they felt would give them honest feedback to come to their classroom. They were asked not to pick anyone that was a close friend or that they felt would not receive valuable feedback from. The design of the walkthroughs showed a progression of building trust and reducing the feeling of vulnerability among colleagues; necessary elements for positive normative values. Because this norm extended across the whole school, it distributed the authentic kind of learning from each other that leads to genuine goal setting, problem solving, and recognition of strengths and challenge areas.

Peer Feedback. A major contributing factor in the success of the Pride Walks at School A was the element of feedback from colleagues. This component of the observations was critical to making changes and helping teachers to plan improvement in positive ways. When the walkthroughs first began, teachers were asked to record only affirmative observations, listing at least one thing they thought was effective that they could take back to their classroom and use.

For the most recent walkthrough, teachers were asked to pick a teacher that they felt would give them honest feedback about their own instruction. ES21 introduced this 
concept as Critical Friends, a component of Lesson Study. Although the walkthroughs

had a different focus each time, feedback was always a part of the process.

[W]e've done that [feedback] as part of, we call them Pride Walks, but they're our walkthroughs. Like I said, we had our focus, and then sometimes we were given a focus, and then we shared that with our team and other times we share that with the person who observed us, or that we observed. We just didn't call it 'critical friends.'

The full implementation of Lesson Study was not present at School A at the time of this study. When discussing the possibility of Lesson Study occurring, one teacher stated:

A: $[O]$ ne of the things we were leery of was going in and, well we didn't do the video taping of a lesson [referring to Lesson Study]. We did go in and observe and then write some positives, and then this past year, she had us go in and kind of where you see that might need to be improved, but that was kind of personal. We really didn't do the video taping.

Q: Why do you think there was apprehension? Just describe what you think.

A: I don't know that I would feel comfortable. And I guess it would be creative criticism, but I think it's hard to do that with one of your peers.

Although giving and receiving feedback appeared to be in the beginning stages of development, teachers at School A knew that peer feedback would be part of their practice. This norm not only helped to distribute knowledge and learning, it also helped to construct or refine procedures and processes, and materials and tools.

Norms for Meetings. This school had firmly established norms around meetings. The teachers routinely engaged in three separate meetings weekly, and at least part if not all, of each meeting was devoted to analyzing student performance and planning next steps. The three different meetings were: staff or faculty meetings, grade group meetings, and job embedded professional development.

These meetings were considered standard operating procedure at School A. Each teacher that was interviewed spoke of all three meetings as part of their weekly routine. 
At times the weight of this routine was felt by the staff, not because of the work, but because of the press for time. As a second grade teacher commented, "We meet to death. We spend lots of time in meetings. If it's not PD, then it's with your team...It all comes back to time."

Norms for Data Use. Teachers and staff at School A knew that using and analyzing data was a process that automatically followed student work. They routinely reported scores on their software tool, CASCADE, and began their analysis individually, even before they came together in a meeting format. Any mention of re-rostering students, planning groups, or planning next steps was preceded by some mention of data. It went without saying that student scores, and progress indicated by those scores, would be displayed in their data room. They also took it for granted that the data would be monitored by the administrator and instructional coach on a regular basis. No teacher appeared to be opposed to their scores being posted, and in fact, when asked about unwritten rules for data use, one teacher observed:

I just feel like we analyze everything. That's what we do here, we analyze everything. You can see the colors up there, too. Everything we do, any type of assessment, that's just the way it is here...to drive your instruction to see what you need to either redo or move on.

Also, even though each teacher realized their responsibility in the data process, there was a certain element of respect for each other's work:

I've noticed when we're in here, nobody really looks at anybody else's but their own. It's really funny, or you track, I see my kids from last year, where are my children falling, and I look at that to see, oh, I must have fallen down in that area. Of course you take it personally, you know. So when it's charted like this I don't look at anybody else's children but my own except for the kids maybe that I've had and were worried about before, and those top children, are they still performing? 
As formative assessment became an emphasis through district-led professional development sessions, and faculty meetings, teachers were beginning to intentionally use this more informal, "close to the ground" method of assessing from data. When speaking generally about data, one teacher identified formative assessment as an important element, and described ways she used formative assessments to plan instruction, including a very low-tech system of using sticky notes. Nonetheless, it was sufficient to give her information "to see who understood what it was that was being taught and who didn't, so that, to me, is a formative assessment."

Norms for Planning Next Steps. It could be argued that all the data in the world would not be beneficial unless it prompted change. Teachers here saw planning next steps as the ultimate point to data analysis. Every teacher described how data were used at School A, and explained that the process included planning next steps. These steps were usually described as reteaching, employing different strategies, forming focus groups for specific content, regrouping students, or working with students individually. The teachers talked about the planning of next steps as an ultimate and logical extension to collecting and analyzing data.

Norms Related to Correlates. Three other normative values that related to the Effective Schools Correlates were repeated in the interviews. Although these are not a direct part of data use, they speak to the overall culture of the schools that show the interdependent nature of targeting increases in student achievement.

Teachers spoke about high expectations for students as a part of everyday life. Each day teachers repeated their "motto" for student expectations. Posters on the walls of 
School A also emphasized what was expected. Even a special education teacher that was interviewed stated:

... I don't know if this is just a personal thing, I mean high expectations, again, my Special Ed background, that's one of my pet peeves is that people don't expect or think that they can or that they will be able to, but we've had kids that you know, 40 IQs, but I'm like, no they can. They may do it differently, but they can.

She reiterated that, from her perspective, regular classroom teachers could have even higher expectations for their students:

I think that maybe there's some people that could have higher expectations. That's just a judgment call on my part, but you have to understand that's my, it's not anything in particular, it's just one of those things that I feel so strongly about.

A second school norm for safe and orderly environment was seen in the school's adoption of the district's initiative, Care for Kids. This program focused on academic, social-emotional, and ethical development of children as they learned to participate in a democratic society. The program emphasized these tenets through activities such as morning and check-in meetings where students discussed their interactions and solved difficult situations. Another related part of Care for Kids was the developmental approach to discipline, emphasizing logical and appropriate consequences. Although promoted by the district, schools had the opportunity whether or not to participate in the program, as demonstrated by a required two-thirds vote of the faculty.

The third school norm that was mentioned often was an emphasis on students' social, emotional, and ethical development. This was a district-led initiative, but it showed that they valued the correlate of Home-School Relationships. Each week, or at least every other week, teachers offered parents a Homeside Activity. This was sent home in newsletters or other forms of communication between teachers and parents. These 
activities were designed to promote shared participation between students and parents. Although these activities were elective, it was a way for the school and teachers to keep lines of communication open and show their support and concern for families.

Summary

Norms and rules were manifested by the understanding that work was distributed; by an open, collaborative environment demonstrated through peer observations and feedback; and by using data and planning next steps. Three norms related to the Effective Schools Correlates were also evidenced. As teachers met and worked together to establish goals and create materials and tools, they constructed both explicit rules (e.g., all data are displayed in the data room), and implicit norms (e.g., we learn from each other). By collaborating together to establish and achieve goals, the teachers coconstructed tacit beliefs and assumptions that served as foundations for the daily work.

Case Study, School B

School B was also one of the 90 elementary schools in the same urban district, and among the four experimental schools in the ES21 program. The following information is based on the latest published information at the time of this study. School B had 501 students ranging from prekindergarten to fifth grade, and of that number $17.8 \%$ were categorized as white, $42.7 \%$ as African-American, and $39.5 \%$ as "Other." The Free and Reduced lunch percentage was $89.6 \%$, which qualified School B for Title 1 funds. The latest mobility rates were $8.11 \%$ for $2008-2009$, and $8.92 \%$ for $2009-2010$. School B had 70 students who were English as Second Language Learners. Per pupil spending was listed at $\$ 9,698$. The latest attendance rate for this school was, like School A, 94.1\%. Pupil to teacher ratio was 14.8:1. There were 4 Exceptional Child 
Education units at School B, along with 1 Head Start unit and 1 Pre-Kindergarten unit for three year old students.

There were 32 professional staff members at School B, and each was considered "Highly Qualified" by NCLB standards. The staff was composed of a principal and counselor, 15 classroom teachers, 1 preferred substitute teacher, and 3 faculty funded by Chapter 1 grants.

The educational levels achieved by the faculty was: 1 Doctorate degree, 7 Master's plus 30 credit hours, 4 Master's plus 15 credit hours, 14 Master's degrees, 4 Bachelor's plus 15 credit hours, and 2 Bachelor's degrees. None of the teachers had emergency certification. Six percent of the staff was African-American males, $25 \%$ were African-American females, $6 \%$ were Other males, and $63 \%$ were Other females. Teacher attendance was 94.1 , and teacher retention was $85.2 \%$.

The priorities of the School Improvement Plan include: (a) increasing scores in math and the overall index and African-American scores, (b) increasing scores in reading, both overall index and African-American scores, (c) improving PTA membership, and (d) decreasing office referrals for student behavior. School B's Site-Based Decision Making Committee was composed of one administrator, three teachers, and two parents. Instruction for the students in School B was delivered through district recommended curriculum. The science and math programs emphasized inquiry and student discovery. The reading curriculum followed a five-block model, emphasizing phonics and word work, shared reading, guided reading, self-selected reading, and writing. The school provided Extended School Services and SuccessMaker for struggling students. Extra-curricular programs included an academic team as well as sports teams. 
Results of the state assessment for School B for the 2008-2009 school year were:

Table 6

Percentage of students achieving Novice, Apprentice, Proficient, or Distinguished performance levels on the 2008-2009 state assessment

\begin{tabular}{lcccc} 
Content Area & \% Novice & \% Apprentice & \% Proficient & \% Distinguished \\
\hline Reading & 12.92 & 41.01 & 42.13 & 3.93 \\
Math & 23.03 & 34.27 & 31.46 & 11.24 \\
Science & 25.00 & 44.22 & 26.92 & 3.85 \\
Social Studies & 18.03 & 52.45 & 29.51 & 12.24 \\
$\begin{array}{l}\text { Writing On- } \\
\text { Demand }\end{array}$ & 9.84 & 44.26 & 44.26 & 1.64
\end{tabular}

No Child Left Behind results indicated that $46.06 \%$ of students were proficient or distinguished in reading, and $42.7 \%$ of students were proficient or distinguished in math. The school did not achieve AYP in 2008-2009 or in 2007-2008, but did reach the target in 2006-2007.

\section{Implementation}

As School B teacher leaders took the information they learned in the ES21 professional development sessions, they worked with classroom teachers and support staff to implement the strategies for using data for whole school and classroom improvement planning.

\section{Procedures and Processes: Meeting Formats}

School B utilized procedures and processes that included a variety of meeting formats, activities, and collaborative efforts that emphasized the use of data for 
improvement planning for increased student performance. These procedures and processes ranged from being formal and led by the administrator, to informal collaborative efforts among teachers, to teacher/student efforts in analyzing their own assessment data.

The meeting formats that were both observed and reported were:

- Leadership Team Meetings

- Cross-site Meetings

- Cross School Visits

- Staff Meetings

- Vertical Team Meetings

- Horizontal (Grade Group) Meetings

- Cross Grade Meetings

- Teacher/Student Assessment Meetings

- Site-Based Decision-Making Council

Leadership Teams. The Leadership Team for School B was in place when the administrator was hired a year into the ES21 project. She did not change any of the members or how their meetings were conducted. The members each had roles they had learned from one of the ES21 professional development sessions (timekeeper, facilitator, recorder, and process observer), and those roles were kept in place. Another strategy that School B incorporated from ES21 for their leadership teams was that they always used the same organization for meeting agendas. In this way, the principal expressed that, "we are all looking at the same format when we look at meeting (agendas) and minutes, and 
that definitely helps." Norms for meetings were established, although the principal stated that they were "not absolutely firm with the norms."

As time in the program continued, there were occasions to replace some of the team members. One of the teachers commented that, although the administrator had the final decision, she was willing to listen to those who wanted to take part. "Usually you're just asked" (by the principal), but also, "You could bring it up to [Mrs. Smith], it's an open door, you can ask for it or you can be asked."

The leadership team consisted of six teachers and the principal. Members would attend each professional development session together. Although this required that a quite a few substitute teachers be employed, the principal felt that the trade-off was good and that the team members gained from the sessions. Following the professional development sessions, the leadership team would come back to the school and meet together.

They [the instructional leadership team] would meet with their teams [grade groups] to distribute information and to instruct on the different areas of content [from the professional development sessions].... Then we would bring that to [grade groups] and then to staff meetings, out to the school, so everybody would have some say into what it would look like in the school...Taking ideas, we got to talk about what we needed to do to make our school better.

Cross- Site Meetings. The cross-site meetings were described in the case study

for School A. The leadership team from School B participated in all three cross-site meetings for ES21. The first meeting was held in Atlanta, Georgia. The purpose of this meeting was for district liaisons and principals to come together to gain an understanding of the correlates and necessary processes for the program. A review of Year 1 activities and preparation of Year 2 also took place. The goals of this session included increased participation in the intervention and goal setting that was coordinated between each 
district, principal, and leadership team. The cross-site format was also used for the schools to be able to share their learning across districts and states.

The second cross-site meeting was held in San Diego, California. District liaisons, principals, and leadership teams from all 16 schools attended this session, with the exception of the liaison from this district. Since the participating schools had been engaging in the same work, and since they had the chance to get to know each other the year before, this session was an active engagement in sharing experiences, and collaborating in work to analyze and plan school work.

The third and final cross-site session was held in Charlotte, North Carolina. Following two years of work together, the participants met to continue their collaborative efforts for reform in their schools, to discuss sustainability for the intervention, to reflect, and share common experiences.

Cross School Visit. School B engaged in a cross school visit with School A as the ES21 intervention was concluding. This visit was described in the previous case study, and was created to be a smaller version of the work done in the cross-site visits. Each school sent teachers to spend a day visiting the other during an instructional day. They took data and made observations on the school culture, instruction, and environment. Following the observations, the teachers from both schools met to hear feedback and comments from the visiting school. The administrator from School B viewed this as a positive experience and expressed that she "would love to do that again." Despite the enthusiasm for this type of work, no other visits had been arranged with another school. As one of the teacher leaders stated, they had participated in:

...cross-site meetings where we have teachers go and come in... [but haven't planned more], probably just the time and the planning of it. It was very helpful 
but just the time restraints of having us go and them come. We have had district people, but not other teachers [come to our school].

Although not on the same scale as a cross school visit, the principal at School B did send her writing lead teacher to another school to observe strategies for their writing program. This was done in an effort to develop and deepen their writing program at each grade level.

Staff Meetings. Staff meetings occurred on Tuesday after school. All regular classroom teachers, ECE teachers, and special area teachers (such as computer, physical education, library, etc.) attended. The staff received the meeting agenda at least 24 hours prior to the session, as stated in the bargain agreement. As with School A, the teachers were sometimes asked to bring prepared documents or student work, and the timely notice aided this process. Also, teachers were free to add items to the agenda. The meetings usually occurred in the library, but the principal had begun to hold staff meetings in different classrooms with teachers taking a part in leading the meeting.

Vertical Teams. Depending on the purpose of the meeting, staff would be organized in different arrangements. Teachers reported that they sometimes sat in vertical teams. The most common mention of vertical teams was when the school gathered to conduct an analysis of the state assessments. Teachers were grouped so that a representative from each grade level was represented on a team, along with support teachers, such as ECE or resource teachers. Each group was responsible for analyzing a content area, and when the staff came back together, each group reported results to the whole school.

Following this exercise, at another staff meeting, the school met in vertical teams to construct their plan for the year, the School Improvement Plan. Having disaggregated 
the data from the state assessment, the staff could discern areas of strength and challenge areas. Goals, objectives, and projected scores were created for the whole school and each NCLB subgroup that needed improvement.

Cross Grade Meetings School B also engaged in cross grade meetings or activities. As previously mentioned, teachers engaged in several peer observations to learn from each other and to take data on teaching practice. The administrator asked all teachers to use one of their planning time periods to visit other classrooms to observe instruction, classroom management, room arrangement, student learning, or anything else they saw that would help them in their own practice. They were to report their observations and bring them to the next staff meeting. One teacher described this process:

...at the beginning of the year, teachers collected their own data as they conducted peer walkthroughs of classrooms, describing room spaces and places that they might implement in their own rooms. They also observed peers during instruction, and in a faculty meeting described what they observed and aligned them with Marzano's strategies.

Teachers from different grade levels also collaborated with each other to better serve students. For example, if students were struggling significantly or excelling significantly in reading, they would "move as needed between reading groups or between classrooms as needed to meet their needs." For the next school year, School B was planning to groups students in reading as a whole school so that teachers could exchange students as needed. As well, one teacher regularly met with teachers from a grade different than her own to support some students that she serviced from that grade.

Grade Groups. Grade group arrangements were the most common format for staff meetings, but they were also the most frequently used format for a variety of other sessions for improvement planning and data analysis: 
...grade group meetings are held weekly to discuss things like arranging groups, collaborating with teachers on curricular content and strategies, etc...Job embedded PD sessions are the primary vehicle for looking at students work

Grade level groups participated in job embedded professional development sessions weekly, or on occasion every other week, focusing predominately on analyzing data and student work. Each grade group had a certain day that they attend job embedded PD. These sessions are not always led by the principal, or even by the same person. Sometimes they are led by a teacher with knowledge in a certain area, or by an instructional coach, or even by a district resource teacher.

During these sessions, teachers analyzed a variety of data sources, and then planned instructional strategies to enhance student improvement. Even though the staff sometimes looked at whole school data, it was more likely that discussions that occurred in grade group meetings were very specific and intentionally related to a need:

We do embedded PD by grade level. They have a focus, either math or reading where we have the need. This year reading focus... about how we can have our teachers master the reading skills that they need, where they need more support, where they are lacking. I have a M.A. from [a local university] with a reading specialist endorsement. I've had the opportunity in working with my third grade, but also with fourth and fifth. If they need fact and opinion, let me help you here main idea, let me pull together materials for that. We have a preferred sub, so sometime when she's extra, I can go talk them through how to use that strategy. I talk with them during their planning time or embedded [time].

The principal also reported that teachers used weekly grade group meetings to have discussions about grouping students by need, and collaborating about curricular content and strategies. One teacher who departmentalized in fourth and fifth grade said that she planned with both grades even though it required her to use her planning twice a week for grade group meetings. She explained that, besides the more formal grade group meetings, she also "talked every day to fourth and fifth grade teachers." She felt this 
really helped the teachers to better group their students for success. Even though she did not teach math, she would also attend sessions when math was discussed because the "fourth and fifth grade teachers [wanted to] support each other," even though a specific topic may not pertain to them.

Grade group meetings were also used for looking at data, such as end of unit math assessments. One teacher even explained that her grade level team would write their own rubrics to track student performance with "each piece of core content." They then created an Excel spreadsheet for tracking novice, apprentice, proficient, or distinguished performance. By analyzing data in this intentional way, they could tell if they needed to reteach "a couple of kids, pull focus groups, or the whole group."

Teachers at School B also used grade groups to contribute to writing the School Improvement Plan. Each grade level looked at the results from the state assessment and broke down the data for their own kids. The teachers then were responsible for writing a portion of the School Improvement Plan, and reviewing progress during the year by completing Implementation and Impact checks. All of the work created by grade groups was also shared with their colleagues in staff meetings.

An important part of what the teachers did in their grade group sessions was to post their data. Like School A, School B also had a room devoted to recording and monitoring student progress. The data came from a variety of sources such as district Core Content Assessments, Diagnostic Reading Assessments, T-Pro, and teacher judgment.

We have a data room, and we have [student performance levels] blocked off in Tier I, Tier II, and Tier III, and we'll periodically... probably if not every Friday, then every other, we look to see if any of [the students] have moved up or down. They look at DRA, DIBELS, T-Pro, and teacher interpretation of 
how they're doing, and that's how we analyze it...We're starting to focus on the core content that we're not meeting, so that's probably one Friday, and then we move the kids on the other Friday.

This shows intentional and regular assessment of student performance aligned with specific areas of content that the students are not meeting. This was designed to assist teachers in knowing exactly which students are in need of support and in what specific content components.

Teacher/Student Assessment Meetings This meeting format was an arrangement that took place between teachers and their students. School B created an assessment folder for each student, and the students were in charge of recording his/her own assessment results. Each time a student took a benchmark assessment, received a DRA score, or other assessments deemed important by the teacher, the student recorded (and in some cases plotted) the score in the folder. Teachers would periodically meet with the student to review their progress, and help the student plan ways to improve achievement. This was done to intentionally encourage students to realize that they are responsible for their own learning, and that scores are a result of their own work, not just a mark given to them by a teacher. The administrator commented:

One thing that [School B] has implemented this year that was touched on in ES21 is the idea of student involvement in assessing their work. [The teachers] have created an assessment binder for each student to record and chart their own SuccessMaker scores, CCAs, and ORQ scores. The students are responsible for their own performance and reflecting on where they are in relation to the goal that is set.

Site Based Decision-Making Council. School B teachers mentioned their Site Based Decision-Making Council (SBDM) several times during their interviews. This council was part of their data decision-making process. As they analyzed the whole school and classroom data throughout the year, they determined how the school and its 
various subgroups, such as African-American students or male students, were progressing relative to the goals they had established in the School Improvement Plan. Scores for each targeted area were recorded as a result of Implementation and Impact checks, and results were reported to the council. As part of its work, the council could make suggestions, make policy, or assign funding to take part in improvement planning for the school.

\section{Procedures and Processes: Activities}

The procedures and processes for data use at School B not only included various meeting formats, but also a variety of activities. They engaged in data analysis for whole school, grade level, cross-grade level, and classroom level improvement. Strategies resulting from this work included re-rostering of students, and school and student celebrations.

Data Analysis. The teachers at School were continuously looking at data. Teachers were consistent in their remarks about the frequency of data analysis, and that data came from multiple sources to portray a complete picture of student work. One teacher stated:

I use CCGPs, CCAs, end of unit math assessments, and teacher made assessments. I use data for everything I do. We are a very data driven school and make all our decisions around using data.

Whole School Activities. The entire certified staff met together for the purpose of looking at whole school data at least three times each year. After the results for the state assessment come in, the teachers reported out by grade level as to what the data revealed about their grade. Along with grade level information, School B compared their 
performance with how the district and state performed. They also looked at the AYP targets for reading and math for NCLB, and analyzed the challenges in achieving them

Following the sharing of information, the teachers contributed to writing the School Improvement Plan goals based on whole school needs. On two other occasions during the year, the staff visited these goals to review the progress that had been made, and to modify strategies, if necessary.

The school also engaged in district benchmark assessments for reading, math, science, and social studies. These CCA scores were entered into the CASCADE data warehouse system, where analysis was immediately available. These results were roughly correlated to state assessment scores, so it gave the school a good idea of how it would perform on that assessment. These benchmark scores would be discussed in a variety of settings, including staff meetings.

Grade Level Activities. Teachers repeatedly emphasized that most data analysis took place in grade level activities. Job embedded professional development sessions, and formal or informal grade group meetings were the two most frequently mentioned formats for these activities.

As teachers met with their grade level colleagues, they engaged in data analysis for CCAs, DRAs, DIBELS, T-Pro, end of unit math assessments, and teacher made tests. The discussions sometimes focused on the assessment itself, exploring explanations for why a majority of students missed a certain question. All grade levels gave CCAs for math and science. Grades three through five administered the district benchmark assessments for reading, as designed by the district. Most frequently, discussions about CCA results involved re-rostering of students for the purpose of "arranging groups, 
collaborating with teachers on curricular content and strategies," and for planning next steps for instruction. For example, one teacher reported that she frequently developed her own rubrics to measure student performance even for teacher-made tests that correlated with state assessment parameters of distinguished, proficient, apprentice, or novice.

It is at the grade level where teachers also collaborated to target strategies for success, or offer to take a struggling student into their classroom for specific content, such as reading. One teacher offered that her grade level teachers planned together at least once a week, always with the view to group and regroup students according to ability levels as they progressed through the content. In this way, the approach to individualized and differentiated teaching was achieved in a fluid way and on the basis of student need.

Grade groups also met to grade student work together, to develop their own knowledge of a concept prior to instruction, or sometimes lead a session themselves. They prepared work to be turned in to the administrator, instructional coach, or for the data room. Another grade level activity that was in the planning stages was for teachers to participate in a Lesson Study. As stated previously, the teachers had engaged in peer observations, and had given feedback, but a structured Lesson Study had not yet taken place. The instructional coach was already planning how to conduct this in a safe and risk-free environment for the teachers:

Next year, we're looking at lesson study and see what was difficult for the kids, and do that content for the lesson study. A grade will sit down together and plan a lesson because the kids are just not getting it. One teacher will teach, other teachers will observe. Then they'll talk about the lesson, what went well, what didn't, what to change. The next day another teacher will teach the revised lesson and modify. Then the third day, the third teacher will do it again. No 
pressures because everyone will teach the lesson. Feedback...I don't know if we'll do it three days in a row or three weeks in a row to give time for feedback.

Classroom Level Activities. The classroom activities around data are similar to the grade group activities. At the classroom level, however, teachers were concerned only with the performance of their own students, and not how they compared to other classrooms or the whole school. Teachers described the work they did to be sure they could understand how their students were performing, and identifying those areas where they struggled. One teacher explained that she went to the trouble of creating assessment rubrics for the end of unit tests in math, so she could determine which parts of the unit her students were struggling with.

Even primary teachers engaged in creating assessments for their students, even though the district had only designed the reading CCAs for the third through fifth grade classes. One second grade teacher explained that teachers at her grade level created their own open response questions to correspond with the shared reading activity. She also administered Running Record assessments twice a month. Primary grades also gave students the T-Pro, which focused on vocabulary, phonemic awareness, substitution and deletion, and reading comprehension.

Yet another teacher described her activities related to data:

I have to look at the data in the units I teach. I do a pre-test and a post-test. I do that quite a bit....then I analyze it and see why I think some students didn't do as well and make up for it somewhere down the line. Like giving them extra center time to focus on an area they lack in, or giving them individual assignments or working with them one on one. T-Pro has a web site to tell you what kind of activities they need for where they are...They have computer activities they could work on.

Another data component that occurred at the classroom level was that School B was beginning to put emphasis on formative assessment. As the instructional coach 
talked about the teachers becoming involved in recording and analyzing data in the data room, she extended the notion of data beyond statistical analysis to describe what teachers found beneficial:

We're doing better with formative assessments. They're trying to do exit slips, charts, or in some way, they're using formative assessments now to drive their instruction. Exit slips, charts, post-its to answer, thumbs up and thumbs down, daily checks...it takes a second to see if that kid got it, that kid didn't.

Re-rostering Students. Re-rostering students became a natural outgrowth of analyzing data related to specific content, especially for reading. As teachers assessed their students' reading levels, they "re-rostered" students by tiers. Tier I represented students who were at or above grade level. Students who were within one year of reading on grade level were placed in Tier II, and Tier III was for students reading more than one year behind grade level. Strategies designed to remediate Tier III students included extended small group instruction and computer activities for an additional hour of reading instruction each day. Tier II students engaged in additional reading activities for 30 additional minutes each day.

Celebrations Related to Data. One data related activity that several teachers from School B mentioned was that the staff and students engaged in celebration activities. As assessment data are posted in the data room, teachers, support staff, and even students have "parties." As the instructional coach described:

People return the data and I put it on the wall. Every predetermined amount of time we go back and look at the assessments, and then have moving parties with faux champagne. Everyone owns their data and you get to move and manipulate it.

Another of these activities centered on student celebrations: 
One thing we do, events for the kids, monthly incentive celebrations for proficient or distinguished on a CCA. They are invited to come, where if they improved they come to the celebration. We do that every month for whatever core content. The first time, it just for proficient or distinguished. Then the next months we compare it and if the student has improved, they come.

Summary

School B exhibited procedures and processes in a variety of meeting formats and activities as they implemented ES21 strategies designed for improvement planning from data. In each format or activity, collaborative efforts of co-construction were observed as teacher leaders, the administrator, and staff engaged in discussions for setting goals, analyzing data, or planning next steps. Meetings were characterized by setting a set of clear goals, especially in the beginning of the year as School B analyzed its performance on state assessments and created the focus and targets for School Improvement Plan. Activities, such as re-rostering of students and grade level planning were characterized by side-by-side or group interactions, and demonstrated an ongoing practice of analyzing decisions. These examples indicate practices reflective of high reliability schools.

\section{Materials/Tools}

School B not only distributed their work with data across procedures and processes, but they also used multiple materials and tools to accomplish this effort. These materials and tools consisted of assessments and their scores, rubrics, spreadsheets, and protocols, and a data warehouse tool to disaggregate data.

Assessments. School B used state, district, school, and classroom level assessments and their scores as tools for improvement planning. From the state level and to the classroom level, the assessments were:

- State Assessments 
- Core Content for Assessment in reading, math, science, social studies (District)

- DIBELS (District)

- DRA (School)

- T-Pro (School)

- Rigby Reading Levels (School)

- On-Demand Writing (School)

- End of Unit Math Assessment (School)

- Teacher-made Tests (Classroom)

- Formative Assessment (Classroom)

Like School A, School B also utilized a number of rubrics, spreadsheets, and other materials to shape and mediate the way they planned from data.

State Assessments. The state assessment tested the areas of reading, math, science, social studies, and on-demand writing. Only third, fourth, and fifth grades were tested, and only in specific content areas. All of these grades participated in the reading and math tests. Grade four also tested in science, and the fifth grade also tested in social studies and on-demand writing. The assessment was administered to students during the month of April, and results were known the following August.

District Benchmarks. The district benchmark assessments given at School B were the Core Content for Assessment in reading, math, science, and social studies, as well as the DIBELS assessment. As described in the previous case study, the CCAs were given to all grades in the content areas of math and science. Reading CCAs were developed for third through fifth grades, and social studies CCAs were given to the fifth grade. They 
were created by district personnel, and were to be administered in the same manner as the state assessments. They were designed to be general predictors of the state assessment results.

The DIBELS assessment was given to the kindergarten through first grades. Only during the most recent school year, 2009-2010, did second grade students also participate in this assessment, completing only one subtest. The DIBELS was given three times during the school year; fall, winter, and spring, and scored students in early reading skills. Teachers used these results to help form reading groups, determine specific challenge areas for students, and to determine progress.

School Assessments. Developmental Reading Assessments were given to all students several times during the school year. This assessment scored students on reading accuracy, fluency, and comprehension. The DRA scores also correlated with the reading levels from the Rigby reading curriculum which were periodically assessed. Both of these sources of data, along with teacher judgment and classroom performance, helped teachers to group like students. As students were subsequently assessed on these measures, their progress was monitored and their groupings changed accordingly. The T-Pro was another assessment used by School B to determine reading skills. This assessment was given twice during the year and was another data source that outlined strengths and weaknesses of students.

On-demand writing was the tool used by School B to assess student writing skills. The students were given a situation, which described an event or a circumstance, and a prompt, which asked students to respond to the situation. They were scored and analyzed for student performance. 
The end of unit math assessments were used in first through fifth grades. These assessments were provided through the math curriculum, and gave information on specific subcomponents that had been taught in each math unit.

Classroom Assessments. Teachers also sometimes constructed their own assessments to monitor student performance. Specifically mentioned were open response questions. These questions were designed to mimic the format used on the state assessment. They required short narratives in response to questions about a reading passage, and were used for all content areas. Some of the other teacher-made tests were designed as a traditional paper and pencil tool, but teachers frequently spoke about using more formative assessments, such as exit slips, journaling, or quick indicators of understanding such as thumbs up or down. School B attended the same district professional development session as School A which focused on using formative assessment for student achievement.

Rubrics and Spreadsheets. The tools of rubrics and spreadsheets described by the teachers at School B included a rubric for the state assessment, a common room for posting data, rubrics for CCA analysis, rubrics for writing analysis, and a spreadsheet created by the principal for student scores.

The Red Flag Analysis was completed by the staff toward the beginning of the year. State assessment results were analyzed with this document, which was designed to disaggregate data by content area, indicating performance by grade level and NCLB subgroups. The rubric was divided among the staff during a whole school meeting, and each grade level was responsible for analyzing the scores. From this work, the School Improvement Plan was developed. The Red Flag analysis tool pointed out which areas 
and strategies were at risk; for example, reading had $45 \%$ of students scoring proficient for the component of Forming a Foundation. As well, the analysis tool helped to determine if multiple choice or open response questions were the more challenging for the students. Although the state did not give trend analysis on the 2008-2009 results, the school still was able to determine if they had improved or declined since the previous year's report.

Like School A, School B also set aside a dedicated room to post and chart data. This room visibly displayed student performance in reading, math, science and social studies as they correlated to state and district assessments. School level scores, such as DRA, Rigby levels, and teacher judgment were also went into determining the placement of students as distinguished, proficient, apprentice, or novice. Although the instructional coach was responsible for getting student names posted, the classroom teachers would move students as they progressed, or perhaps declined, during the year.

CCA rubrics accompanied the district benchmark assessments in each content area. They correlated a score of "B", zero, one, two, three, or four with descriptions of possible answers. Figure 1 contains a CCA rubric for a reading passage about a meteorite that crashed into Antarctica. The question was written with Part A, which asked for four facts about meteorites, and Part B which asked for two living conditions in Antarctica.

\begin{tabular}{|l|l|}
\hline 4 & $\begin{array}{l}\text { Student completely answers part A by clearly listing } 4 \text { text-based facts about } \\
\text { meteorites. For part B, student completely describes TWO living conditions that } \\
\text { people experience in Antarctica. The details and explanation the student gives show } \\
\text { that he/she COMPLETELY understands the question and how to answer it. }\end{array}$ \\
\hline & $\begin{array}{l}\text { Student generally answers part A by listing } 3 \text { or } 4 \text { facts about meteorites. For part } \\
\text { B, student generally describes TWO living conditions that people experience in } \\
\text { Antarctica. Student gives text-based details to support each part. Student answer } \\
\text { shows that he/she understands the big ideas, but there may be a few small mistakes } \\
\text { or misunderstandings. }\end{array}$ \\
\hline
\end{tabular}




\begin{tabular}{|c|l|}
\hline 2 & $\begin{array}{l}\text { Student response shows partial understanding, and only some of the directions are } \\
\text { followed. Student's choices of facts, ways, or supporting details are not the best } \\
\text { choices or are limited, and explanation is weak. He/she has forgotten some } \\
\text { important information or has shown some misunderstanding of the text. } \\
\text { OR student only completes part A OR student only completes part B }\end{array}$ \\
\hline 1 & $\begin{array}{l}\text { Student demonstrates minimal understanding. Student follows only a few of the } \\
\text { directions, and only answers a small part of the question correctly. }\end{array}$ \\
\hline 0 & Response is completely wrong or has nothing to do with the question. \\
\hline B & Blank or no response \\
\hline
\end{tabular}

Printed with permission

Figure 2. CCA rubric for reading passage.

Since these documents were designed by the district and given by most every elementary school, this enabled teachers to compare their class performance to others in the district at the same grade level. The data reporting tool displayed a comparison graphic that showed this comparison. Teachers and administrators also compared scores within the schools, both by grade level and across grade levels.

Rubrics created by the district were also used for analyzing student writing. Writing portfolio pieces were analyzed by a rubric that indicated whether the piece was "developing, progressing, or competent" in the nine areas including writing purpose, audience awareness, idea development, and organization. Conventions of writing such as sentence structure and grammar usage were also analyzed. There were actually two versions of this rubric available; one with a point system that could reflect a numeric score to be used as a summative tool, and one with no points to assess progress or current performance for a student.

There were two rubrics to evaluate on-demand writing pieces. One was a checklist and one was a spreadsheet. The checklist was tailored specifically for each of 
the three required on-demand styles of writing: writing to narrate an event, writing to persuade, and writing to inform. This type of data collection allowed the teacher to determine which elements of the pieces were present or absent for each student. The spreadsheet also allowed a teacher to determine this information, but had the added element of showing the data for the whole class. In this way, a teacher could see how the class as a whole was performing, and what topics needed to be revisited.

Another spreadsheet developed by School B was one that the administrator developed for the student assessment binders. These binders were created to promote the idea that students are responsible for their own learning. This spreadsheet called for students to record their own CCA results for multiple choice, which was a numeric score or percentage. Also, the open response score was recorded. Both scores together indicated a score of novice, apprentice, proficient, or distinguished. Students also recorded scores for their on-demand writing. Other scores of interest, depending on grade level, were also recorded. Teachers met with students informally to review results and to discuss new goals and strategies for progress.

Teachers at School B spoke on several occasions about creating their own rubrics or spreadsheets. A second grade teacher explained that she was able to determine student performance by designing rubrics for math helped her analyze the end of unit assessments in math:

CASCADE is good for entering data, [but] you can do it for your own data, too. A lot of the rubrics I make myself, especially for math. I look at the end of unit assessments, and come up with my own rubric. They usually have a one through four. Three means that they met [the benchmark]. I usually have no more than three objectives I'm looking for. What do I want the benchmark to be. Then a four usually exceeds a three; once I do it, it makes it more clear and the kids know what I'm expecting. 
Technology. Materials and tools that relate to technology included the CASCADE data warehouse system, the website for T-Pro and SuccessMaker. Teachers use the CASCADE system to record student scores on multiple choice and open response sections of the CCA benchmarks. The program then disaggregated the data to show the percentage of students who performed at a novice, apprentice, proficient, or distinguished level. It also showed the percentage of students who correctly answered each multiple choice question. There was also a report that showed the percentage of student responses for each possible answer on multiple choice questions (A, B, C, or D). This informed teachers what percentage of students has a misconception on any given question.

Teachers also mentioned the use of T-Pro analysis tool which analyzed students' reading performance in the areas of vocabulary, phonemic awareness, substitution and deletion, and comprehension. The results indicated areas of strength and areas needing improvement, "It gives us something that says where the benchmark (is), but we're the ones that read it and figures out what it means."

Another important technology tool used in School B was SuccessMaker. This was a computer program that provided intervention strategies for students struggling in math and/or reading. Students completed lessons or sessions that lasted approximately $15-20$ minutes. The program was designed to progress the student to grade level as they successfully completed each session. The reports generated from SuccessMaker gave much information about the students' performance such as total time spent on each session, time spent on each session, and percentage of correct answers. This report helped the teacher to determine if the students were being successful on this intervention, or if other interventions should be explored. 
Other Materials. Another material that was discussed by teachers at School B that helped the school to plan from data. An end of the year wish list was generated by teachers and given to the grade immediately below them. This wish list was based on the culmination of student performance over the whole year. As teachers reflected on student achievement, they were able to construct a picture of those strategies they felt were important for students to learn in the previous grade. After the list was constructed, it was given to the teachers in the grade below, and discussed.

\section{Summary}

The materials and tools used by School B illustrate how leadership was distributed. Even though materials and tools are inanimate objects, they nevertheless have a place in the concept of distributive work. For example, as School B used the district's benchmark assessments and the data warehouse system for reporting and analyzing scores, these materials and tools were not only necessary for distributing work with data across the school, they also became the vehicles for distributing collaborative discussions, decision-making, and planning next steps. As well, they became part of the normative values at School B regarding improvement planning from data. This exemplifies how the element of materials and tools mediates or shapes the ES21 strategies for improvement planning from data.

\section{Norms/Rules}

School B demonstrated many norms and rules for data use. Among the norms and rules identified from on-site observations and interviews were collegial work, such as peer observations and feedback, routine meetings, data analysis, charting data, and celebrating successes. These were all part of the standard operating procedures that 
comprised their work on a daily basis. This work was conducted without question or challenge because it was "what we do." The fact that the work was distributed across the three elements in my conceptual framework was clear.

Distributed Leadership. Even though this study proposes three separate components of distributed leadership, the concept itself is worthy of foregrounding when discussing norms. Although not explicitly mentioned as a norm, School B spoke about working with data as being distributed among and between all elements of school work. ES21 information was distributed to all teachers by the leadership team, but clearly it was not just that information that was shared with others, but the work was described as being distributed across the processes, the materials, and the norms for data use as it became part of the practice of their work:

[We would have leadership] team meetings....and then we would bring that to the grade groups, and then to staff meeting, out to the school, so everybody would have some say into what it would look like in this school.

Job embedded is by grade group and every group has a day that they go to job embedded...they are led by different people...Vertical teams in faculty meetings, even where we've done one person from each grade level doing different activities in reading, writing, etc...Cross site meetings where we have teachers go and come in...We looked at each others' classrooms of the beginning of the year we walked around to different rooms and saw how they had their rooms set up, etc.

When one of the teacher leaders described how she tried to implement some of the ES21 strategies in School B, she spoke readily about the processes that occurred (job embedded PD), materials and tools that were used, and school beliefs were unspoken ways of working. She identified job embedded PD as a primary forum to distribute work across the school. She also spoke about the process of offering her expertise as a reading specialist to the third, fourth, and fifth grades. This process had become such an expected 
part of the culture, that when the preferred sub was extra, she would serve as a substitute for the classroom teacher so she could meet with those who needed support. She also spoke about gathering materials that were pertinent and appropriate to offer this support:

We do embedded PD by grade level. They have a focus, either math or reading, where we have the need. This year reading focus, about how we can have our teachers master the reading skills that they need, where they need more support, where they are lacking. I have an MA... with a reading specialist endorsement. I've had the opportunity in working with my third grade, but also with fourth and fifth. They need fact and opinion, let me help you here, main idea, let me pull together materials for that. We have a preferred sub, so sometime when she's extra, I can go talk them through how to use that strategy. I talk with them during their planning time, or embedded. I've led embedded PDs after school.

Peer Observations and Feedback. The staff at School B spoke about the peer walkthroughs they had done as something they took for granted that happened over the course of the year. Teachers engaged in a number of peer observations looking for different things each time. They looked for instructional practices, room management and organization, or something they might implement in their own classrooms. They only reported on their positive observations, which was a first step in building a culture of trust. The instructional coach then explained that because the teachers had confidence in this process, the norm could be deepened as they constructed the process of a Lesson Study for the next year. All teachers in a grade group would equally participate in the process, "No pressures because everyone will teach that lesson." Feedback was mentioned as part of this process, although it was spoken of generally.

Norms for Meetings. One of the strongest norms at School B was that of meeting together in various formats. Everyone interviewed spoke of meeting as a whole staff, in vertical teams, grade or cross-grade groups, and even informal collaborative groups between teachers. Most teachers spoke about weekly meetings, but others spoke about 
meeting with their grade groups or with other teachers on more occasions than just once a week. One teacher explained that it was "standard operating procedures to meet weekly in job embedded and in grade groups," but that she "meet(s) almost daily with my core group of fourth or fifth grade teachers." Another teacher elaborated more specifically, saying, "Job embedded is by grade group and every group has a day that they go to job embedded...The norm is that Thursday is my embedded day."

Norms for Data Use and Planning Next Steps. The most frequently mentioned norm was that of recording and analyzing data. Each teacher and the administrator interviewed spoke about routinely recording data, disaggregating data (including using the data warehouse system), analyzing data and planning next steps.

They just know that every time they come to job embedded PD, we always start with data, it's what we do. Everyone can also change their kids [in the tiering levels] at any time. I think the teachers think it's a lot more useful [that way]. You can use it, you can touch it.

This analysis and planning was done at all grade levels, and all content was targeted for at least one grade level. Reading and math data were utilized at all grade levels. Teachers took it for granted that scores and other student work would be analyzed for this process. The instructional coach in charge of displaying the data in the data room said:

You have to turn in their data to me for the data room. They turn in everything they get. Everyone can see it, it's not to penalize or to judge, but to see where everyone is. An unwritten rule is to get it back more timely...we're working on that.

Data analysis was not isolated to one component of school work, but was conducted for whole school, grade level, and classroom improvement. For example, it was standard practice to bring data to the table when constructing the School Improvement Plan. In fact, the plan could not be completed without the reporting of 
current data, followed by the setting of goals and objectives to be evidenced by data. Each teacher regularly analyzed district benchmarks, DRAs, end of the unit math assessments, and SuccessMaker reports.

An important part of the activities with student data were the charting that took place in the data room. All teachers spoke about this as part and parcel of daily life at School B. In fact, it seemed to be such a part of their work that they had grown past the idea of being threatened or judged by it, as stated above, "Everyone can see it, (but) it's not to penalize or to judge, but to see where everyone it."

Another related point about charting their data in the data room was that teachers took it for granted that these scores were to be reported in a timely manner to the coach. Although teachers were granted the liberty to move their students between the Tier levels according to their professional knowledge about their students, it was understood that in order for a system to work effectively, data must be timely. Although the instructional coach knew that they did not yet have this mastered, she explained, "An unwritten rule is to get it back more timely... we're working on that."

Other Norms. A few other norms that were unique to School B deserve mention. This school routinely conducted celebrations with the staff and students for progress in student performance. This was an expected part of the assessment process for improved student performance. As the staff re-rostered their students, moving them from Tier 3 to Tier 2 or 1, they had "moving parties," and even served faux champagne. They also planned monthly incentive celebrations for students. The first celebration was held for students who scored proficient or distinguished on the first reading CCA. The following 
celebrations were for any student to improve their score from their previous performance. These celebrations took place every month.

This activity linked nicely to the overall culture promoted in the Care for Kids program the school had adopted. The teachers mentioned how Care for Kids was implemented in their school as an agent to promote academic, social-emotional, and ethical development of students.

One last norm to be mentioned was that of a spirit of collaboration that can be illustrated by the wish lists the school put together at the end of the year. Each grade group created a list of skills and instructional strategies that they wished students knew as they came back to school in the next highest grade. The lists were shared with the prospective teachers and discussed. This activity demonstrated a highly developed climate of collaboration, and it would not be difficult to imagine that an exercise like this would not work in schools where collaboration was not an established part of the culture.

\section{Summary}

These normative values of distributed leadership, peer observations and feedback, and for meetings, data use, and planning next steps were ways of distributing the leadership in School B. Assumptions and beliefs about how work would be done helped to enact the distributive nature of work across groups and peers, and across the materials and tools necessary to enact the work. This was demonstrated by School B in its norm for peer observations and feedback. Teachers stated that this was something that they took for granted as part of their work. Because this was standard operating procedure, this norm both mediated and was mediated by documents created for the process, which in turn, influenced the procedure and process as it was carried out. 


\section{CHAPTER VI \\ CROSS-CASE ANALYSIS}

When looking at the data across both schools, it became clear that the schools had many practices for data use and improvement planning in common, and a few characteristic unique to each school. By using a content ordered display, the similarities and differences between the schools were visually displayed, and are described here.

\section{Procedures and Processes}

Similarities. The two schools described many similarities in procedures and processes. Only nine of 24 of them were not shared. Both School A and School B engaged in data analysis for whole school, grade level, and classroom planning. Elements relating to this analysis included engaging in state, district benchmark, and classroom assessments, including formative assessments. As well, all teachers from both schools used the CASCADE data warehouse system to help with analysis, when appropriate. Teachers that did not give assessments suited to CASCADE used web based analysis tools.

Assessments were given across all content areas. District benchmarks were given at the third, fourth, and fifth grades for reading, math, science, and social studies. Ondemand writing prompts were also given to the students as planned by each school. In the primary grades, the DIBELS or T-Pro assessments were administered. 
Both schools mentioned three instructional strategies that grew out of data analysis. When scores indicated students were struggling (in any content area), teachers would pull small groups to remediate mistaken or unlearned concepts. Because teachers often analyzed together, they would "share" students to form groups that needed help on similar problems, or that were learning at the same level (reading levels, for example). The third strategy teachers would use to help make instructional decisions was rerostering. Both schools re-rostered (or rank ordered) students to strategize how to improve student performance. This data analysis could impact how instruction was carried out in a number of ways. For example, teachers could form small group as mentioned above, or offering individualized help, one by one, to those students who were barely under the proficiency standard. Other strategies to increase student performance could also result from re-rostering.

The largest number of procedures and processes were seen in the various types of meetings that were held at both schools. Interviews revealed that staff meetings were held once a week, and during most weeks job embedded professional development and grade group meetings were also conducted. Besides these, both schools regularly met with the leadership team. Less frequently, but still mentioned by both schools were vertical teams, cross-grade meetings, and on a small scale, a cross-school visit.

One other procedure and process mentioned by teachers at both schools were peer observations, called walkthroughs, pride walks, or ghost walks. Even though the specifics of the walkthroughs differed at each school, they both engaged in these observations to begin the process of learning from each other and offering constructive feedback in collegial ways. Both schools started this process in a safe, nonthreatening way, with 
teachers observing positive strategies they thought would be useful in their classrooms. They offered feedback to their colleagues based on their observations.

Differences. There were several differences in procedures and processes between the two schools. School B identified seven more procedures and processes than School A as they implemented improvement efforts. Although some of these differences appeared to be "in the details," it precisely illustrates how both schools intentionally co-constructed and executed their plans to fit their own capacity, and environmental and contextual needs. These differences also exemplify how leadership extended to actors and activities beyond the recognized "leadership team" as the work became distributed among teachers who independently created ways to support reform efforts.

The meeting formats of cross-grade groups and cross-school meetings showed variations, but both were mentioned in the interviews. During cross-grade groups at School B, an intermediate teacher met with her own grade level at least twice a week, and then planned informally with teachers in the adjacent grade to ability group students. Teachers in these adjacent grades grouped students according to their instructional need, regardless of whose classroom they were assigned to.

During the cross-school visits, the administrator from School B chose this format to send a teacher leader to another school that had a good reputation for their writing program. The teacher leader observed strategies and engaged in collegial conversations with teachers there to bring back ideas that could improve the writing instruction at her school. The administrator from School A used the cross-school format to increase the performance of her fifth grade students as they prepared for transition to middle school. 
The team of fifth grade teachers visited a nearby middle school to have conversations and observe sixth grade students.

Other small differences were apparent in some of the other procedures and processes. At School B, the walkthroughs focused on both instructional and classroom environmental strategies, but at School A only instructional strategies were observed. Also at School B, students were involved in recording their own data in student assessment binders. Teacher and student informal meetings were held to discuss student performance and goals. Student and staff celebrations were regularly scheduled as students increased their scores. As well, teachers at School B mentioned intentional, specific use of teachers with specializations, such as a reading specialist.

As the schools engaged in the process of Lesson Study, both School A and School B began the process by conducting peer observations. School A conducted many more observations that School B, and the principal had attempted to deepen the focus each time. Neither school, however, had fully implemented a formal Lesson Study. In School B, there had been fewer walkthroughs, but they were in the process of planning for at least one formal Lesson Study.

These differences indicate that, even though both schools engaged in similar procedures and processes, they were refined in different ways. The unique strategies at School A utilized structures (committees and the fifth grade teachers) to plan improvement efforts. School B demonstrated procedures and processes that extended some of these procedures and processes. For example, in walkthroughs, School B added observations about the school environment. School B also extended strategies for assessment to include student assessment binders, individual student-teacher conferences, 
and celebrations and parties for successes. Lesson Study was also being more fully developed. It should be noted that many of these strategies were described by a content specialist who had previous experience in other districts, and who led many of these initiatives. This individual was a significant contribution to the will and capacity at School B to implement strategies and lead others. It gives credence to the notion that it takes capacity to build capacity (Hatch, 2001).

\section{Materials and Tools}

Similarities. Of 31 materials and tools mentioned and observed, 14 were shared by both schools. These materials and tools were created or promoted by the state or district. Assessments and analysis tools were the most frequently mentioned for this variable. Both schools shared more items in this area than for any other materials and tools. Although test administration was mentioned above as a procedure/process, the assessments themselves deserve mention as a material or tool for data use. (Descriptions of the assessments were given in detail in each case study.) The assessments that the schools had in common were: state assessments, which were given once a year toward the close of school; district benchmarks in reading, math, science, and social studies; DIBELS; and T-Pro. These assessments were either required, or strongly encouraged by the district. Along with these assessments, both schools also conducted DRAs, ondemand writing prompts, and formative assessments.

Most data analysis tools were used commonly between the schools. The most frequently mentioned was the CASCADE data warehouse and analysis tool. Teachers utilized this for each district benchmark, and spoke of the usefulness of the analysis items generated by this program. The district-provided rubrics for scoring the CCAs were also 
used in both schools for each benchmark assessment. For whole school planning, both schools mentioned the Red Flag Analysis, which disaggregated state assessment scores to look for patterns and challenge areas.

As well, the schools created a space solely dedicated to charting and analyzing scores. Each student's performance level on benchmark assessments was color coded and charted for a quick, visual picture of how the school was performing overall in each content area. This was used as a general predictor of performance on the state assessment. In the area of reading, the students were also leveled according to the curriculum guidelines. Those scores, along with DRA levels, also were also used to help determine performance.

Another tool that both schools shared was SuccessMaker. This computer program was used as an intervention in math and reading, and was required for students not reading on grade level. Teachers spoke about the analysis tools and reports that it generated as being helpful in identifying and breaking down into subcomponents those areas of challenge for struggling students.

A final shared tool was the School Improvement Plan. Both schools created this document as a guide for their work during the school year. Based on scores and other factors, teacher leaders and administrators assessed school needs and charted goals and objectives to be achieved over the course of the year. The team revisited the document periodically during the year to determine their progress.

The fact that these materials and tools were shared and similarly implemented in both schools could be attributed to the fact that they were products that were standardized at the state or district levels, or were research-based items purchased through educational 
vendors. As the leadership teams developed specific foci for their schools, each school co-constructed more materials and tools that helped them to plan and implement reform efforts for their own needs.

Differences. There were more differences between the schools in the area of materials and tools than in any other area. Six of the 31 materials and tools were unique to School A, and 11 of the 31 were unique to School B. School A used two rubrics in their efforts to improve instruction. The Classroom Instructional Framework (CIF) was a district guide for presenting instruction, and was used as a focus throughout the year at School A. This tool was also used in at least one of the peer observations at this school as teachers participated in walkthroughs. Another rubric at School A was created by the administrator for peer observations. It was created to help organize observations into areas they found helpful, areas for inquiry, and feedback on what they had learned.

School A also used materials and tools such as posters and a school pledge to explicitly communicate high expectations for students. They also used Homeside Family Activities as a tool to make connections between home and school. They applied for and received materials and tools as part of a Read to Achieve grant to help struggling readers. School A also utilized an on-line strengths-based assessment for leadership to help teachers explore how they might best use their abilities.

These materials and tools, whether provided by the district, or created at the school level, helped to shape how reform efforts were operationalized. For example, the CIF was a district document, but was the focus of job embedded PD sessions at School A where it became adapted to be used as a vehicle for peer observation and feedback. This 
illustrates how the work of planning improvement in schools is influenced as it is coconstructed and distributed across various materials and tools.

School B had almost as many materials and tools that were not shared as they did those that were shared. Fourteen materials and tools were shared, while twelve were mentioned only by teachers from their school. Five of those were assessments. Math end of unit assessments were mentioned in interviews as a school based tool to determine student performance. Math pre-and post-tests were also mentioned, created to determine student performance both prior to and following math units. In the area of literacy, School B used Running Records to monitor student progress between district benchmark assessments. Teachers also created their own open response questions and other content related tests.

The teachers at School B created two rubrics or spreadsheets unique to their school. Rubrics for the end of unit math assessments were made and aligned with scores to indicate distinguished, proficient, apprentice, or novice. A spreadsheet to visually organize the results was also used to help determine student performance, areas of strength and challenges. From this data, areas of content were retaught, or small focus groups or individualized instruction was planned.

School B had a few other unique materials and tools. The teachers spoke of using an on-line website for data analysis for the T-Pro. This tool helped to identify specific areas of need for students. They also created a standardized meeting agenda to align and focus their work during meeting formats. Toward the end of the school year, teachers were asked to list what they would like to see in the students they would have in their classrooms at the beginning of the next year. This included content knowledge as well as 
learning skills. Using this list, grade level teachers reviewed their own instruction during the year, and began to work with students who needed help in these areas. One final "tool" that was present at School B, was that teacher interpretation of scores and student work was a contributing factor in determining where students would be charted for data analysis.

School B demonstrated many uniquely created materials and tools to help them determine school need to plan improvement. Although three of these items were vendor produced, nine of them were tools that were created at the school level by the administrator or teachers. Some were constructed by the whole school, some in grade groups, and some by individual teachers. Each of these products was mentioned as elements that shaped how the school or teachers planned for improvement. Not only does this demonstrate that materials and tools constitute an element of how leadership is distributed, it also clearly illustrates that as this distribution occurs, co-construction springs from multiple sources (such as vendors or whole schools), and it also generates new sources for creating new materials and tools (through grade groups or individual teacher created items.)

\section{Norms and Rules}

Similarities. Twenty norms and rules were identified across both schools. Fourteen of those norms were shared by both schools. The most frequently identified norm was for the components of data use and analysis. All teachers and administrators spoke about the many sources and uses of data as they planned improvement strategies. This work was so fundamental to their daily jobs, that it was difficult for some teachers to see it as a normative value. It had become so institutionalized that it was no longer 
explicitly identified as a separate component of their schools. The fact that they collected data, analyzed it, reported and charted it for each school level (whole school, grade level, and classroom level), and that it was available for common viewing had become a tacit standard operating procedure at both schools. The developer of the professional development sessions also recognized their ability to work with data when he commented:

I think both [School A and School B] had a lot of data and used it, then certainly they were focusing on areas where they had not done well in previous years, and were trying to build...adult activities in that area and have the students learn it...I would say it was informing a lot of what the decision making they were doing.

...[They] certainly knew how to do it and to do it, because that was part of what we did at one of the sessions. In fact, that was the session for the whole day where they traded [cross-school visits]. And they stated that that felt successful to them.

Another identified norm was for frequent meetings to present, analyze, or plan from data. Although at times other business was also conducted, most meetings included discussions about student performance and data. As stated previously, meeting formats varied between staff meetings, grade group (horizontal meetings), vertical meetings, and job embedded professional development meetings.

Peer observations and feedback were also identified as a norm that was expected by the staff. Resulting feedback was also assumed to be a part of this activity. One school conducted the walkthroughs on more occasions that the other, but both schools recognized this activity as the way things were done, and the staff expected them to continue. The teachers at both schools viewed this activity as valuable, but the instructional coach at School B stated that the staff at her school was ready to implement a formal Lesson Study. 
One final norm that was identified at both schools was the Care for Kids initiative. Both schools identified this as a way to approach teaching and learning to contribute to successful performance. Although this program did not target instruction or planning based on data, the perspective of meeting students' social and emotional needs was valued as an important part of student achievement.

These shared norms served as a foundation for the way both schools planned for improvement. Data analysis, the frequency and varied formats of meetings, peer observations, and school culture driven by Care for Kids had all become implicit ways of operating at both schools. This environment drove, and actually was part of, how work became distributed. For example, because the schools held norms for data analysis, improvement planning included recognizing the status of student performance, modifying structures such as student groups, and establishing objective goals.

Some practices at both schools were being implemented, but had not yet become an implicit way of doing things. For example, Lesson Study was in the process of being learned, but was not yet fully developed or ingrained within the schools. It could be argued that if this practice was deeply institutionalized, improvement planning could have also included strategies for deepened pedagogy or instruction.

Differences. Three norms and rules were characteristic only of School A, and three were characteristic of School B, as well. Teachers from school A made explicit their values for high expectations for their students. There were posters on the hallway walls stating and defining what expectations were important for student achievement. Also, one of the special education teachers spoke about having high expectations for those students 
who are usually associated with struggling through academic content and low performance.

School A identified home-school relationships as an important part of their work. Almost every teacher identified this component in their interviews, with only one teacher describing how she believed they could make improvements in this area. This norm was evidenced in weekly Homeside Family Activities that were sent home to establish a connection between the classroom and home, weekly newsletters, family and literacy nights after school, and health and fitness nights.

Although this norm was not explicitly stated, the interviews and observations indicated that this school valued open and collegial interaction among peers. The amount of walkthroughs, open discussions among colleagues, frequency of meetings for data analysis, as well as an element of "reading between the lines" for peer interactions, nonverbal body language, tone of voice, and general attitude during the observations and interviews, all support the idea that the teachers were building a community of inquiry.

School B exhibited a norm for celebrations for success. Teachers engaged in "moving parties" as they came together to make changes on the charts in their data room as students made progress. This practice became part of how the school recognized and rewarded the efforts of teachers to plan and improve instruction. As well, student celebrations were also a part of the norm at School B. They held monthly parties as incentives and to reward students who improved in any content area on district benchmarks or classroom performance.

Two additional norms were mentioned in interviews at School B that related to data use and analysis. The instructional coach specifically mentioned timely reporting of 
data for analysis and charting had been explicitly established as an unwritten rule, but she recognized that the norm was not yet consistent across all teachers. She reported that the staff was continuing to work on this. The final norm that was unique to School B was to include teacher judgment as an element of placing students into performance categories.

The differences in norms between the two schools, again, demonstrate the way that schools develop in terms of their own needs, environments, and capacities. The norms, then serve as an elemental building block of distributing leadership throughout the school setting. Once more it is evident; as with procedures and processes, and materials and tools, this variable constitutes a part of distributed leadership, and it is also influenced and shaped by these other elements

\section{Summary}

When looking at how both schools implemented ES21 strategies, the similarities outweighed the differences. Even so, the implementation was shaped and mediated by each school as they engaged in procedures and processes, materials and tools, and norms and rules unique to their own contexts, capacities, and requirements. The differences between the schools sometimes appeared in the depth of work, sometimes "in the details," and sometimes as different applications of the strategies that were implemented. This sheds light on how school work and leadership is distributed in highly specific, intentional ways using multiple sources of information, and utilizing both human and material resources that are uniquely their own to plan improvement efforts for reform. 


\section{CHAPTER VII}

\section{CONCLUSIONS, IMPLICATIONS, AND FUTURE RESEARCH}

This study began with a review of educational policy that has led to increased accountability in schools, culminating in the No Child Left Behind Act of 2001. Because of the requirements in student achievement imposed by this legislation, educators are feeling the pressure to identify areas of challenge and to implement changes. The goal of these changes is to bring about satisfactory levels of performance, namely meeting the Annual Yearly Progress goals outlined in NCLB, resulting in 100\% of students reaching proficiency levels by 2014 . To do this work, districts, schools, and classroom teachers have found it necessary to become familiar, even expert, at using data.

The purpose of this study was to examine how three organizational elements of distributed leadership mediated whole school and classroom improvement planning, using ES21 strategies in the context of No Child Left Behind. Specifically, I refined the notion of distributed leadership as consisting of mediating variables of procedures and processes, materials and tools, and norms and rules. The data illuminated how these elements shaped ES21 strategies as they were implemented in individual school contexts. Findings also clearly indicated that the work was not just distributed across individuals, but was stretched across the three constructs, and that each mediating variable influenced each other variable. Using this framework allowed for foregrounding of each individual variable in the system of practice (Spillane, Halverson \& Diamond, 2004) for analysis. 
Current literature is recognizing the need for a practical description of distributed leadership and how it is operationalized (Maxwell, Scheurich, \& Skrla, 2009). Studies of this nature are beginning to emerge; for example, in a recent qualitative study of distributed leadership, Maxwell (2008) described school leadership that extended even to those support personnel that are not typically recognized as school leaders. The focus of her study was her grandfather who was a rural school custodian for fifty-three years. The true power of his leadership was not recognized until, upon his passing, many of the school procedures and processes, materials and tools, and norms and rules began to weaken because leadership at his school had application even to "non-professional" personnel.

The model that was used for my study provides three constructs that encompass the daily work of educators. The framework also extends the idea of distributed leadership by providing a sociocultural lens through which practice can be analyzed. It allows a look at leaders in action, investigating purposeful activity within natural contexts (Spillane, 2005; Spillane, Halverson \& Diamond, 2004). Louis, et al. (2010) state that "to understand the distribution of leadership one needs to explore evidence of actual behaviors and influences associated with core leadership practices and specific focal points of school-improvement activity" (p.64). This study adds to the body of literature that seeks to understand the how of distributed leadership as it is actually seen and heard in school contexts.

This chapter summarizes important conclusions drawn from the data collected and presented in Chapter V. As well, implication and directions for future research are discussed. 
Conclusions

Distributed Leadership and Mediated Agency

The results of this study clearly indicate that distributed leadership was the vehicle used to implement strategies of ES21 (Chrispeels, 2004; Copland, 2003; Elmore, 2000; Leithwood, Seashore-Louis, Anderson, \& Wahlstrom, 2004; Spillane, 2005; Spillane, Halverson, \& Diamond, 2004). As the work was built together at the professional development sessions between administrators, teacher leaders, and the ES21 team, the school leaders took this knowledge back to their schools. Through joint efforts between the administrator, teacher leaders, teachers, and support staff, the schools coconstructed work together (Datnow, Hubbard \& Mehan, 1998; Datnow \& Stringfield, 2000) within the political context of No Child Left Behind and the mandates to reach proficiency levels.

Not only was it evident that distributed leadership was the vehicle for implementing ES21 strategies, the notion of distributed leadership was extended beyond the idea that work was distributed across individuals, but that it was also distributed across the elements of procedures and processes, materials and tools, and norms and rules that existed in each school context, as hypothesized. Each and every one of these elements shaped and mediated the way ES21 was implemented in the individual schools. The implementation was not identical in both schools, which evidenced that as policies or initiatives enter schools, they are modified, altered, and co-constructed by the unique qualities of the schools (Datnow \& Stringfield, 2000; Rogoff, 1990; Tharp \& Gallimore, 1988; Vygotsky, 1962; Wertsch, Tulviste, \& Hagstrom, 1993). 


\section{Procedures and Processes}

Although the ES21 sessions were not designed around the framework presented in this paper, the content of the professional development sessions emphasized distribution of the work across procedures and processes. Using data (including data analysis), meeting formats, peer observations, meeting roles, and re-rostering of students were all examples of this element of my conceptual framework. As teacher leaders engaged in improvement planning at their own schools, it was apparent that they valued the variety of these procedures and processes. As they understood the role of these procedures and processes, and how they could be used in powerful ways, they utilized the various formats in both formal and informal settings.

Perhaps the strongest evidence from this study showed that both schools were highly engaged in using data, and that the process spanned whole school, grade level, and classroom level improvement. Although this investigation specifically looked at distributed leadership as a vehicle for improvement planning, it also clearly showed the ways these schools distributed the work of data use brought about intentional changes in the way students were taught, who taught which students, the environment in which students were taught, and what they were taught. It also showed that data served as the predominate impetus for the work of implementing instruction and planning improvement in the current federal policy context.

Examining the procedures and processes around data use at both schools reveals that teachers valued data from multiple sources, which researchers have recognized as essential for effective use of data (Bernhardt, 2000; Brunnet, et al., 2005; Council of Chief State School Officers, 2001; Jandris, 2001; Khanna, Trousdale, Penuel, \& Kell, 
1999; Lachat, 2002; Lachat \& Smith, 2004; Levesque, Bradby \& Rossi, 1996; Massel, 2001; Rallis \& MacMullen, 2000). Each school mentioned using seven or eight different sources of data to determine student performance in reading, depending on grade level.

Each teacher also mentioned and went into detail about the data room where student progress was charted and monitored (Brunner, et al., 2005). This process involved more than just reporting scores on a wall, but involved planning to coordinate the giving of assessments, scoring them, entering them on the CASCADE system, and turning in the scores to be displayed. Although it took some effort to get this practice aligned among all the teachers, it was a solid example of distributed work.

It should be noted that the principals at each school supported data use, and were intentional and instrumental in the work. It was important to the principals that time was set aside to conduct the procedures and processes for improvement planning, and that the teachers understood that "collaborative data teams are a positive force in supporting data use for improved educational practice" (Wayman, Midgley, Stringfield, 2005, p. 7). They often attended or led the professional development sessions, and worked with instructional coaches or support personnel to co-construct their work.

Data analysis was an on-going process which permeated the daily work of educators at both schools, which shaped and informed improvement planning. It also directly influenced what and how students were taught. Teachers spoke about planning from data as they identified students at risk (Chen, Heritage, \& Lee, 2005; Brunner, et al. 2005), then re-rostering the students to intentionally target those in need of intervention. Two examples of planning strategies resulting from this process were: (a) forming small focus learning groups for struggling students, and (b) "sharing" students among teachers 
who could best meet their instructional needs. These examples clearly show that improvement planning was co-constructed and distributed across procedures and processes (Datnow, Hubbard, \& Mehan, 2002; Datnow \& Stringfield, 2000). All teachers spoke about this work being intentionally designed to shape instruction for learning.

One of the most frequently mentioned procedures was the variety and frequency of meetings to analyze and plan from data. Teacher leaders that served on the ES21 leadership teams took the information they learned in the professional development sessions back to their schools to discuss and teach the strategies they had learned. However, as schools began their own work, school meetings and teacher teams not only followed the formats learned in the sessions (such as whole school, grade level, and vertical teams), but they sometimes took on different arrangements, such as smaller grade group meetings (between two or three teachers), or cross grade meetings as they built their work together. Depending on the purpose of each gathering, the information that was learned became redistributed, interconnected, and interdependent across various arrangements of actors. Both of the schools recognized the need for specific work related to their school or classroom needs, and mediated procedures and processes to adapt strategies and information across settings (Rogoff, 1990, Tharp \& Gallimore, 1998; Vygotsky, 1962; Wertsch, Tulviste, \& Hagstrom, 1993).

In fact, in one of the schools, the teachers had begun to take on the responsibility to call their own meetings as they reviewed data or changed student groupings. This showed that as procedures and processes become institutionalized, teachers not only utilized familiar formats, but adapted them for their own individual and specific needs, operating with meditational means (Wertsch, Tulviste, and Hagstrom, 1993). 
Both schools also gathered and analyzed data collected from peer walkthroughs to observe instruction. This procedure served as a vehicle to engage in Critical Friend feedback (Bambino, 2002; Coalition of Essential Schools, 2006; Cushman, 1998). As this process was carried out in the schools, it was mediated and adapted not only for their individual needs, but also to the normative values held by each one. School A engaged in more peer observations than School B, and varied the focus of the walkthroughs. They visited a variety of grade levels, and targeted different instruction or management strategies. School A targeted both instructional and environmental strategies that the teachers felt they could implement themselves. There were also plans at School A underway to fully implement Lesson Study.

Another example of how a process was used to mediate improvement planning was seen in cross-school visits. These visits were an extension of the work both schools engaged in during the last year of ES21. As each school determined their own specific needs, they implemented this process on a small scale. At school B, the administrator saw the need increase the capacity for instruction in writing. She arranged to have her writing lead teacher visit another school that had a reputation for successful work in student writing to observe activities and strategies that could be incorporated for her students. The other administrator saw the need to increase the performance of her fifth grade students as they neared the transition to middle school. Based on communication she received from a nearby middle school, she was supportive of their desire to deepen the work of her fifth graders as they neared graduation, and sent the fifth grade teachers to the middle school to observe. These examples show that as data reveal the individual 
needs of schools, the decisions and actions can be adapted not just within the schools but across schools as well (Datnow, Park, \& Wohlstetter, 2007).

Summary. The variety of ways that the variable of procedures and processes was seen in both schools was a clear indication that the schools were actively engaged in coconstructing work. The fact that procedures and processes were evidenced in a multitude of strategies and formats also provides evidence of how they were distributed. It should also be noted that this mediating variable impacted the use and creation of materials and tools, and norms and rules, which will be seen below. Briefly stated, as teachers engaged in the processes of meetings, data analysis, and peer observations, they created materials to organize, clarify, or assist in carrying out the activities. The processes also helped establish tacit expectations, beliefs, and values as teachers saw the power of how the procedures and processes impacted improvement planning.

\section{Materials/Tools}

Not only did the schools distribute their work across procedures and processes, the ES21 strategies were also distributed across materials and tools. These tools were created at all educational levels: federal, state, district, school, and classroom. Findings indicate that many materials and tools were provided by the federal, state, or district levels, such as AYP goals, assessments and rubrics. Halverson (2006) refers to these as received artifacts, having their origin outside the local school, "already developed by identifiable sources (e.g., districts or curriculum developers) and are adapted by leaders and teachers to local uses" (p. 11). Besides these, teachers had, in groups or individually, developed enough expertise themselves to create and design, or modify rubrics and 
protocols for their own specific school and classroom needs, or local artifacts (Halverson, 2006, p. 11).

These materials and tools highlight the interconnectedness of planning for student achievement. As federal assessments shape the use and creation of more local instruments, they, in turn, can help district and state policy makers understand student achievement as it is enacted. As well, the administrators and teachers in this study made an effort to align (Coburn \& Talbert, 2006; Cromey, VanderPloeg, \& Mansini, 2000; Datnow, Park, \& Wohlstetter, 2007; Dembowksy, Pane, Barney, \& Christinia, 2005; Doyle, 2003) or "calibrate" their work with district and state efforts (Wayman, Midgley, \& Stringfield, 2005), demonstrating how materials and tools link across educational domains (Lasky \& Datnow, 2006).

Data showed that the way the materials and tools were created and used in the schools demonstrate how implementation of a reform effort requires team collaboration to be successful. As schools and teachers engaged in this social co-construction of materials and tools, they explored together the best practices for improvement. For example, as districts and schools received their scores from state assessments, they began to develop assessments, rubrics, and spreadsheets to target individual classrooms and students for improvement. This process of planning with materials and tools was seen along the spectrum from whole school to group formats to individual teachers who developed their own materials, such as exit slips or spreadsheets, modified to their classroom needs, and to the individual student.

All teachers and administrators indicated that they were familiar with and consistently used software to help them with data. The CASCADE system, provided by 
the district, was a tool they considered timely, easy to use, and accessible. They discussed the fact that they relied on the analysis tools to help them understand the specifics of student performance. Other technologies were used by specific grade levels for their reading or phonics programs, and each teacher that referenced them indicated they were comfortable with at least the major components of the programs and reports. The widespread use of technology tools clearly helped mediate improvement planning as it provided specific and detailed analysis of student performance provided by data warehouses (Bernhardt, 2000; Creighton, 2001; Cromey, Van der Ploeg, \& Mansini, 2000; Daniels \& Johnson-Ferguson, 2001), from multiple sources of data (Brunnet, et al., 2005; Massel, 2001; Rallis \& MacMullen, 2000), that was accessible and timely (Choppin, 2000).

Even the teachers, who were not in heavily assessed grades and did not utilize these tools, referenced the software programs that were used and what assessments they were used for. This speaks powerfully to the fact that the work of data use was being distributed. One topic of discussion was the enormous amounts of data that could be generated by technology and software. Although the teachers appeared to know exactly what they were looking for as they analyzed data, it should be noted that it was not just the fact that data were used, but that specific and useful data, applicable to the schools' own context, was what uniquely shaped the planning for each site (Choppin, 2002).

Other examples also illustrate how elements of ES21 were mediated by the materials and tools in each individual school context. The principal at School A created a rubric specifically for their peer observations. The principal at this school also emphasized using a procedure for classroom teaching called the Classroom Instructional 
Framework. At School B, assessment binders with an administrator-made rubric were provided to each student to chart and keep up with their own progress. Not only was this information used by the teacher to plan appropriate levels of instruction, students also reflected on their performance and were motivated to blaze their own trail of learning.

Schools that distribute work across materials in this way involve actors at each level to implement "policy." As viewed by Estes and Edmonds (1981), "the process becomes the policy outcome-that is, the outcome is generated in the process so that the policy is the process" (p. 81). One teacher even made reference to involving the students in creation of rubrics used in her room. Viewed through a sociocultural lens, this work demonstrates learning that is influenced and shaped by context and culture. It is an example of work that is highly interconnected and integrated. It not only requires accountability from students, it also teaches it. It is also an example of the idea expressed by Hall \& McGinty (1997):

Policy is considered here as a transformation of intentions where policy content, practices, and consequences are generated in the dynamics across time and space. Policies are vehicles for the realization of intentions (p. 441).

As the work of improvement planning became distributed across materials and tools, the iterative nature of distributed leadership was seen. Not only did the materials and tools serve a practical purpose for planning, they also became drivers of the work, not just a result of the work. Because materials, whether provided or created, most always included tasks and timelines for reporting data, they became part of defining what the work was, who was to do the work, when it was to be done, as it was distributed across the school context (Cole \& Wertsch, 2006; John-Steiner \& Mahn, 2008). 
Summary. The materials and tools used by the schools to implement ES21 strategies for improvement planning served to modify and shape how the strategies were executed. This was evidenced in the various types of assessments from annual state testing to individual teacher-made tests or rubrics. These materials and tools influenced how the schools received data, what they analyzed, and what components were available to them to plan next steps. The fact that schools recognized the need to build their own materials or tools that reflected timely, local, and relevant data, showed that constructing these resources together was valued, linking the elements of procedures and processes and materials and tools. Further evidenced were the connections between these two elements and norms and rules.

\section{Norms/Rules}

One interesting note deserves mention before describing the norms and rules identified and observed in the schools. Of all the questions in the interviews, the ones related to norms and rules were the most difficult for teachers to answer. Some of the teachers at first indicated that there were no norms at their school. However, upon follow up questions or probes, they began to talk about what happened at their schools as "standard operating procedure." For instance, after a teacher indicated that she did not know of any unwritten rules or norms observed by the staff, I asked a follow up question about routine analysis of data. She indicated, "Well of course, that goes without saying!" Many tacit behaviors and ways of doing things were hard to identify, but nonetheless, existed.

Both schools exhibited these tacit rules and standard operating procedures for planning from data. Implicit in their interviews was the fact that analyzing and planning 
from data was part and parcel of what constituted their work as educators, and was stretched across all three mediating variables. Those most frequently mentioned normative values were that meetings would be held on a regular (at least weekly) basis in the formats of grade groups (including job embedded PD), and staff meetings. Teachers at both schools acknowledged the fact that these meetings were standard operating procedure as a way to engage in data analysis for improvement planning for whole school, grade level, and classroom improvement. It was also taken for granted that the data would stem from multiple sources, be regularly displayed in common areas for viewing by all educators, and be aided by the use of data warehouse tools. There was no doubt about the normative value of using data at both schools, and that it directly shaped how they planned together.

Another norm that was mentioned by both schools was an atmosphere of collegiality, evidenced by peer observations and feedback, an essential part of Critical Friends (Bambino, 2002; Coalition of Essential Schools, 2006; Cushman, 1998). Although both schools began their observations with safe and simple tasks, it became a common assumption that teachers would observe and learn from each other, as well as give and receive feedback in an effort to improve practice toward student achievement. This norm showed that no longer were these schools operating under an isolated system, as exemplified by a statement heard recently, "I want to be left alone, close my door, and do my own teaching." Even with all the current emphasis on data use, distributed leadership, and collaborative work, it is not uncommon to find teachers who still hold to this philosophy. This clearly was not the case at the two schools in this study. They were 
moving toward an open, integrated system of teaching and learning from data (Halverson, 2006) without challenging what it takes to get there.

Other norms and rules were identified that evidenced how the ES21 intervention strategies would be adapted as they entered the school contexts. These norms and rules included having high expectations for student performance, emphasizing home school relationships, opening their work and classrooms to each other, and celebrations for student achievement. Teachers were also allowed to express their wishes to their colleagues for skills that they wanted to see students have when they entered their classrooms. The timely reporting of data to the instructional coach was a norm that had not yet been mastered, but one which was explicit in the culture. Also, mention of teacher judgment was recognized as a valued part of assessing student performance.

Summary. When looking at the standing norms and rules for these schools, it would be safe to say that they played a vital role in distributing the work of using data for improvement planning. Like the other two elements of my distributed leadership model, the norms and rules shaped the ES21 strategies in planning from data. These normative values demonstrate how policy is implemented as "an expression of peoples' values and beliefs, and political and moral purposes that are embedded within the contexts of power, relational, and societal norms or conventions...that are unique to the time in which policies are generated" (Datnow, Lasky, Stringfield, \& Teddlie, 2006, p. 95; Lasky, 2005).

\section{Interdependent Connections}

Even though the framework used for this study allowed each variable to be foregrounded for analysis, it would be careless if not negligent, not to stress that these 
variables work together and impact each other. Just as using data for improvement planning is, itself, an iterative process (Hamilton, Halverson, Jackson, Mandinach, Supovitz, \& Wayman, 2009), distributed leadership, by its conceptual nature, works independently as it stretches across and links to each component that constitutes it (Spillane, 2005; Spillane, Halverson, \& Diamond, 2004). Once actors and work become integrated and interdependent in this process, it is hard to determine what drives what. No longer is it the case that all work is driven by inspirational personalities or hierarchical models. Previous models of leadership relied on these concepts, but a distributed model of leadership shows that leadership can be driven by materials or tools, processes or procedures, and norms or rules, and that these elements help to create organizations that are energetic and progressive in nature. The results are intentional, integrated, and interdependent (Elmore, 2000; Leithwood, Seashore-Louis, Anderson, \& Wahlstrom, 2004; Spillane, 2005; Spillane, Halverson, \& Diamond, 2004).

It was evident by the observations, the interviews, and the willingness to share information, that teachers felt ownership in the process of improvement planning as they engaged in distributed leadership (York-Barr \& Duke, 2004). This stands in stark contrast to a top-down leadership where initiatives are imposed arbitrarily from the principal. The teachers often spoke of connecting with the principal and with colleagues to work out solutions, create documents or rubrics, or analyze data. Using a distributed approach in planning improvement also promoted an interdependent approach for giving input, discussing multiple approaches to problems, and gaining support from each other. Even though most teacher felt connections to their grade group colleagues, teachers also spoke about the assistance and collaboration from other teachers and support personnel 
This atmosphere of co-construction and ownership in the process of planning helped teachers to depend on each other for camaraderie and trust. Often when decisions are made unilaterally and the work to be done is dictated, a feeling of mistrust and skepticism occurs. Nowhere in the interviews or observations of meetings, was there a hint of suspicion or doubt about the direction the schools were taking. They all had a clear understanding of what the work was, where the challenges were, and where they wanted to take their schools. This clear mission provided a connection for their work across all three elements of procedures and processes, materials and tools, and norms and rules.

\section{Unanticipated Findings}

An unanticipated finding from my experiences as a researcher on the ES21 project, and specifically from planning my work on this dissertation, came as I utilized the framework of organizational structures that was developed to organize how people "think, talk, and work with colleagues in their schools and across the [ES21] project in ways that furthered system-wide learning" (Lasky, Schaffer \& Hopkins, 2008, p. 99) as they attempted to create more highly reliable schools. I found that this framework could also be used to describe elements of distributed leadership. As mentioned above, the PD developer viewed distributed leadership as a delivery system, or an operating procedure, to implement ES21 strategies in schools; however, I found that by extending the concept of distributed leadership to include the organizational elements of procedures and processes, materials and tools, and norms and rules, allowed me to explore the how of distributed leadership, or specific applications of the system in practice. 


\section{Proximal and Distal Outcome.}

ES21 was a complex reform intervention with many components. It stands to reason, that with this type of reform, implementation will have challenges. For these two schools, there were variations in the level of implementation for the strategies learned in ES21. Because the teachers did not remember which ES21 activities and implementations occurred in which years, it would be difficult to pinpoint proximal and distal changes in temporal terms. It would be possible, however, to discuss their progress in terms of surface and deep implementation. Coburn (2003) discussed implementation in these terms, contrasting changes in surface concepts, such as changes in materials or specific activities only, with deep change that is supported by "beliefs, norms of social interaction, and pedagogical principles as enacted in the curriculum (p. 4).

It appeared that the most deeply developed element, implying more distal implementation, at both schools was data analysis. The schools had established normative values and rules supporting data use. They clearly valued what data could do for their students and realized its power in instructional planning. Their meeting formats (leadership teams, grade groups, vertical groups, cross-grade groups, and job embedded PD), frequency of meetings (at least weekly), expectations for analysis (using websites, CASCADE, or collaborative discussions), and planning next steps from data (rerostering, reteaching, "sharing" students, working in small groups or one on one) were a given. Also both schools had a multitude of materials and tools (both provided and created) to support their work from data, such as rubrics, spreadsheets, data rooms, assessments (including summative, benchmarks, and formative). 
There were two ES21 strategies that appeared to be at a surface level of implementation. Although the two schools had been involved in cross-school visits, neither school had followed up with another cross-site visit to each other's school, or to a different school. Both principals and teachers at School A and School B had seen the visits as positive and of value, but difficult to plan and manage operationally. The participants from both schools spoke about the benefits of having outside participants conduct walkthroughs and hearing their insight. One of the teachers stated that it was difficult to hear some of the feedback, but overall, found the experience a positive one for the school.

The second strategy that was in the early stages of implementation was Lesson Study. As one teacher explained, she did not think she would be comfortable being videotaped and receiving feedback about her teaching. It appeared that the element of Critical Friends, or constructing feedback in a particular way, had not been utilized on a deep level. School B was in the process of planning a Lesson Study for next year, and the instructional coach stated that she thought the teachers were on board, so this was yet a continuing step in developing this strategy. Both of these proximal strategies have in common the notions of personal vulnerability and trust, which could explain the slower implementation since this must develop over time.

\section{Implications}

This study provides evidence that leadership can be distributed. The concept of leadership has been operationalized in many ways, and continues to evolve and develop. History has reported cases of charismatic leaders, leaders who are authoritarian, and those who are managerial. Leadership now incorporates the idea of more than one individual, 
and current literature describes it as being extended to include elements such as artifacts, tasks, roles, structures, materials, activities, project tools, processes, and routines (Copland, 2003; Chrispeels, 2004; Darling-Hammond, Bullmaster, and Cobb, 1995; Halverson, Grigg, Prichet \& Thomas, 2005; Timperley, 2005). By creating a framework for systematic analysis of distributed leadership, data from this study show that it can be evidenced across procedures and processes, materials and tools, and norms and rules.

Teachers and administrators in this study readily use language and give examples of how these elements distributed their work, who did the work, even exactly who would be recipients of the work. However, it is not just that their work was "spread out," but that each element of the work was an essential part of leading them to successful planning for improvement. In this way, work becomes led not only by singular, or even groups of individuals, but by those procedures and processes, materials and tools, and norms and rules that stretch across each school environment.

Results of this study show that distributed leadership is a highly interdependent construct. For example, all teachers participated in data analysis for their students and classrooms, but the impact of their analysis often extended beyond themselves. Sometimes the analysis determined that another classroom teacher, an intervention teacher, or content specialist was best suited to provide instruction. This shows how specific tasks are completed only in concert with work done by others. The movement between teachers was fluid, and could change during the course of the year as student needs changed. This showed that teachers' work was not constructed independent of others, but, in fact, was enacted only in concert with the efforts of others. Teachers were dependent on each other to be as intentional as possible, to know what their work would 
be, and to carry it out. This type of interaction is characteristic of highly reliable organizations (LaPorte \& Consolini, 1991).

As leadership was distributed across the three constructs, it was also interconnected. Teachers and administrators worked in vertical teams, connecting grade levels to each other, to analyze state assessments so that contributions could be made from each level to form a school wide picture of student performance. For example, as the schools analyzed their scores in reading, they realized that student scores could best be improved if they worked together to be more efficient at delivering reading instruction. Following whole school analysis, they met in grade groups (and in adjacent grade groups, e.g., kindergarten and first, first and second, etc.) to intentionally match student reading levels to teacher and curriculum. This was evidence that highly interconnected work can occur around data, distributed across actors, procedures and processes, materials and tools, and norms and rules.

Results from this study indicate that as initiatives or policies enter a school, educators respond to the interventions in certain ways. As the initiatives become enacted, they conform to the capacities, resources, and constraints of each educational domain. As the schools implemented the activities and tasks across these three elements of distributed leadership, they were not carried out identically, rather in ways that fit their schools. This shows that as new policies are legislated, districts and schools are the active agents of implementation. Although it may seem rational that people are morally bound to carry out mandates, Bascia reminds us that "policy is powerful, but practitioners weave a complicated web of possibilities" (Bascia, 2001, p. 263). 
The data from this study also suggest that work can be successfully co-constructed (Datnow, Hubbard \& Mehan, 1998; Datnow \& Stringfield, 2000; Park \& Datnow, 2009). Teacher leaders, administrators, and ES21 developers constructed work together as they discussed instructional and data needs, and gave feedback and input into needed sessions. Also as teacher leaders brought information back to their schools, they co-constructed the best ways for implementation that would fit their context and environment. One important piece of the co-construction was that the principals valued the collegiality and designed schedules and meetings for teachers to work together. They were actively involved in leading the school with a spirit of improvement and a sense of urgency, and either led or engaged in data analysis sessions, job embedded professional development sessions, and in building plans for improvement. These efforts imply that active involvement and modeling from the school administrator may impact how and to what extent school work is actually constructed. Results also showed that as co-construction became institutionalized in the schools, teachers took ownership of the process, calling their colleagues together or seeking out others to plan with.

A subscript to this study implies that relevant data, when used intentionally for specific purposes such as determining student performance, analyzing student strengths and challenge areas, and planning next steps, are powerful tools in leading and monitoring change. The two schools used data as an influential and potent factor in making decisions for improvement planning. It was embedded in the work of teaching and learning, and was engrained in everyday practice. The work of implementing reform initiatives will, hopefully, continue to be data-driven, and this study bears out the fact it 
provides the substance and foundations of whether change is needed, what changes are needed, and how it will be measured.

\section{Future Research}

It is important that research continue to investigate how schools distribute leadership in their efforts for reform. In an educational context of increasing complexity, distributing leadership is not only expedient, it is becoming a necessity. In an era of mounting accountability, data have a solid place in the process of improvement planning. These two concepts are tightly linked as schools co-construct work that is characteristic of high reliability organizations. As schools build their work together with data to plan improvements, they have the opportunity to be alert to lapses and small failures, to triangulate on key issues, to regularly engage in cross-checking by multiple groups, and to make decisions based on relevant and timely information, all of which describe high reliability organizations. Distributing this work across procedures and processes, materials and tools, and norms and rules is essential for success.

In theory, the concept of distributed leadership appears to have promise, but gathering evidence on how it is carried out is needed. Research is now beginning to operationalize how it looks in everyday practice, but there needs to be a larger body of evidence before an accurate picture can develop. For example, in this study the leadership teams were already in place when both principals came on board. No changes were intentionally made, but there were changes over the three years due to transfers or mobility issues. The developer of the professional development sessions stated that this was a real challenge as the ES21 team attempted to establish continuity over the sessions and years. He also posed the question of whether or not using content teacher leaders 
instead of grade group leaders would have promoted exploration of instructional practices as well as their work with data. Studying who makes up leadership teams, and what or who makes leadership teams productive and stable could have a big impact on learning how leadership is best distributed.

Because distributed leadership is multifaceted and multidimensional, research needs to be conducted at each educational domain as educators at each level contribute to its operation. Research can help provide the answers to questions about how organizations learn, modify their actions, and explore their values and assumptions as they engage in learning. It could also shed light on whether or not distributed leadership helps schools to plan more effectively and efficiently, whether or not it is more likely to happen in some schools rather than others, whether or not it impacts instruction, and whether or not it impacts student achievement.

Implications for proximal and distal implementation of reform interventions also stem from this study. The practice of using data, analyzing data, and planning next steps was fairly sophisticated in both schools. However, the strategy of using Lesson Study to deepen knowledge and practice of instruction was more of a challenge, even though both concepts were introduced in the same year. This validates that as initiatives enter the school context, they are, indeed, shaped and modified by each school environment (Tharp \& Gallimore, 1998; Wertsch, Tulviste, \& Hagstrom, 1993; Vygotsky, 1962), as framed by the three constructs of the distributed leadership model. However, the fact that the schools were continuing to develop this construct speaks to the fact that it may take longer than expected to fully implement reform strategies. It also may be unrealistic to expect all aspects of a reform to develop simultaneously. Further, as procedures and 
processes, materials and tools, and norms and rules become institutionalized, how do schools recognize when they are no longer useful, or become obsolete?

Another area of interest to researchers may be to look beyond the school and/or school district for evidence of distributed leadership. As systems of practice become more integrated through advanced communication and technologies, political and legislative domains may become participants in this process, which at times appear to be removed from the actual daily practice of educators. Also, as policymakers create reform efforts, the knowledge that implementation may show both proximal and distal stages of development may help them to design strategies or outcomes that are realistic and reasonable in their goals and objectives.

This study has refined and extended the notion of distributed leadership to include the elements of procedures and processes, materials and tools, and norms and rules. By investigating the concept of leadership and how it looks in practice, these elements provide a working framework to encompass the daily work of educators. This is a relatively new area of investigation, and definitely deserves more research and study. This study found that these elements of distributed leadership mediated and shaped the process of implementing intervention strategies for improvement planning from data, and may have influenced how deeply the strategies were developed. Policymakers and educators could benefit greatly from investigations yielding clearer understanding about how intervention efforts are implemented. This information could help policymakers create more informed and realistic mandates for reform, and help educators in their efforts to implement strategies for increased student achievement. 


\section{REFERENCES}

Ainsworth, L. (2008). Common formative assessments. Retrieved May 16, 2009, from the Leadership and Learning Center Web site: http://www.weraweb.org/pages/activities/WERA_Spring09/Ainsworth\%20Keynote\%20.pdf

Anson, A., Cook, T., Habib, F., Grady, M., Haynes, N., \& Comer, J. (1991). The comer school development program: A theoretical analysis. Urban Education, 26, 56-82.

Armstrong, J., \& Anthes, K. (2001). How data can help. American School Board Journal, 1881, 38-41. Retrieved March 14, 2009, from http://curtboswell.com/6011/docs/armstrong_anthes.pdf

Association for Effective Schools. (1996). Retrieved June 27, 2010, from http://www.mes.org/correlates.html

Bambino, D. (2002). Redesigning professional development: Critical friends. Educational Leadership, 59, 25-27.

Bascia, N. (2001). Pendulum swings and archaeological layers: Educational policy and the case of ESL. In J. Portelli \& P. Solomon (Eds.), The erosion of democracy in education: From critique to possibilities (pp. 245-268). Calgary, Alberta: Detselig.

Bascia, N., \& Hargreaves, A. (2000). The sharp edge of educational change: Teaching, leading and the realities of reform. London: Routledge Falmer.

Bateson, G. (1972). Steps to an ecology of mind: Collected essays in anthropology, psychology, evaluation, and epistemology. Chicago: University of Chicago Press.

Berman, P. \& McLaghlin, M. (1978). Implementing innovations: Revisions for an agenda for a study of change agent programs in education (WN-8450-1HEW). Office of Education (DHEW). Santa Monica: Rand Corp.

Bernhardt, V. (2000). Databases can help teachers with standards implementation. Retrieved March 7, 2009, from the Education for the Future Initiative Web site: http://eff.csuchico.edu/downloads/Dbases.pdf 
Bloom B. (1956). Taxonomy of educational objectives, handbook I: The cognitive domain. New York: David McKay Co., Inc.

Boaler, J. (2008). When politics took the place of inquiry: A response to the national mathematics advisory panel's review of instructional practices. Educational Researcher, 37, 588-594.

Brunner, C., Fasca, C., Heinze, J., Honey, M., Light, D., Mandinach, E., \& Wexler, D. (2005). Linking data and learning: The growth network study. Journal of Education for Students Placed at Risk, 10, 241-267.

Chen, E., Heritage, M., \& Lee, J. (2005). Identifying and monitoring students' learning needs with technology. Journal of Education for Students Placed at Risk, 10, 309333.

Choppin, J. (2002). Data use in practice: Examples from the school level. Paper presented at the annual meeting of the American Educational Research Association, New Orleans, LA.

Chrispeels, J. (Ed.). (2004). Learning to lead together: The promise and challenge of sharing leadership. Thousand Oaks: Sage.

Chrispeels, J. \& Andrews, C. (2007). System supports for teacher learning and school improvement. In T. Townsend (Ed.), International handbook on school effectiveness and improvement. Dordrecht: Springer.

Chrispeels, J., Castillo, S. \& Brown, J. (2000). School leadership teams: A process model of team development. School Effectiveness and School Improvement, 11, $22-56$.

Chrispeels, J. \& Colleagues. (2000). Effective schools guidebook for grade level and department teams. San Diego: University of California.

Chrispeels, J., \& Daly, A. (2005). From problem to possibility: Leadership for implementing and deepening the processes of effective schools. Journal for Effective Schools, 4, 7-26.

Chrispeels, J. \& Gonzalez, M. (2006). The challenge of systemic change in complex educational systems: A district model to scale up reform. In A. Harris \& J. H. Chrispeels (Eds.), Improving schools and educational systems (pp. 241-273). London: Routledge.

Clandinin, D., \& Connelly, F. (2000). Narrative inquiry: Experience and story in qualitative research. San Francisco: Jossey Bass. 
Clare, L. \& Aschbacheri, P. (2001). Exploring the technical quality of using assignments and student work as indicators of classroom practice. Educational Assessment, 7 , 39-59.

Clune, W. (1989). Research and conclusions from three views of curriculum policy in the school context: The school as policy mediator, policy critic and policy constructor. Report for the Center for Policy Research in Education, Center for the Research on the Context of Secondary School Teaching.

Coalition of Essential Schools Northwest. (2006). Critical friends summer workshop. Retrieved June 25, 2010, from http://www.cesnorthwest.org/index.php

Coburn, C. (2001). Collective sensemaking about reading: How teachers mediate reading policy in their professional communities. Educational Evaluation and Policy Analysis, 23, 145-170.

Coburn, C., \& Talbert, J. (2006). Conceptions of evidence use in school districts: Mapping the terrain. American Journal of Education, 112, 469-495.

Cole, M., \& Wertsch, J. (2006). Beyond the individual/social antimony in discussions of Piaget and Vygotsky. Retrieved November 1, 2008, from the Prometheus Research Group Web site: http://www.des.emory.edu/mfp/VygColeWer.pdf

Coleman, James S. (1966). Equality of Educational Opportunity (COLEMAN) Study (EEOS), 1966 [Computer file]. ICPSR06389-v3. Ann Arbor, MI: Inter-university Consortium for Political and Social Research [distributor], doi:10.3886/ICPSR06389. Retrieved January 2, 2010, from http://www.icpsr.umich.edu/icpsrweb/ICPSR/studies/06389

Conrad, W., \& Eller, B. (2003). District data-informed decision making. Paper presented at the annual meeting of the American Education Research Association, Chicago, IL.

Cooper, H. \& Valentine, J. (2001). Using research to answer practical questions about homework. Educational Psychologist, 36, 143-154.

Copland, M. (2003). Leadership of inquiry: Building and sustaining capacity for school improvement. Educational Evaluation and Policy Analysis, 25, 375-395.

Council of Chief State School Officers. (2001). Proceedings from state and district support to low-performing schools. Selected Presentations from a Working Conference of the High Poverty Schools Initiative, Baltimore, MD. Retrieved November 1, 2008, from http://www.eric.ed.gov/PDFS/ED466508.pdf

Creighton, T. (2001). Data analysis and the principalship. Principal Leadership, 1, $52-57$. 
Cresswell, J. (2005). Educational research: Planning, conducting, and evaluating quantitative and qualitative research. Upper Saddle River: Pearson.

Cromey, A. (2000). Using student assessment data: What can we learn from schools? Policy Issues, 6. Oak Brook, IL: North Central Regional Educational Laboratory. Retrieved January 30, 2009, from http://www.eric.ed.gov/PDFS/ED452593.pdf

Cromey, A., Van der Ploeg, A., \& Mansini, B. (2000). The call for data-driven decision making in the mid-west schools: NCREL's response. Oak Brook, IL: NCREL.

Cushman, K. (May, 1998). How friends can be critical as schools make essential changes. Oxon Hill, MD: Coalition of Essential Schools.

Cushman, K. (1999). The cycle of inquiry and action: Essential learning communities. Horace, 15. Retrieved March 17, 2009, from http://old.essentialschools.org/cs/resources/view/ces_res/74

Daniels, H. (1996). An introduction to vygotsky. London: Routledge.

Daniels, R., \& Johnson-Ferguson, V. (2001). Using data to help students achieve. Principal Leadership, 1, 58-60.

Darling-Hammond, L., Bullmaster, M., \& Cobb, V. (1995). Rethinking teacher leadership through professional development schools. The Elementary School Journal, 96, p. 87.

Darling-Hammond, L., Hightower, A., Husbands, J., Lafors, J., Young, V., \& Christopher, C. (2005). Instructional leadership for systemic change: The story of San Diego's reform. Lanham: Scarecrow Education.

Datnow, A., Borman, G., Stringfield, S., Overman, L., \& Castello, M. (2003). Comprehensive school reform in culturally and linguistically diverse contexts: Implementation and outcomes from a four-year study. Educational Evaluation and Policy Analysis, 25, 143-170.

Datnow, A., Hubbard, L. \& Mehan, H. (2002). Extending educational reform: From one school to many. London \& New York: Routledge/Falmer.

Datnow, A., Lasky, S., Stringfield, S., \& Teddlie, C. (2006). Integrating educational systems for successful reform in diverse contexts. Cambridge: Cambridge University Press.

Datnow, A., Park, V., \& Wohlstetter, P. (2007). Achieving with data: How high performing school systems use data to improve instruction for elementary students. Retrieved October 25, 2008, from the University of Southern California: 
Center on Educational Governance, Rossier School of Education Web site: http:// newschools.org/files/AchievingWithData.pdf

Datnow, A. \& Stringfield, S. (2000). Working together for reliable school reform. Journal of Education for Students Placed at Risk, 5, 183-204.

Dembowsky, J., Pane, J., Barney, H., \& Christinia, R. (2005). Data driven decisionmaking in southwestern Pennsylvania school districts. Working paper. Santa Monica, CA: RAND. Retrieved October 25, 2008, from http://www.rand.org/pubs/working_papers/2006/RAND_WR326.pdf

Doyle, D. (2003). Data-driven decision-making: Is it the mantra of the month or does it have staying power? The Journal. Retrieved October 25, 2008, from http://thejournal.com/articles/2003/05/01/datadriven-decisionmaking.aspx

DuFour, R., \& Eaker, R. (1998). Professional learning communities at work: Best practices for enhancing student achievement. Bloomington: National Education Service.

DuFour, R., DuFour, R., Eaker, R., \& Karhanek, G. (2004). Whatever it takes: How professional learning communities respond when children don't learn. Bloomington: National Education Service.

DuFour, R., DuFour, R., Eaker, R. \& Many, T. (2006). Learning by doing. Bloomington: Solution Tree Press.

Earl, L. (2005). From accounting to accountability: Harnessing data for school improvement. Paper presented at the 2005 Annual Meeting of the Australian Council for Educational Research. Retrieved October 25, 2008, from http://www.acer.edu.au/documents/RC2005_Earl.pdf

Earl, L., Fullan, M., Leithwood, K., Watson, N., Jantzi, D., Levin, B., et al. (2001). Watching and learning: Second annual report for the national numeracy and national literacy learning strategy. Report commissioned by The Ontario Secondary Teachers' Federation. Toronto, Ontario: OISE/UT.

Earl, L., \& Katz, S. (2006). Leading schools in a data-rich world: Harnessing data for school improvement. Thousand Oaks: Corwin Press.

Earl, L., \& LeMahieu, P. (1997) Rethinking assessment and accountability. In A. Hargreaves (Ed.), Rethinking educational change with heart and mind: 1997 $A S C D$ yearbook. Alexandria, VA: Association for Supervision and Curriculum Development.

Earl, L., \& Timperley, H. (2007). Using conversations to make sense of evidence: Possibilities and pitfalls. New York: Springer. 
Edmonds, R. (1979a). Effective schools for the urban poor. Educational Leadership, $37,15-18,20-24$.

Edmonds, R. (1979b). Some schools work and more can. Social Policy, 9, 28-32.

Elmore, R. (1979-1980). Backward mapping: Implementation research and policy decisions. Political Science Quarterly. 94, 601-616.

Elmore, R. (2000). Building a new structure for school leadership: The logic of standards-based reform and the institution of publiceducation. Retrieved August 29, 2009 from the Albert Shanker Institute Web site: info.worldbank.org/etools/docs/library/94838/richardelmore.pdf

Elmore, R., \& Burney, D. (1997). School variation and systemic instructional improvement in community school district \#2, New York City. Retrieved September 13, 2008, from http://www.lrdc.pitt.edu/hplc/publications/school\%20variation.pdf

Elmore, R., \& Burney, D. (1998). Continuous improvement in community district \#2, New York City. Retrieved September 13, 2008, from http://www.lrdc.pitt.edu/hplc/Publications/ContinuousImprove.pdf

Estes, C. \& Edmonds, B. (1981). Symbolic interaction and policy analysis. Symbolic interaction, 4, 75-86

Feldman, J., \& Tung, R. (2001). Using data-based inquiry and decision making to improve instruction. ERS Spectrum, 19, 10-19.

Feldman, J., \& Tung, R. (2002). The role of external facilitators in whole school reform: Teachers' perceptions of how coaches influence school change. Paper presented at the American Education Research Association, New Orleans, LA.

Feuer, M., Towne, L., \& Shavelson, R. (2002). Scientific culture and educational research. Educational Researcher, 31, 4-14.

Fullan, M. (2004). Leadership and sustainability. Thousand Oaks: Corwin Press.

Gordon, E., \& Bridglall, B. (2003). Toward a relational data management system for education. Pedagogical Inquiry and Praxis. Retrieved October 11, 2008, from http://www.eric.ed.gov/PDFS/ED472481.pdf

Greenleaf, R. (1997). Servant leadership: a journey into the nature and legitimate power of greatness. Mahwah, NJ: Paulist Press.

Guba, E. \& Lincoln, Y. (1985). Naturalistic inquiry. Newberry Park: Sage Publications, Inc. 
Hall, P. \& McGinty, P. (1997). Policy as the transformation of intentions: Producing program from statute. The Sociological Quarterly, 38, 439-467.

Halverson, R. (2006). A distributed leadership perspective on how leaders use artifacts to create professional community in schools (WCER Working Paper No. 2004-4). Wisconsin Center for Education Research, University of Wisconsin, Madison.

Halverson, R., Grigg, J., Prichett, R., \& Thomas, C. (2005). The new instructional leadership: Creating data-driven instructional systems in schools. Paper presented at the National Council of Professors of Educational Administration, Washington, D.C.

Hamilton, L., Halverson, R., Jackson, S., Mandinach, E., Supovitz, J., \& Wayman, J. (2009). Using student achievement data to support instructional decision making. What Works Clearinghouse, U. S. Department of Education, NCEE 2009-4067. Retrieved June 26, 2010, from http://ies.ed.gov/ncee/wwc/pdf/practiceguides/dddm_pg_092909.pdf

Hardy, L. (2003). Information please. American School Board Journal, 90, 20- 22.

Hatch, T. (2001). It takes capacity to build capacity. Education week, 20, 44-46.

Henke, K. (2005). From vision to action: How school districts use data to improve performance. Washington, D.C.: Consortium for School Networking. Retrieved January 16,2010 from http://www.cosn.org/Initiatives/3DDataDrivenDecisionMaking/3DResourceCente r/tabid/5065/id/118/Default.aspx

Herman, J. (2005). Making accountability work to improve student learning (CSE Report 649). Retrieved October 25, 2008 from http://www.cse.ucla.edu/products/reports/r649.pdf

Herman, J., \& Gribbons, B. (2001). Lessons learned in using data to support school inquiry and continuous improvement: Final report to the stuart foundation (CSE Technical Report 525). Retrieved March 7, 2009, from http://www.cse.ucla.edu/products/Reports/TR535.pdf

Holcomb, E. (1999). Getting excited about data: How to combine people, passion, and proof. Thousand Oaks: Corwin Press.

Huffman, D., \& Kalnin, J. (2003). Collaborative inquiry to make data-based decisions in schools. Teaching and Teacher Education, 19, 569-580.

Hursh, D. (2006). The crisis in urban education: Resisting neoliberal policies and forging democratic possibilities. Educational Researcher, 35, 19-25. 
Hutchins, E. (1995a). Cognition in the wild. Cambridge: MIT Press.

Hutchins, E. (1995b). How a cockpit remembers its speeds. Cognitive Science 19, 265288.

Ingram, D., Seashore-Louis, K., \& Schroeder, R. (2004). Accountability policies and teacher decision making: Barriers to the use of data to improve practice. Teacher College Record 106, 1258 - 1287.

Jandris, T. (2001). Data-based decision making: Essentials for principals. Alexandria, VA: National Association of Elementary School Principals. (Eric Document Reproduction Service No. 459523).

John-Steiner, V., \& Mahn, H. (2008). Sociocultural approaches to learning and development: A Vygotskian framework. Educational Psychologist, 31, 191-206.

Johnson, J. (1997). Data-driven school improvement. Eric Digest, 109. (Eric Document Reproduction Service No. 401595).

Karcher, M., Kuperminc, G., Portwood, S., Sipe, C., \& Taylor, A. (2006). Mentoring programs: A framework to inform program development, research, and evaluation. Journal of Community Psychology, 34, 709-725.

Kentucky Education Reform Act of 1990 (KERA, House Bill 940). Retrieved December 13, 2008, from http://www.wku.edu/Library/kera/keralaw.html

Khanna, R., Trousdale, D., Penuel, W., \& Kell, J. (1999). Supporting data use among administrators: Results form a data planning model. Paper presented at the annual meeting of the American Educational Research Association, Montreal, Quebec, Canada. (Eric Document Reproduction Service No. 433348).

Killion, J., \& Bellamy, T. (2000). On the job: Data analysts focus on school improvement efforts. Journal of Staff Development, 21, 27-31.

Kinder, J., \& Bellamy T. (2000). On the job: Data analysts focus on school improvement efforts. Journal of Staff Development, 1, 27-31.

Knapp, M., Copland, M., \& Swinnerton, J. (2007). Evidence and decision making: 106 $6^{\text {th }}$ yearbook of the national society for the study of education. In P. Moss (Ed.), Malden: Blackwell.

Kowalski, T., \& Lasley, T. (2008). Handbook of data-based decision making. New York: Routledge.

Lachat, M. (2002). Data-driven high school reform: The breaking ranks model. 
Providence: RI: Northeast and Islands Regional Educational Laboratory at Brown University. Retrieved February 21, 2009, from

http://www.alliance.brown.edu/pubs/hischlrfm/datdrv_hsrfm.pdf

Lachat, M., \& Smith, S. (2004). Data use in urban high schools. The Educational Alliance. Brown University. Retrieved February 21, 2009, from http://www.alliance.brown.edu/pubs/data_use/datuse_urbhs.pdf

LaPorte, T. \& Consolini, P. (1991). Working in practice but not in theory: Theoretical challenges of "high-reliability organization." Journal of Public Administration Research and Theory, 1, 19-48.

Lashway, L. (2001). The state of standards. Clearinghouse on Educational Policy and Management. College of Education, University of Oregon. Retrieved September 13,2008 , from

https://scholarsbank.uoregon.edu/xmlui/bitstream/handle/1794/3485/roundups_Su mmer_2001.pdf?sequence $=1$

Lasky, S. (2001). Proposed whole school reform intervention, Spring. Grant Proposal to the Olin Foundation.

Lasky, S. (2005). A sociocultural approach to understanding teacher identity, agency, and professional vulnerability in a context of secondary school reform. Teaching and Teacher Education, 21, 899-916.

Lasky, S., \& Datnow, A. (2006). Systemic linkages in the implementation of comprehensive school reform models. Paper presented at the annual meeting of the American Educational Research Association, San Francisco.

Lasky, S., Schaffer, G., \& Hopkins, T. (2008). Learning to think and talk from evidence: Developing system-wide capacity for learning conversations. In Earl L., \& Timperley, H. (Eds.), Professional learning conversations (pp. 95-107). New York: Springer.

Leithwood, K., Seashore-Louis, K., Anderson, S., \& Wahlstrom, K. (2004). How leadership influences student learning. Center for Applied Research and Educational Improvement, University of Minnesota.

Levesque, K., Bradby, D., and Rossi, K. (1996). Using data for program improvement: How do we encourage schools to do it? Centerfocus,,12. Retrieved July 1, 2010, from http://vocserve.berkeley.edu/centerfocus/CF12.html

Lewis, C. (1995). Educating hearts and minds: Reflections on Japanese preschool and elementary education. New York: Cambridge University Press.

Lewis, C., Perry, R., Hurd, J., \& O'Connell, M. (2006). Lesson study comes of age in North America. Phi Delta Kappan International, 88, 273-281. 
Lezotte, L. (1991). Correlates of effective schools: The first and second generations. Retrieved April 15, 2008 from the Effective Schools Products, Ltd. Web site: http://www.effectiveschools.com, and http://www.mes.org/correlates.html

Light, D., Wexler, D., \& Heinz, J. (2004). Keeping teachers in the center: A framework data-driven decision making. New York, New York: Center for Children \& Technology, Education Development Center, Inc. (Eric Document Reproduction Service No. 486112). Retrieved March 7, 2009 from http://cct.edc.org/admin/publications/speeches/LightWexlerHeinze2005.pdf

Maxwell, J. (1996). Qualitative research design: An interactive approach. Sage: Thousand Oaks, CA.

McDonald, L., \& Elmore, R. (1987). Getting the job done: Alternative policy instruments. Educational Evaluation and Policy Analysis, 9, 133-152.

McLaughlin, M. (1987). Learning from experience: Lessons from policy implementation. Educational Evaluation and Policy Analysis, 9, 171-178.

Massel, D. (2001). The theory and practice of using data to build capacity: State and local strategies and their effects. In S.H. Fuhrman (Ed.), From the capitol to the classroom: Standards-based reform in the states (pp. 148-169). Chicago: University of Chicago Press.

Maxwell, G. (2008). Distributed leadership includes staff: My grandfather as a case. UCEA Conference Proceedings for Convention 2008. Retrieved September 25, 2010, from http://coe.ksu.edu/ucea/2008/Maxwell_UCEA2008.pdf

Maxwell, G., Scheurich, J., \& Skrla, L. (2009). Distributed leadership includes staff: One rural custodian as a case. Journal of School Leadership, 19, 466-496.

Maxwell, J. (2005). Qualitative research design: An interactive approach. Thousand Oaks: Sage Publications, Inc.

Mayer, R. (2003). Learning environments: The case for evidence-based practice and issue-driven research. Educational Psychology Review, 15, 359-366.

McTighe, J., \& Williams, J. (2004) Understanding by design. Alexandria, VA: Association for Supervision and Curriculum Development.

Miles, M., \& Huberman, A. (1994). Qualitative data analysis. Thousand Oaks: Sage.

No Child Left Behind Act of 2001, Pub. Law No 107-110.

Noyce, P., Perda, D., \& Traver, R. (2000). Creating data-driven schools. Educational 
Leadership, 57, 52-56.

Park, V., \& Datnow, A. (2009). Co-constructing distributed leadership: District and school connections in data-driven decision making. School Leadership and Management, 29, 477-494.

Pattison, C., \& Brukas, N. (2000). Integrating standards into the curriculum. Critical North Learning Issue: Integrating Standards into the Curriculum. Central Regional Educational Laboratory: Point Associates Political Action. Retrieved October 25, 2008 from http://www.ncrel.org/sdrs/areas/issues/content/currclum/cu300.htm

Protheroe, N. (2001). Improving teaching and learning with data-based decisions: Asking the right questions and acting on the answers. ERS Spectrum. Retrieved October 25, 2008 from http://www.ers.org/spectrum/sum01a.htm

Rallis, S., \& MacMullen, M. (2000). Inquiry-minded schools: Opening the doors for accountability. Phi Delta Kappa, 81, 766-773.

Rogoff, B. (1990). Apprenticeship in learning. New York: Oxford University Press, Inc.

Rossi, R., \& Stringfield, S. (1997). Education reform and students at risk: Studies of education reform. Office of Educational Research and Improvement, U.S. Department of Education.

Rudalevige, A. (2005). Adequacy, accountability, and the impact of "No Child Left Behind." Prepared for Adequacy Lawsuits: Their Growing Impact on American Education conference at Harvard University, October.

Schugurensky, D. (2002). History of education: Selected moments of the $20^{\text {th }}$ century. Department of Adult Education, Community Development and Counseling Psychology. The Ontario Institute for Studies in Education of the University of Toronto (OISE). Retrieved December 6, 2008 from http://www.oise.utoronto.ca/research/edu20/moments/1965elemsec.html

Sergiovanni, T. (1992). Moral leadership. San Francisco: Jossey-Bass.

Shadish, W., Cook, T., \& Campbell, D. (2002). Experimental and quasi-experimental designs. Boston: Houghton Mifflin Co.

Spillane, J. (2005). Distributed leadership. The Educational Forum, 69, 143-150.

Spillane, J., Halverson, R., \& Diamond, J. (2001). Investigating school leadership practice: A distributed perspective. Educational Researcher, 30, 23-27. 
Spillane, J., Halverson, R., \& Diamond, J. (2004). Towards a theory of leadership: A distributed perspective. Journal of Curriculum Studies, 36, 3-34.

Spillane, J. \& Jennings, N. (1997). Aligned instructional policy and ambitious pedagogy: Exploring instructional reform from the classroom perspective. Teachers College Record, 98, 449 - 481.

Stiggins, R. (2006). Assessment for learning: A key to motivation and achievement. Edge, 2, 3-16.

Stiggins, R. (2008). Notes from Power Point presentation. April 28, Louisville, KY.

Stiggins, R., \& Chappuis, J. (2008). Enhancing student learning: Create profound achievement gains through formative assessments. District Administrator, January.

Stringfield, S. (1995). Attempts to enhance students' learning: A search for valid programs and highly reliable implementation techniques. School Effectiveness and School Improvement. 6, 67-96.

Stringfield, S. (1997). Underlying the chaos of factors explaining exemplary U.S. elementary schools: The case for High Reliability Organizations. In T. Townsend (Ed.), Restructuring and quality: Problems and possibilities for tomorrow's schools (pp. 143-160). London: Routledge.

Stringfield, S. (1998). Organizational learning and current reform efforts. In K. Leithwood \& K.S. Louis (Eds.), Schools as learning communities (pp. 255-268). Lisse, NL: Swets \& Zeitlinger.

Stringfield, S., \& Land, D. (Eds.) (2002). Educating at-risk students. Chicago, L: National Society for the Study of Education.

Stringfield, S. \& Lasky, S. (2004) The four quartets: Proposed school effectiveness study. Proposal prepared for the Olin Foundation.

Stringfield, S. (2006). ES21 report of planning year and first year of implementation: 2004-2006. Report prepared for the Olin Foundation.

Stringfield, S., Reynolds, D., \& Schaffer, G. (2008). Improving secondary students' academic achievement through a focus on reform reliability: Four- and nine-year findings from the high reliability schools project. CfBt Education Trust. Retrieved June 27, 2010, from http://www.cfbt.com/evidenceforeducation/PDF/High\%20Reliability_v5\%20FIN AL2.pdf 
Stringfield, S., Lasky, S., Overman, L., Schaffer, E., Chrispeels, J., Burke, P., et al. (2010). "The four quartets:" Effective Schools for the $21^{\text {st }}$ Century Project final report. Report prepared for the Olin Foundation.

Supovitz, J., \& Weinbaum, E. (2008). The implementation gap: Understanding reform in high schools. New York: Teachers College Press.

Tashakkori, A., \& Teddlie, C. (1998). Mixed methodology: Combining qualitative and quantitative approaches. Thousand Oakes: Sage.

Teddlie, C., \& Reynolds, D. (2000). The international handbook of school effectiveness research. New York: Falmer Press.

Teddlie, C., \& Stringfield, S. (2007). A history of school effectiveness and improvement research in the USA focusing on the past quarter century. In T. Townsend (Ed.) The international handbook of school effectiveness research, $1,131-166$. Dordrecht, Netherlands: Springer.

Tharpe, R., \& Gallimore, R. (1988). Rousing minds to life. Cambridge: Cambridge University Press.

Thomas, G. (2004). Introduction: Evidence and practice. Evidence-based practice in education. Maidenhead, UK: Open University Press.

Thomas, R. (2003). Blending qualitative \& quantitative research methods in theses and dissertations. Thousand Oaks: Corwin Press, Inc.

Timperley, H. (2005). Instructional leadership challenges: The case of using student achievement information for instructional improvement. Leadership and Policy in Schools, 4, 3-22.

Tongeri, W. \& Anderson, S. (2003). Beyond islands of excellence: What districts can do to improve instruction and achievement in all schools: A leadership brief. Baltimore, MD: Learning First Alliance.

U.S. Department of Education. (1983). A nation at risk. Retrieved September 13, 2008, from http://www.ed.gov/pubs/NatAtRisk/intro.html

Vygotsky, L. (1962). Thought and language. Cambridge, MA. MIT Press.

Wagner, T. (2003). Beyond testing: The 7 disciplines for strengthening instruction. Education Week, 23, 28-30.

Wayman, J., Midgley, S., \& Stringfield, S. (2005) Collaborative teams to support databased decision making and instructional improvement. Paper presented at the 
2005 Annual Meeting of the American Educational Research Association, Montreal, Canada.

Wayman, J., Midgley, S., \& Stringfield, S. (2006). Leadership for data-based decisionmaking: Collaborative Educator Teams. Paper presented at the 2006 Annual Meeting of the American Educational Research Association, San Francisco, CA.

Wayman, J., Stringfield, S. (2003). Teacher-friendly options to improve teaching through student data analysis. Paper presented at the 2003 Annual Meeting of the American Association for Teaching and Curriculum, Baltimore, MD. Retrieved March 17, 2009, from http://www.nclb4dccharters.com/documents/wayman_springfield_study.pdf

Wayman, J., Stringfield, S., \& Millard, M. (2004). Software for disaggregating and reporting student data: Moving beyond "no child left behind" to support teachers. Paper presented at the 2004 Annual Meeting of the American Educational Research Association, San Diego, CA. Retrieved March 17, 2009 from http://www.csos.jhu.edu/datause/papers/wayman_data_systems_nclb.pdf

Wayman, J., Stringfield, S., \& Yakimowksi, M. (2004). Software enabling school improvement through the analysis of student data. Baltimore: MD: John Hopkins University Center for Research on the Education of Students Placed at Risk. Retrieved March 17, 2009 from http://www.csos.jhu.edu/crespar/techReports/Report67.pdf

Wertsch, J., Tulviste, P., \& Hagstrom, F. (1993). A sociocultural approach to agency. In A. Forman, N. Minick, \& A. Stone (Eds.), Contexts for learning sociocultural dynamics in children's development (pp. 336-357). New York: Oxford University Press.

Whitehurst, G. (2002). Evidence-based education. Educational Research and Improvement, USDOE. Retrieved December 13, 2008, from http://www.ed.gov/ nclb/methods/whatworks/eb/evidencebased.pdf

Wiggins, G., \& McTighe, J. (1998). Understanding by design. Alexandria, VA: Association for Supervision and Curriculum Development.

Williams, F. (1993). The cognitive-affective interaction model for enriching gifted programs. In J.S. Renzulli (Ed.), Systems and models for developing programs for the gifted and talented (pp. 461-484). Mansfield: Creating Learning Press.

Wood, D. (2000). Narrative inquiry: Experience and story in qualitative research. Anthropology and Education Quarterly, 31. Retrieved April 5, 2009 from http://www.aaanet.org/sections/cae/aeq/br/clandinin.htm

Yin, R. (1994). Case study research: Design and methods. Thousand Oaks: Sage. 
York-Barr, J., \& Duke, K. (2004). What do we know about teacher leadership? Findings from two decades of scholarship. Review of Educational Research, 74, 255316.

Young, V. (2006). Teachers' use of data: Loose coupling, agenda setting, and team norms. American Journal of Education, 112, 521-548. 
Appendix 1

Interview Protocols

Interview Questions for Principals and Leadership Team Members

1. In reflecting back on your involvement with ES21, will you describe what elements of the professional development related to distributed leadership that you tried to implement in your school?

Probes - Protocols for holding/focusing teacher meetings on data use Cross-site meetings

Cross-site meeting strategies (leadership styles, grouping formats, lesson study, etc.)

2. In reflecting back on your involvement with ES21, will you describe what elements of the professional development related to data use for improvement planning that you tried to implement in your school?

Probes - Protocols for holding/focusing teacher meetings on data use Rubrics for assessment/monitoring

Procedures

Utilizing technologies (software, data warehouses)

3. Can you talk a bit about strategies you used in implementing these elements?

4. Can you talk a bit about why you did not implement elements of the PD?

5. Can you talk a bit about challenges or constraints you had when trying to implement elements of ES 21?

6. When you think about the ways you use data for improvement planning in your school, can you think of any elements of ES21 that you use or that help you with the planning process?

Interview Questions for Developer of PD Sessions

1. Why did you teach/present the content you did?

2. What areas were you working in to develop teacher and principal capacity for improvement planning? 
3. Will you talk with me about your impressions of what elements of the PD were implemented in the following schools?

School A

School B

4. Why were these elements chosen?

5. Can you identify what kinds of challenges schools had in implementing content they learned in the PD?

\section{Interview Questions for Teachers}

Purpose This interview will be to explore the use of data for planning. Before we start, tell me a little about yourself.

1. How long have you been teaching? How many schools have you taught in? Do you have experience in other grades than the one you are teaching this year?

2. When you hear the word data, what comes to mind?

(Covers Question 2 - Kinds of Data)

3. What kinds of data do you use for whole school planning? (KCCT, NCLB, CCA, etc). What kinds of data do you use for classroom planning?

(Covers Question \#1-Processes/Procedures)

4. Can you talk about the procedures you have for using data at your school?

Probes - group arrangement (whole school, grade groups, vertical teams) purposes (KCCT, NCLB, benchmark, classroom analysis)

5. Tell me about any events or routines that your school has to learn about data?

Probes - peer observations, lesson study, Red Flag Analysis, critical friends,

(Covers Question \#1 - Materials/Tools)

6. Tell me about the materials and tools you have for planning from data.

What kinds of materials do you have for analyzing data? (rubrics, Red Flag

Analysis, pencil/paper, teacher/administrator protocols, etc.) How does technology fit into data use at your school?

Probes - Red Flag Analysis, district/school protocols, rubrics

(Covers Question \#1 - Rules/Norms)

7. Can you talk about the unspoken or unwritten "rules" you school has about data?

Probes - frequency of procedures, usefulness, timeliness, reporting 
Appendix 2

Framework for Analysis

\begin{tabular}{|c|c|c|c|c|c|}
\hline $\begin{array}{l}\text { The } \\
\text { Intervention } \\
\text { system }\end{array}$ & $\begin{array}{l}\text { Core } \\
\text { Elements } \\
\text { of the } \\
\text { Interventio } \\
\text { n } \\
\text { (HRO; } \\
\text { CREST; } \\
\text { Lesson } \\
\text { Study; The } \\
\text { Correlates; } \\
\text { Strengths- } \\
\text { based, } \\
\text { Distributed } \\
\text { Leadership) }\end{array}$ & $\begin{array}{c}\text { Proximal } \\
\text { Schoolwide } \\
\text { Outcomes } \\
\text { Transitioning } \\
\text { to } \\
\text { Core Elements }\end{array}$ & $\begin{array}{l}\text { Distal } \\
\text { Schoolwide } \\
\text { Outcomes } \\
\text { Institutionalized } \\
\text { Core Elements }\end{array}$ & $\begin{array}{l}\text { Proximal } \\
\text { Staff \& } \\
\text { Student } \\
\text { Outcomes } \\
\text { Transitioning }\end{array}$ & $\begin{array}{l}\text { Distal } \\
\text { Staff \& } \\
\text { Student } \\
\text { Outcomes } \\
\text { Embody }\end{array}$ \\
\hline $\begin{array}{l}\text { Federal } \\
\text { Policy, } \\
\text { funding, } \\
\text { supreme } \\
\text { court } \\
\text { rulings }\end{array}$ & $\begin{array}{l}\text { Classroom } \\
\text { teaching and } \\
\text { learning reflect } \\
\text { the commonly } \\
\text { shared belief } \\
\text { among faculty, } \\
\text { teachers, and } \\
\text { parents that the } \\
\text { educational } \\
\text { failure of any } \\
\text { child is a } \\
\text { disaster }\end{array}$ & $\begin{array}{l}\text { Rules \& } \\
\text { Policy }\end{array}$ & Norms & $\begin{array}{l}\text { Highly } \\
\text { engaged in } \\
\text { learning } \\
\text { processes }\end{array}$ & $\begin{array}{l}\text { Highly } \\
\text { engaged in } \\
\text { learning } \\
\text { processes }\end{array}$ \\
\hline $\begin{array}{l}\text { State policy, } \\
\text { funding, } \\
\text { professional } \\
\text { developmen } \\
t\end{array}$ & $\begin{array}{l}\text { Physical } \\
\text { environment } \\
\text { supports \& } \\
\text { reflects A } \\
\text { Highly Reliable } \\
\text { Learning } \\
\text { Organization } \\
\text { with Distributed } \\
\text { Leadership }\end{array}$ & $\begin{array}{l}\text { Materials/Tool } \\
\mathrm{s}\end{array}$ & Materials/Tools & $\begin{array}{l}\text { Independent } \\
\text { yet } \\
\text { Interdepende } \\
\text { nt } \\
\text { Learner }\end{array}$ & $\begin{array}{l}\text { Independent } \\
\text { yet } \\
\text { Interdependent } \\
\text { Learner }\end{array}$ \\
\hline $\begin{array}{l}\text { District } \\
\text { policy, } \\
\text { funding, } \\
\text { professional } \\
\text { developmen } \\
t \\
\text { reform } \\
\text { initiatives }\end{array}$ & $\begin{array}{l}\text { Small number } \\
\text { of clear goals } \\
\text { internalized by } \\
\text { staff and } \\
\text { students who } \\
\text { hold a strong } \\
\text { sense of the } \\
\text { primary } \\
\text { mission. } \\
\text { Valid evidence } \\
\text { and student data } \\
\text { from multiple }\end{array}$ & $\begin{array}{l}\text { Operating } \\
\text { Procedures } \\
\text { and Processes }\end{array}$ & $\begin{array}{l}\text { Operating } \\
\text { Procedures and } \\
\text { Processes }\end{array}$ & $\begin{array}{l}\begin{array}{l}\text { Critical } \\
\text { problem } \\
\text { solver }\end{array} \\
\text { Strong sense } \\
\text { of self as a } \\
\text { learner } \\
\text { Helps others } \\
\text { learn }\end{array}$ & $\begin{array}{l}\text { problem solver } \\
\text { Strong sense of } \\
\text { self as a } \\
\text { learner } \\
\text { Helps others } \\
\text { learn } \\
\text { Learning }\end{array}$ \\
\hline
\end{tabular}




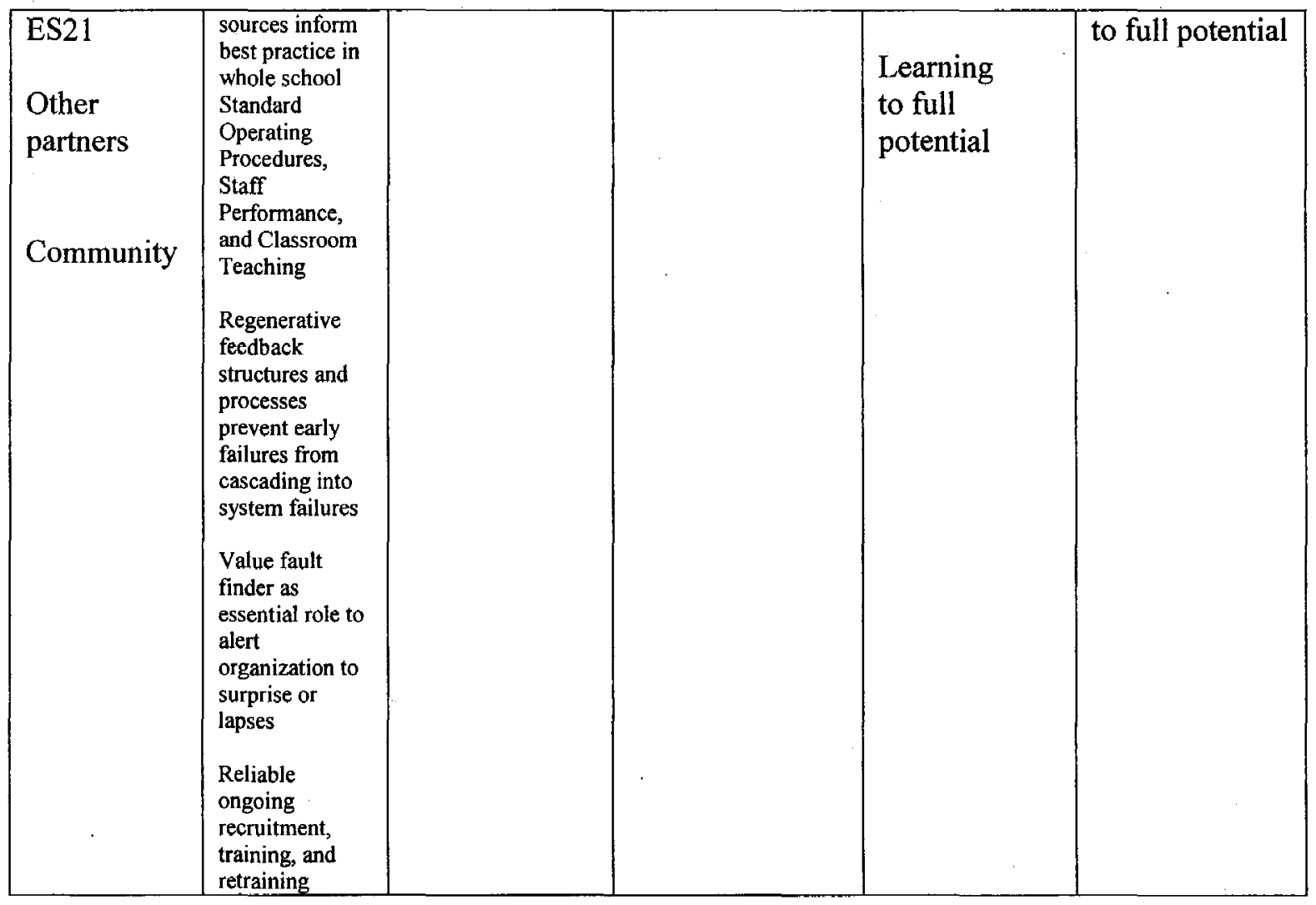




\section{Appendix 3}

Schedule of Observations

Cross-site sessions for all 17 experimental schools

February $1-3,2007$

September $27-29,2007$

School A - May 15, 2008

December 10, 2008

June 4, 2009

September 29, 2009

School B - February 5, 2008

May 15, 2008

October 14, 2008
San Diego, CA

Charlotte, NC

Last ES21 Professional Development Session School Based Job Embedded PD Staff Meeting Focusing on Literacy Strategies Analysis of State Assessment

Cross School Session

Last ES21 Professional Development Session Staff Meeting

\section{$\underline{\text { Schedule of Interviews }}$}

School A

ES21 Leadership Team: Administrator Four teachers

February 4, 2010

Not on ES 21 Team: Three teachers

School B

ES21 Leadership Team: Administrator

Two Teachers

March 12, 2010

Not on ES21 Team: Two teachers 


\section{Appendix 4}

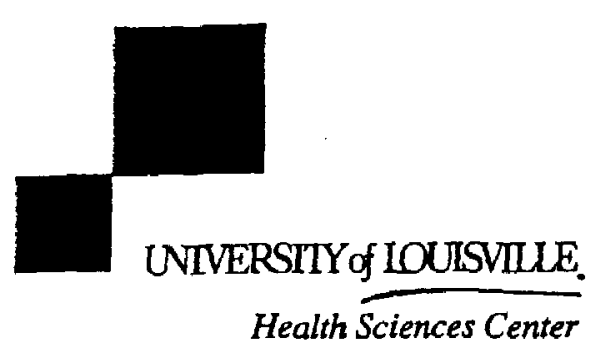

- hyMAN SUABECTS

MedCenter One. Suite 200 sol East Broschay Loulsville. Kentucky 40207-1798 Office: 502-852-5188 Fax: $502-452-216$

Thursday, November 18, 2004

Samuel Stringfield, PhD

(Sue Lasky, PhD)

College of Education

ELFH, Room \# 332, Belknap

RE: 588.04: 21st Century School Effects Study

\section{EXEMPT}

Dear Doctor Stringfield:

The above study has been received by the Human Subjects Protection Program Office. It has been determined by the chair of the Institutional Review Board that the study is exempt according to 45 CFR 46.101(b) 2 since (2) Research involving the use of educational tests (cognitive, diagnostic, aptitude, achievement), survey procedures, interview procedures or observation of public behavior. The study is exempt only if information that could identify subjects is not recorded.

The purpose of this study is to provide assistance to schools that have been identified as lowperforming or as in need of assistance.

Since this study has been found to be exempt, no additional reporting, such as submission of Progress Reports for continuation reviews, is needed. Best wishes for a successful study.

Sincerely,

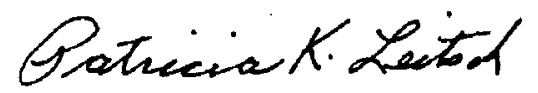

Patricia K. Leitsch, Ph.D., Chair Behavioral/Social/Educational Institutional Review Board

PKLlelh 
Subject Fwd: 588.04

From Susan G Lasky <sue.lasky@louisville.edu>

Date Friday, February 27, 2009 11:34

To bpickup@insightbb.com

Here you go, Betsy,

It's always the minor details!

-

Dr. Lasky-

I was looking at your study in our database and realized that it is exempt. That means you do not have to send amendments for personnel changes. I'm sorry I hadn't caught this sooner. Ms. Pickup may begin on your study at any time. Once again, I apologize for the oversight.

Melanie

Assistant Professor

Leadership, Foundations, and Human Resources Education

College of Education and Human Development

University of Louisville

(502)852-0634

\section{_ Original Message __ \\ From "Melanie H Zelem" <mhzele0t@gwise.louisville.edu> \\ Date Fri, 27 Feb 2009 11:25:06 -0500 \\ To "Susan G Lasky" <sglask01@gwise.louisville. edu> Subject $\mathbf{5 8 8 . 0 4}$}

\section{Dr. Lasky-}

I was looking at your study in our database and realized that it is exempt. That means you do not have to send amendments for personnel changes. I'm sorry I hadn't caught this sooner. Ms. Pickup may begin on your study at any time. Once again, $I$ apologize for the oversight.

Melanie 


\section{CURRICULUM VITAE}

NAME: Jean Elizabeth "Betsy" Pickup

ADDRESS: 6932 Colrain Circle

Louisville, KY 40258

DOB: $\quad$ Fairfield, AL - May 2, 1954

EDUCATION

\& TRAINING: A.A., Liberal Arts

Florida College

$1972-1974$

B.S., Communication Disorders

University of Cincinnati

$1987-1990$

M.A., Communication Disorders

University of Cincinnati

$1990-1992$

PROFESSIONAL SOCIETIES: Phi Beta Kappa

Jefferson County Association of School

Administrators

American Speech-Language-Hearing Association

PUBLICATIONS:

Stemple, J., Lee, L., D'Amico, \& Pickup, B. (1994). Efficacy of vocal function exercises as a method of improving voice production. Journal of voice, 8(3), $271-278$.

NATIONAL MEETING

PRESENTATIONS:

American Educational Research Association New York, NY, March (2008).

An Exploration of Highly Skilled Principals in "Low Performing" Schools 
American Educational Research Association San Diego, CA, April (2009).

PD Perspectives: Different Views from Different Roles 